INSTITUTO DE PESQUISAS ENERGÉTICAS E NUCLEARES

Autarquia Associada à Universidade de São Paulo

Determinação de Fatores de Interferência de Produtos de Fissão do Urânio na Análise por Ativação Neutrônica

Iberê Souza Ribeiro Júnior

Dissertação apresentada como parte dos requisitos para obtenção de grau de Mestre em Ciências na Área de Tecnologia Nuclear - Aplicações

Orientador:

Dr. Frederico Antonio Genezini

São Paulo

2014 


\section{AGRADECIMENTOS}

Agradeço ao meu orientador Dr. Frederico Antonio Genezini pela orientação, amizade, paciência e confiança.

À minha família pelo incentivo em relação à busca pelo aprendizado.

Agradeço especialmente à minha mãe Luciara, meu irmão Rafael e minha sobrinha Afrodite pela devida paciência nos momentos difíceis e pela fonte de inspiração que são para mim.

Agradeço aos professores Dr. Guilherme Soares Zahn, Dr. Maurício Moralles, Dr. Mauro da Silva Dias e Dr. Renato Semmler pelas discussões e sugestões pertinentes à realização deste trabalho.

Aos novos colegas de estudo que conheci no IPEN pela amizade.

Ao IPEN pela oportunidade de realização desse estudo.

Aos funcionários do $\mathrm{CRPq}$, em especial à equipe de proteção radiológica pelos serviços prestados.

À Comissão Nacional de Energia Nuclear pela bolsa concedida para realização deste trabalho e ao CNPq pelo suporte financeiro.

Agradeço especialmente à professora Dra. Mitiko Saiki por estar sempre presente na realização desse estudo, não tenho palavras que expressem minha gratidão por sua ajuda, colaboração, ensinamentos e sinceridade. Obrigado. 


\title{
DETERMINAÇÃO DE FATORES DE INTERFERÊNCIA DE PRODUTOS DE FISSÃO DE URÂNIO NA ANÁLISE POR ATIVAÇÃO NEUTRÔNICA
}

\author{
Iberê Souza Ribeiro Júnior
}

\section{RESUMO}

A análise por ativação com nêutrons é um método utilizado na determinação de diversos elementos em diferentes tipos de matrizes. Entretanto, quando a amostra contém altos teores de $U$ ocorre o problema de interferência devido aos produtos de fissão do isótopo ${ }^{235} \mathrm{U}$. Um dos métodos de tratar este problema é fazer a correção usando fatores de interferência devido à fissão do $U$ para os radionuclídeos utilizados nas análises dos elementos.

No presente estudo foram determinados os valores dos fatores de interferência devido à fissão do $U$ para os radioisótopos ${ }^{141} \mathrm{Ce},{ }^{143} \mathrm{Ce},{ }^{140} \mathrm{La},{ }^{99} \mathrm{Mo}$, ${ }^{147} \mathrm{Nd},{ }^{153} \mathrm{Sm}$ e ${ }^{95} \mathrm{Zr}$ no reator nuclear de pesquisas IEA-R1 do IPEN-CNEN/SP. Esses fatores de interferência foram determinados experimentalmente, por meio da irradiação dos padrões sintéticos em uma determinada posição do reator, e teoricamente, determinando a razão dos fluxos de nêutrons epitérmicos e térmicos na mesma posição onde os padrões sintéticos foram irradiados e utilizando parâmetros nucleares da literatura. Os fatores de interferência obtidos foram comparados com os valores reportados em outros estudos. Para avaliar esses fatores de interferência, eles foram aplicados em análises dos elementos alvo deste estudo, nos materiais de referência certificados NIST 8704 Buffalo River Sediment, IRMM BCR-667 Estuarine Sediment e IAEA-SL-1 Lake Sediment. 


\title{
DETERMINATION OF URANIUM FISSION PRODUCTS INTERFERENCE FACTORS IN NEUTRON ACTIVATION ANALYSIS
}

\author{
Iberê Souza Ribeiro Júnior
}

\begin{abstract}
Neutron activation analysis is a method used in the determination of several elements in different kinds of matrices. However, when the sample contains high $U$ levels the problem of ${ }^{235} \mathrm{U}$ fission interference occurs. A way to solve this problem is to perform the correction using the interference factor due to $\mathrm{U}$ fission for the radionuclides used on elemental analysis.

In this study, the interference factors due to $U$ fission for the radioisotopes ${ }^{141} \mathrm{Ce},{ }^{143} \mathrm{Ce},{ }^{140} \mathrm{La},{ }^{99} \mathrm{Mo},{ }^{147} \mathrm{Nd},{ }^{153} \mathrm{Sm}$ and ${ }^{95} \mathrm{Zr}$ in the research nuclear reactor IEA-R1 at IPEN-CNEN/SP were determined. These interference factors were determined experimentally, by irradiation of synthetic standards in a selected position in the reactor, and theoretically, determining the epithermal to neutron fluxes ratio in the same position where synthetic standards were irradiated and using reported nuclear parameters on the literature. The obtained interference factors were compared with values reported by other works. To evaluate the reliability of these factors they were applied in the analysis of studied elements in the certified reference materials NIST 8704 Buffalo River Sediment, IRMM BCR667 Estuarine Sediment e IAEA-SL-1 Lake Sediment.
\end{abstract}




\section{SUMÁRIO}

1 INTRODUÇÃO

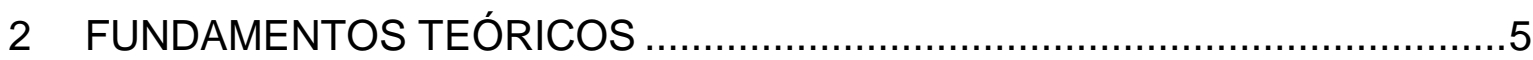



2.1.1 Princípio do método da análise por ativação com nêutrons ................7

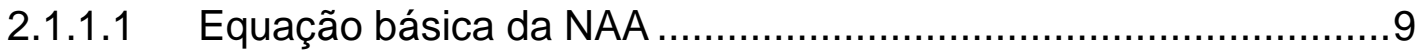



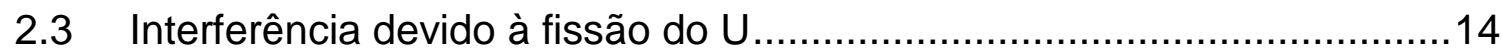

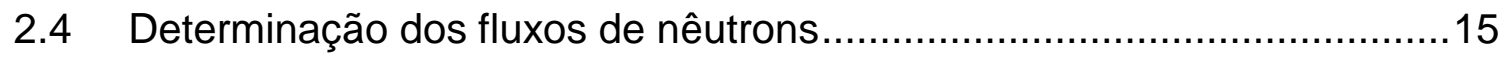

2.4.1 Distribuição energética do espectro de nêutrons em um reator de



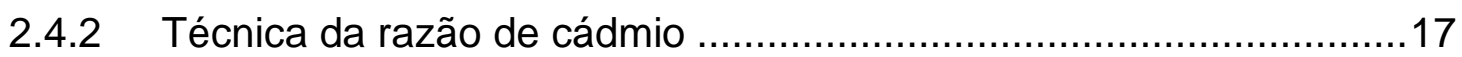

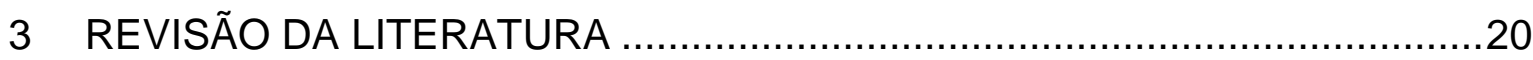





4.1.1 Materiais de referência certificados (MRCs) ....................................23

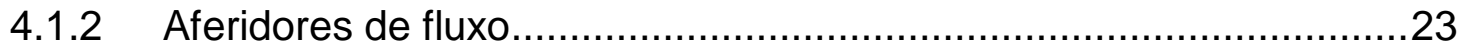



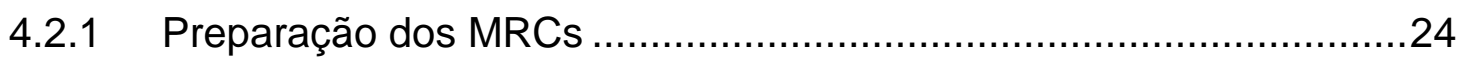

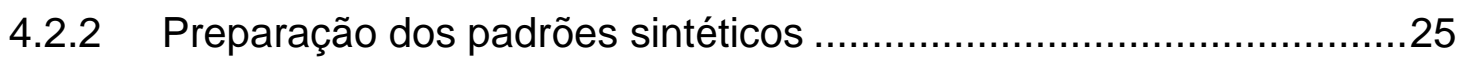

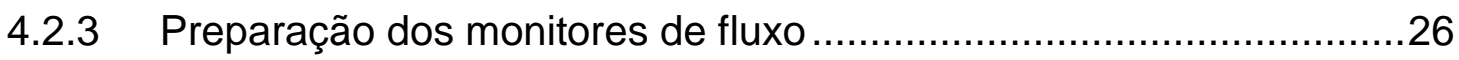

4.2.4 Determinação dos fatores de interferência experimentais.................27

4.2.5 Determinação teórica dos fatores de interferência ............................31



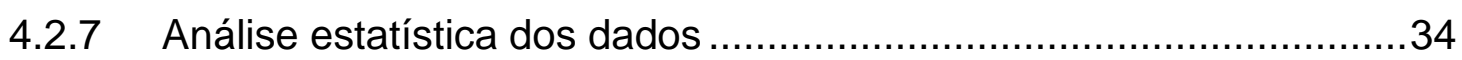



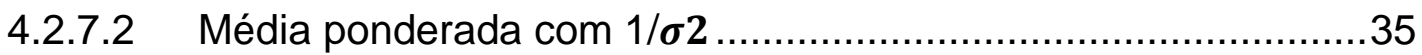

4.2.7.3 Método dos Resíduos Normalizados ........................................36

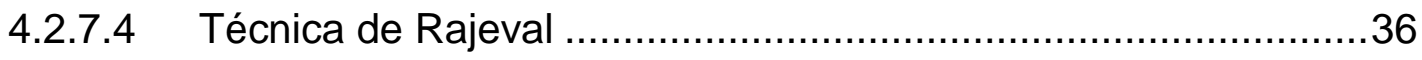

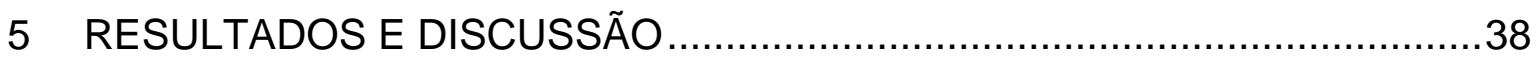

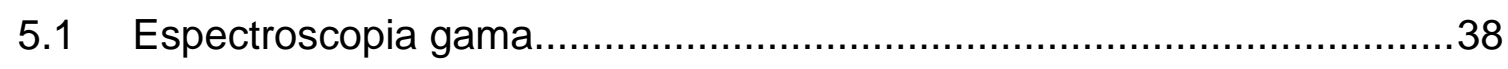

5.2 Fatores de interferência determinados experimentalmente .....................45

5.2.1 Fator de interferência experimental obtido para o ${ }^{141} \mathrm{Ce} \ldots \ldots \ldots \ldots \ldots \ldots . . . . . . .47$

5.2.2 Fator de interferência experimental obtido para o ${ }^{143} \mathrm{Ce} \ldots \ldots \ldots \ldots \ldots \ldots . . . . . .49$ 
5.2.3 Fator de interferência experimental obtido para $0^{140} \mathrm{La} \ldots \ldots \ldots \ldots \ldots \ldots . . . . .51$

5.2.4 Fator de interferência obtido experimentalmente para o ${ }^{99}$ Mo...........55

5.2.5 Fator de interferência experimental obtido para o ${ }^{147} \mathrm{Nd}$.....................57

5.2.6 Fator de interferência experimental obtido para o ${ }^{153} \mathrm{Sm}$..................60

5.2.7 Fator de interferência experimental obtido para o ${ }^{95} \mathrm{Zr}$.....................62

5.3 Balanço das incertezas dos fatores experimentais .................................64

5.4 Fatores de interferência determinados teoricamente ..............................65

5.4.1 Determinação da razão entre fluxo de nêutrons epitérmicos e

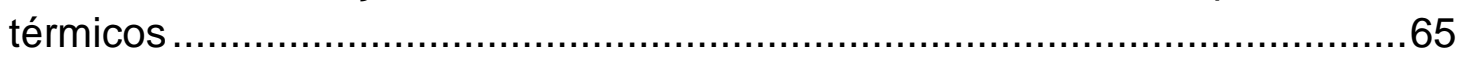

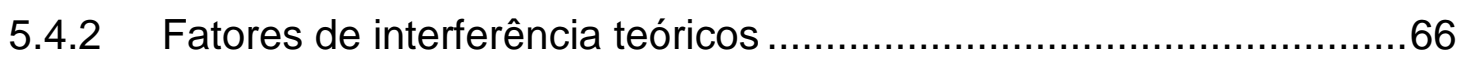

5.4.2.1 Fator de interferência obtido teoricamente para o ${ }^{141} \mathrm{Ce}$.............67

5.4.2.2 Fator de interferência obtido teoricamente para o ${ }^{143} \mathrm{Ce}$.............68

5.4.2.3 Fator de interferência obtido teoricamente para o ${ }^{140} \mathrm{La}$.............69

5.4.2.4 Fator de interferência obtido teoricamente para o ${ }^{99} \mathrm{Mo} \ldots \ldots \ldots \ldots . . . .70$

5.4.2.5 Fator de interferência obtido teoricamente para o ${ }^{147} \mathrm{Nd}$..............71

5.4.3 Fator de interferência obtido teoricamente para o ${ }^{153} \mathrm{Sm} . . . \ldots \ldots \ldots \ldots \ldots . . . .72$

5.4.3.1 Fator de interferência obtido teoricamente para o ${ }^{95} \mathrm{Zr}$...............75

5.5 Aplicação dos fatores de interferência nas análises de MRCs. ...............77

5.5.1 Material de referência NIST 8704 - Buffalo River Sediment ..............78

5.5.2 Material de referência IRMM BCR-667- Estuarine Sediment ............80

5.5.3 Material de referência IAEA-SL-1 Lake Sediment ............................ 82

5.5.4 Considerações sobre os resultados obtidos nas análises dos MRCs83

5.6 Determinação da magnitude da interferência .......................................84

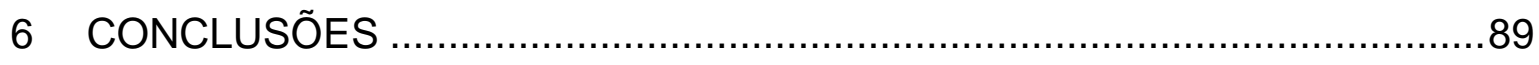

7 REFERÊNCIAS BIBLIOGRÁFICAS ..................................................... 


\section{LISTA DE TABELAS}

TABELA 4.1- Materiais de referência utilizados neste trabalho.

TABELA 4.2 - Concentração e massa dos elementos de interesse nos padrões sintéticos preparados.

TABELA 4.3 - Parâmetros nucleares dos radioisótopos utilizados na determinação das atividades (LNHB).

TABELA 4.4 - Parâmetros nucleares utilizados no cálculo do fator de interferência teórico.

TABELA 5.1 - Fatores de interferência determinados experimentalmente neste trabalho e valores reportados por outros pesquisadores.

TABELA 5.2 - Valores obtidos para os fatores de interferência do ${ }^{141} \mathrm{Ce}$ (em mg $\mathrm{kg}^{-1}$ ) utilizando diferentes tratamentos estatísticos.

TABELA 5.3 - Valores obtidos para os fatores de interferência do ${ }^{143} \mathrm{Ce}$ (em mg $\mathrm{kg}^{-1}$ ) utilizando diferentes tratamentos estatísticos.

TABELA 5.4 - Valores obtidos para a constante $\boldsymbol{k}$ do ${ }^{140} \mathrm{La}\left(\mathrm{em} \mathrm{mg} \mathrm{kg}^{-1}\right)$ utilizando diferentes tratamentos estatísticos.

TABELA 5.5 - Valores obtidos para os fatores de interferência do ${ }^{99} \mathrm{Mo}$ (em mg $\mathrm{kg}^{-1}$ ) utilizando diferentes tratamentos estatísticos.

TABELA 5.6 - Características nucleares do ${ }^{133}$.

TABELA 5.7 - Valores obtidos para os fatores de interferência do ${ }^{147} \mathrm{Nd}$ utilizando diferentes transições gama.

TABELA 5.8 - Valores obtidos para os fatores de interferência do ${ }^{153} \mathrm{Sm}$ utilizando a transição gama de $103 \mathrm{keV}$.

TABELA 5.9 - Valores obtidos para os fatores de interferência do ${ }^{95} \mathrm{Zr}$ utilizando as transições gama de 724 e $756 \mathrm{keV}$.

TABELA 5.10 - Balanço das incertezas envolvidas na determinação do fator de interferência experimental.

TABELA 5.11 - Valores obtidos para a razão do entre os fluxos de nêutrons térmicos e epitérmicos na posição 14 b prateleira 3 do reator IEA-R1. 
TABELA 5.12 - Fatores de interferência da fissão do $U$ determinados teoricamente e experimentalmente.

TABELA 5.13 - Valores obtidos para a constante $k$ do fator de interferência do ${ }^{140}$ La por três metodologias diferentes.

TABELA 5.14 - Concentrações dos elementos no material de referência NIST RM 8704 Buffalo River Sediment e valores do certificado, em mg kg${ }^{-1}$

TABELA 5.15 - Concentrações de elementos no material de referência IRMM BCR-667 Estuarine Sediment e valores do certificado, em mg kg${ }^{-1}$.....................80

TABELA 5.16 - Concentrações dos elementos no material de referência IAEA-SL1 Lake Sediment e valores do certificado, em mg kg${ }^{-1}$ 


\section{LISTA DE FIGURAS}

FIGURA 2.1 - Esquema de formação e desexcitação do núcleo irradiado (Fonte:

http://nmi3.eu/neutron-research/techniques-for-/chemical-analysis.html).

FIGURA 2.2 - Esquema de desexcitação do ${ }^{140} \mathrm{Ce}$ utilizado na determinação da concentração de La

FIGURA 2.3 - Distribuição do número de massa dos fragmentos resultantes da fissão do ${ }^{235} \mathrm{U}$ por nêutrons (Fonte: Tipler, 2001)...

FIGURA 2.4 - Distribuição da densidade do fluxo de nêutrons em função da energia dos nêutrons (Fonte: Costa, 2007).

FIGURA 2.5 - Seção de choque do ${ }^{113} \mathrm{Cd}$ em função da energia do nêutron incidente.

FIGURA 4.1 - Dimensões da caixa de Cd utilizada

FIGURA 4.2 - Foto dos padrões sintéticos preparados e das pinças utilizadas....26

FIGURA 4.3 - Dimensão dos monitores de fluxo utilizados. 27

FIGURA 4.4 - Configuração do reator IEA-R1 do IPEN-CNEN/SP. A posição 14B prateleira 3 (4⿳亠丷厂 coluna, $3^{\underline{a}}$ linha) é onde as medidas foram realizadas

FIGURA 4.5 - Esquema de sequência da preparação e irradiação das amostras.

(a) padrões embrulhados em folha de alumínio; (b) padrões inseridos no coelho;

(c) irradiação no reator nuclear; (d) contagem das atividades.

FIGURA 4.6 - Foto da amostra fixada no suporte de aço inoxidável. 29

FIGURA 4.7 - Diferentes posições de contagem utilizadas na aquisição de dados.

FIGURA 4.8 - Arranjo experimental montado para a irradiação dos monitores de fluxo.

FIGURA 4.9 - (a) foto dos padrões e amostras envoltos individualmente em folha de alumínio; (b) foto do conjunto padrões e amostras dentro do dispositivo de irradiação.

FIGURA 5.1 - Valores dos fatores de interferência obtidos para o ${ }^{141} \mathrm{Ce} \mathrm{em}$ diferentes tempos de decaimento. 
FIGURA 5.2 - Valores dos fatores de interferência obtidos para o ${ }^{143} \mathrm{Ce}$ em diferentes tempos de decaimento.

FIGURA 5.3 - Formação do ${ }^{140}$ La pelo decaimento do produto de fissão ${ }^{140} \mathrm{Ba} . . .52$ FIGURA 5.4 - Dispersão dos valores experimentais obtidos para a constante $k$ do ${ }^{140}$ La.

FIGURA 5.5 - Variação do fator de interferência do ${ }^{140} \mathrm{La}\left(\mathrm{em} \mathrm{mg} \mathrm{kg}^{-1}\right)$ em função do tempo de decaimento.

FIGURA 5.6 - Valores dos fatores de interferência obtidos para o ${ }^{99} \mathrm{Mo} \mathrm{em}$ diferentes tempos de decaimento.

FIGURA 5.7 - Valores dos fatores de interferência obtidos para o ${ }^{147} \mathrm{Nd}$ em diferentes tempos de decaimento.

FIGURA 5.8 - Fatores de interferência obtidos para o ${ }^{153} \mathrm{Sm}$ em três diferentes tempos de decaimento.

FIGURA 5.9 - Valores obtidos para o fator de interferência para o ${ }^{95} \mathrm{Zr}$ em diferentes tempos de decaimento.

FIGURA 5.10 - Comparação entre valor do fator de interferência obtido experimentalmente e o valor teórico em função da razão entre fluxo de nêutrons térmicos e epitérmicos para o ${ }^{141} \mathrm{Ce}$.

FIGURA 5.11 - Comparação entre valor do fator de interferência obtido experimentalmente e o valor teórico em função da razão entre fluxo de nêutrons térmicos e epitérmicos para $0{ }^{143} \mathrm{Ce}$.

FIGURA 5.12 - Comparação entre os valores dos fatores de interferência para o ${ }^{99}$ Mo determinados experimentalmente e teoricamente entre diferentes autores. 71

FIGURA 5.13 - Comparação entre valor do fator de interferência obtido experimentalmente e o valor teórico em função da razão entre fluxo de nêutrons térmicos e epitérmicos para ${ }^{147} \mathrm{Nd}$.

FIGURA 5.14 - Variação do fator de interferência teórico do ${ }^{153} \mathrm{Sm}$ em função da razão entre fluxos térmicos e epitérmicos.

FIGURA 5.15 - Comparação entre valores de fatores de interferência para o ${ }^{95} \mathrm{Zr}$ determinados experimentalmente e teoricamente entre diferentes pesquisadores. 
FIGURA 5.16 - Valores de $E_{n}$-score obtidos para Ce e U no material de referência NIST RM 8704 Buffalo River Sediment.

FIGURA 5.17 - Valores de En-score obtidos para o material de referência IRMM BCR-667 Estuarine Sediment.

FIGURA 5.18 - Valores de En-score obtidos para o material de referência IAEASL-1 Lake Sediment.

FIGURA 5.19 - Erro percentual devido à fissão do $U$ em função da razão entre as concentrações de $\mathrm{U}$ e do elemento de interesse para os radioisótopos ${ }^{141} \mathrm{Ce}$, ${ }^{143} \mathrm{Ce},{ }^{99} \mathrm{Mo},{ }^{147} \mathrm{Nd} \mathrm{e}{ }^{95} \mathrm{Zr}$.

FIGURA 5.20 - Erro percentual devido à fissão do U em função da razão entre as concentrações de $\mathrm{U}$ e de La para diferentes tempos de decaimento.

FIGURA 5.21 - Erro percentual na concentração de $S m$ devido à fissão do $U$ em função da razão entre as concentrações de $U$ e de $\mathrm{Sm}$ para diferentes tempos de decaimento. .88 


\section{INTRODUÇÃO}

A Análise por Ativação Neutrônica (NAA) é considerada uma metodologia bem estabelecida utilizada na determinação de concentração multielementar em diversos tipos de matrizes, sejam elas de origem geológicas, biológicas ou ambientais. Esta técnica foi consolidada ao longo dos anos como uma poderosa ferramenta analítica devido às suas vantagens, podendo-se destacar: a possibilidade de análise multielementar; alta sensibilidade, isto é, a determinação de elementos em baixas concentrações; qualidade dos resultados em relação à exatidão e precisão; e possibilidade de análise puramente instrumental (sem a necessidade de digestão da amostra e uso de calibrações) sendo essa variedade da NAA, chamada de Análise por Ativação Neutrônica Instrumental (INAA) ,classificada por alguns autores como técnica primária (Greenberget al., 2011).

Devido a estas vantagens, a INAA vem sendo amplamente utilizada pelo grupo do Laboratório de Análise por Ativação com Nêutrons (LAN) localizado no IPEN-CNEN/SP nas análises de amostras de matrizes geológicas, biológicas e ambientais.

Contudo, uma das dificuldades de aplicação da NAA é a presença de problemas de interferências que podem ser espectrais; reações interferentes primárias e problemas de interferência devido à fissão do U (De Soete et al., 1972).

As interferências espectrais ocorrem quando radioisótopos possuem transições gamas iguais ou com energias próximas, desta maneira o sistema utilizado nas análises não consegue distinguir a origem desses raios gama.

As reações interferentes primárias ocorrem quando o mesmo radioisótopo é formado a partir de dois ou mais núcleos estáveis em reações com nêutrons.

O problema de interferência devido à fissão do $U$, objeto de estudo deste trabalho, ocorre quando os radioisótopos utilizados na INAA coincidem com os produtos de fissão. Desta maneira os resultados analíticos obtidos em amostras com alto teor de $U$ são superestimados, uma vez que parte da atividade 
dos radioisótopos utilizados nas análises pela INAA é devida aos produtos de fissão do U.

Dentre os elementos analisados pela NAA que sofrem interferência devido à fissão do $\mathrm{U}$ temos o $\mathrm{Ce}, \mathrm{La}, \mathrm{Mo}, \mathrm{Nd}, \mathrm{Sm}$ e $\mathrm{Zr}$ cujas determinações são de grande importância em diversos tipos de matrizes.

Os elementos $\mathrm{Ce}$, La, Nd e Sm fazem parte do grupo dos Elementos de Terras Raras (ETRs) e são de grande interesse econômico devido às suas aplicabilidades em diversos campos da indústria moderna, dentre as quais destacam-se: a metalurgia, catálise, cerâmicas, ótica, magnetos permanentes, lasers, medicina, indústria eletrônica, entre outras (Loureiro, 1994).

Em virtude dessa ampla aplicabilidade, a exploração e o comércio dos ETRs ocupam grande importância econômica, principalmente em países cujas reservas destes elementos são significativas. Daí a necessidade de determinação da concentração com precisão e exatidão elevadas destes elementos (Capannesi et al., 2012).

Além disso, a determinação de certos elementos químicos pela INAA, por exemplo os lantanídeos, produz resultados com grande precisão em amostras geológicas, viabilizando a possibilidade de estudos petrogenéticos das rochas, fornecendo valorosas informações sobre a origem e composição (Capannesi et al., 2012; Lins, 1992; Park et al., 1993), assim como a possibilidade de extração de elementos de interesse da indústria e a viabilidade da extração.

Atualmente a China é o maior produtor de ETRs do planeta, com cerca de $97 \%$ da produção mundial (Rocio et al., 2012). As preocupações em relação ao fornecimento destes elementos se intensificaram em 2010 em virtude de algumas medidas adotadas pela China que tendem a encarecer o custo destes elementos e torná-los mais escassos nos demais países (Rocio et al., 2012, p. 384-386). Em consequência destas medidas adotadas pela China, alguns países, dentre eles o Brasil, iniciaram pesquisas sobre novas fontes de ETRs.

Por consequência da ampla aplicação e utilização dos ETRs na indústria, e também por sua concentração no meio ambiente, existe a possibilidade de sua entrada na cadeia alimentar do homem podendo gerar problemas de saúde. Foi verificado por Pietra et al. (1985) a ocorrência de pneucomuniose em algumas classes de trabalhadores que foram expostos aos ETRs por um longo período. Neste grupo de indivíduos, foi aferido um elevado 
valor das concentrações de ETRs quando comparado a um grupo de controle. Daí a importância da sua determinação com grande precisão e exatidão em matrizes biológicas e ambientais.

Outro elemento que requer atenção é o Mo, pois este, é considerado um elemento essencial para a vida quando presente em baixas concentrações, porém tóxico em altas concentrações (Danko \& Dybcczynski, 1997). A determinação deste elemento pode ser feita pela INAA. Entretanto em amostras contendo $\mathrm{U} \mathrm{o}$ analista deve estar atento em relação ao problema de interferência oriunda da fissão do $\mathrm{U}$, conforme reportado por alguns autores (Armelin \& Piasentin, 1996; Martinho, 1999).

A determinação da concentração de $Z r$ com grande exatidão é de suma importância para estimar o potencial econômico de prospecção deste elemento. $O$ valor econômico deste elemento se deve a sua boa resistência mecânica, alto ponto de fusão $\left(1852^{\circ} \mathrm{C}\right)$ e resistência à corrosão. Em virtude da sua baixa seção de choque para nêutrons térmicos o $\mathrm{Zr}$ é amplamente utilizado na parte estrutural de reatores nucleares (Lins, 1992).

Com relação ao $U$, vale ressaltar que o Brasil possui a sexta maior reserva deste elemento do planeta com cerca de 309.000 toneladas deste mineral, segundo dados oficias das Indústrias Nucleares do Brasil (INB). Portanto, amostras ambientais provindas de regiões ricas em $U$ no Brasil podem apresentar altos teores de $U$ em sua composição, e consequentemente os resultados analíticos obtidos pela técnica da INAA podem ser tendenciosos e necessitarem de correção, daí a motivação para se determinar os fatores de interferência devido à fissão do $U$.

A interferência devido aos produtos de fissão do $U$ pode ser eliminada de duas maneiras distintas: 1 ) realizando a separação de $U$ da amostra antes da irradiação; ou 2) determinando os fatores de correção da interferência para descontar a contribuição devido à fissão do $U$ da concentração aparente (que é a soma da concentração oriunda da fissão do $U$ mais a provinda da ativação do elemento de interesse). O segundo modo apresenta vantagem em relação ao primeiro uma vez que tendo o valor do fator de correção de interferência basta aplicá-lo para que seja feita a correção. Na primeira maneira a separação química do $U$ é demorada e deve ser feita antes de cada irradiação, o que torna o método 
mais trabalhoso, além da necessidade do uso de reagentes o que tira a característica que torna a INAA um método primário.

A determinação dos fatores de correção da interferência devido à fissão do $U$ tem sido objeto de estudo de vários autores (Al-Jobari et al., 1990; Glascock et al., 1996; Park et al., 1993; Tshiashala, 2005; Landsberger, 1986; Myamoto et al., 1999; De Corte \& Van Lierde, 2001 entre outros). Isto porque os valores de fatores de correção de interferência dependem do produto de fissão a ser considerado e também do fluxo de nêutrons do reator, mais precisamente da razão entre o fluxo de nêutrons térmicos e epitérmicos a qual varia com a posição em que as amostras são irradiadas e com as características do reator.

Portanto julgou-se de grande interesse a obtenção dos fatores de correção de interferência da fissão do $U$ em uma posição do reator nuclear de pesquisa IEA-R1 localizado no IPEN-CNEN/SP e um estudo comparativo entre os valores reportados na literatura.

Para verificar a magnitude da correção dos valores dos fatores de interferência obtidos neste trabalho e sua validade, correções utilizando os fatores foram aplicadas na análise de Materiais de Referência Certificados (MRCs).

A estrutura desta dissertação é dividida em 5 capítulos além desta introdução.

No Capítulo 2 dessa dissertação são descritos os fundamentos teóricos necessários referentes à determinação dos fatores de interferência.

No Capítulo 3 é feita uma breve revisão dos trabalhos presente na literatura incluindo uma descrição sucinta sobre como os demais autores realizaram a determinação dos fatores de interferência.

A parte experimental adotada na determinação dos fatores de interferência e preparação dos materiais de referência certificados são descritas no Capítulo 4.

No Capítulo 5 são apresentados os resultados e a discussão dos fatores de interferência obtidos neste trabalho comparando-os com resultados obtidos por outros autores, além de ser apresentada a aplicação da correção em materiais de referência certificados.

No capítulo 6 são discutidas as perspectivas futuras e as conclusões em relação aos valores obtidos para os fatores de interferência. 


\section{FUNDAMENTOS TEÓRICOS}

\subsection{Análise por ativação neutrônica}

A Análise por Ativação Neutrônica (NAA) foi proposta em 1936 por Von Hevesy \& Levi (De Soete et al., 1972). Hevesy \& Levi (1934), propuseram a aplicação do método da "atividade artificial", baseada na captura de nêutrons, a fim de complementar os métodos químicos utilizados nas determinações de elementos terras raras. Contudo, esta metodologia apresentava limitações devido ao pouco conhecimento sobre a absorção de nêutrons, e à falta de equipamentos que emitissem feixe de nêutrons em diversas faixas de energia.

Posteriormente Brown \& Goldberg (1949) realizaram a determinação da concentração de alguns elementos em meteoritos utilizando um reator nuclear com fluxo de nêutrons da ordem de $10^{12} \mathrm{~cm}^{-2} \mathrm{~s}^{-1}$.

A rápida construção de reatores nucleares de pesquisa após a segunda guerra, o desenvolvimento de separações radioquímicas e o surgimento dos contadores Geiger foram passos essenciais para o desenvolvimento da NAA entre o final da década de 40 e início dos anos 50. O desenvolvimento dos detectores de cintilação da década de 50, a eletrônica associada e analisadores de alta resolução foram essenciais para o aperfeiçoamento da espectroscopia gama e por conseguinte do método de NAA.

$\mathrm{Na}$ década de 60 foram fabricados os primeiros detectores de $\mathrm{Ge}$ dopados com $\mathrm{Li}$, estes detectores apresentaram uma resolução em energia cerca de 30 vezes melhor em relação aos detectores de cintilação, aprimorando desta forma a espectroscopia gama empregada na NAA.

Com a confecção de detectores de Germânio hiperpuro (HPGe) na década de 80, a NAA se consolidou como um método analítico que apresenta alta resolução na espectroscopia gama possibilitando a análise multielementar.

Hoje, a NAA constitui em uma das aplicações mais importantes dos reatores nucleares de pesquisa, e esta técnica tem sido amplamente utilizada no Laboratório de Análise por Ativação Neutrônica (LAN) do IPEN-CNEN/SP.

A NAA tem sido amplamente utilizada para a determinação das concentrações de elementos em diversos tipos de matrizes sejam elas: biológicas tais como sangue, unhas, dentes e cabelo; geológicas tais como minérios, solos e 
rochas; e em amostras ambientais tais como materiais particulados, biomonitores e plantas.

A grande variedade de aplicações desta técnica está relacionada com as suas vantagens:

1. Capacidade de análise multielementar, ou seja, é possível determinar a concentração de vários elementos em uma única análise;

2. Possibilidade de determinação de cerca de $70 \%$ dos elementos da tabela periódica que apresentam características favoráveis a esta técnica;

3. Facilidade na preparação das amostras não requerendo a etapa de dissolução, conferindo a característica de método primário à NAA;

4. Independe do estado químico, pois as reações utilizadas nesta técnica ocorrem no núcleo do elemento de interesse;

5. Possibilidade de determinação de elementos presentes em baixas concentrações da ordem de $\mu \mathrm{g} \mathrm{kg}^{-1}$ (Costa, 2007) dependendo da composição da amostra;

6. Ausência do problema de contaminação da amostra após a irradiação;

7. A NAA permite obter resultados com alta precisão e exatidão.

Entretanto, como as demais técnicas analíticas, a NAA apresenta suas desvantagens e limitações (Costa, 2007):

1. Dependendo da composição da amostra e do elemento que se deseja determinar a concentração há a necessidade de um fluxo de nêutrons elevado para a ativação, que são obtidos somente em reatores nucleares de pesquisa, fato este que envolve alto custo no investimento e manutenção;

2. Esta técnica não permite a identificação da forma química do elemento, uma vez que a análise é realizada por meio de reações nucleares;

3. Alguns elementos tais como $\mathrm{C}, \mathrm{H}, \mathrm{Li}$ e $\mathrm{Pb}$ não podem ser determinados na NAA por não apresentarem características nucleares favoráveis à ativação;

4. Ocorrência de problemas causados por reações nucleares de interferências. 


\subsubsection{Princípio do método da análise por ativação com nêutrons}

O princípio da análise por ativação consiste em submeter uma amostra a um feixe de nêutrons a fim de que ocorra a reação de captura $(n, \gamma)$. Neste processo, ocorre a formação de um elemento radioativo, ou seja, o radioisótopo formado pela reação de captura pode decair de diferentes maneiras: mais frequentemente pela emissão de partículas beta menos $\left(\beta^{-}\right)$, e em algumas ocasiões pela emissão de beta mais $\left(\beta^{+}\right)$ou captura eletrônica, e subsequentemente pode haver a emissão de raios gama. Desta maneira a identificação do elemento na NAA é realizada por meio da análise da meia vida e das energias das transições gama característica de cada radioisótopo.

$\mathrm{Na}$ FIG. 2.1 está representado o esquema de formação de um radioisótopo por meio da reação de captura de nêutrons.

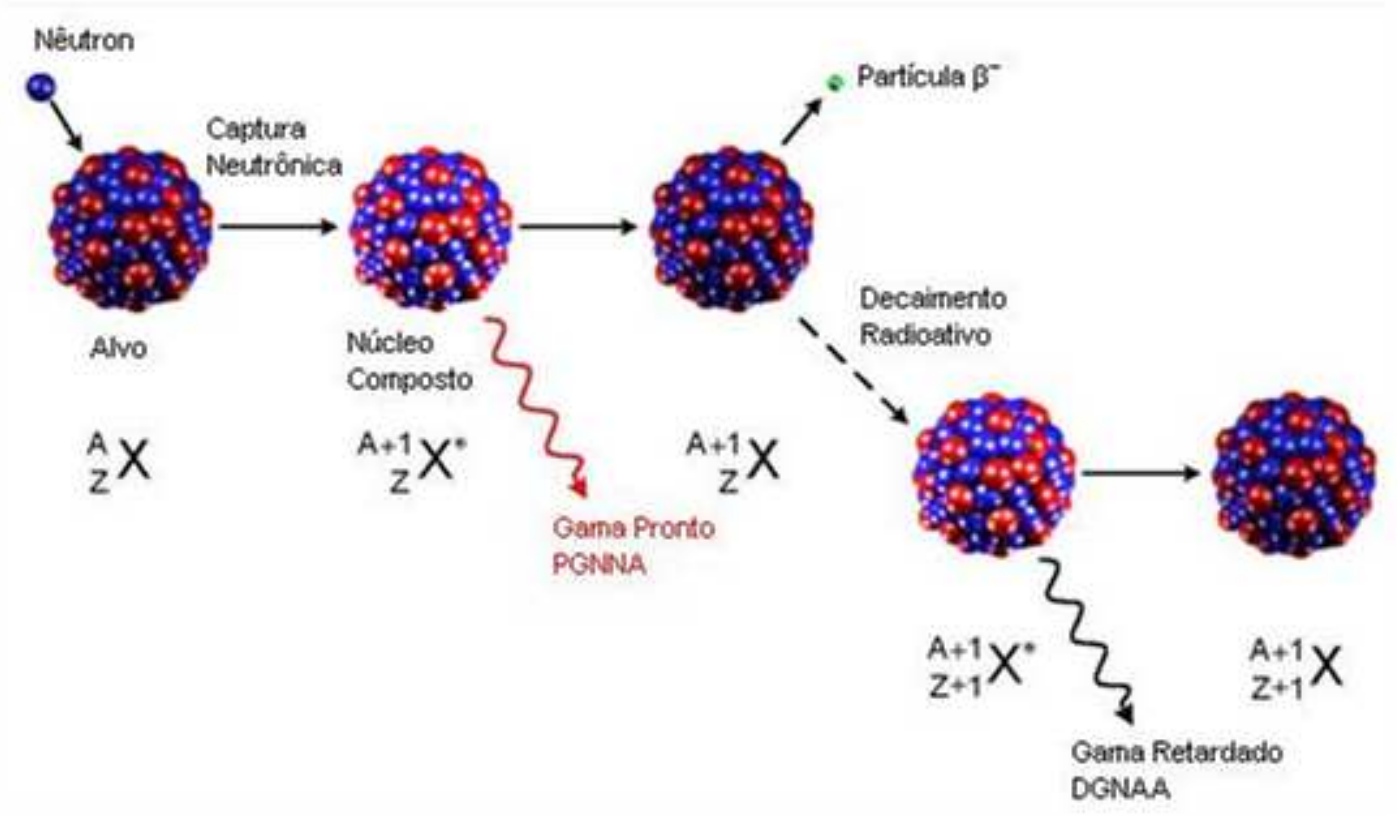

FIGURA 2.1 - Esquema de formação e desexcitação do núcleo irradiado (Fonte: http://nmi3.eu/neutron-research/techniques-for-/chemical-analysis.html).

Quando ocorre a reação de captura é formado um núcleo composto $\left({ }_{Z}^{A+1} X^{*}\right)$ em estado excitado, este núcleo perde energia emitindo radiação gama com tempos de meia vida da ordem de $10^{-16}$ a $10^{-14} \mathrm{~s}$. A NAA pode ser realizada por meio da medida da quantidade desses raios gama, denominados por raios gama pronto. Essa metodologia de análise é conhecida por "Prompt Gamma 
Neutron Activation Analysis (PGNAA)", a qual é realizada durante a irradiação devido ao curto tempo de meia vida do núcleo composto formado.

$\mathrm{Na}$ maioria das vezes o radioisótopo formado $\left({ }^{A+1} X\right)$ decai para um outro nuclídeo $\left({ }_{Z+1}^{A+1} Y\right)$ emitindo uma partícula $\beta$. Este novo nuclídeo formado pode estar em um estado excitado e emitir radiação gama de desexcitação. A NAA pode ser realizada por meio da medida desses raios gama, denominados por raios gama atrasados ou de decaimento. Esta metodologia de análise é denominada por "Delayed Gamma Neutron Activation Analysis (DGNAA)", ou simplesmente por Análise por Ativação com Nêutrons (NAA).

A título de exemplo, pode-se utilizar aplicação da NAA na determinação de lantânio, que ocorre por meio da reação da captura de um nêutron do isótopo estável ${ }^{139} \mathrm{La}$ formando ${ }^{140} \mathrm{La}$ (meia vida de $1,675 \mathrm{~d}$ ) que decai para $0{ }^{140} \mathrm{Ce}$. A determinação do lantânio é realizada por meio das medidas dos raios gama emitidos na desexcitação do ${ }^{140} \mathrm{Ce}$, mostrados na FIG. 2.2.

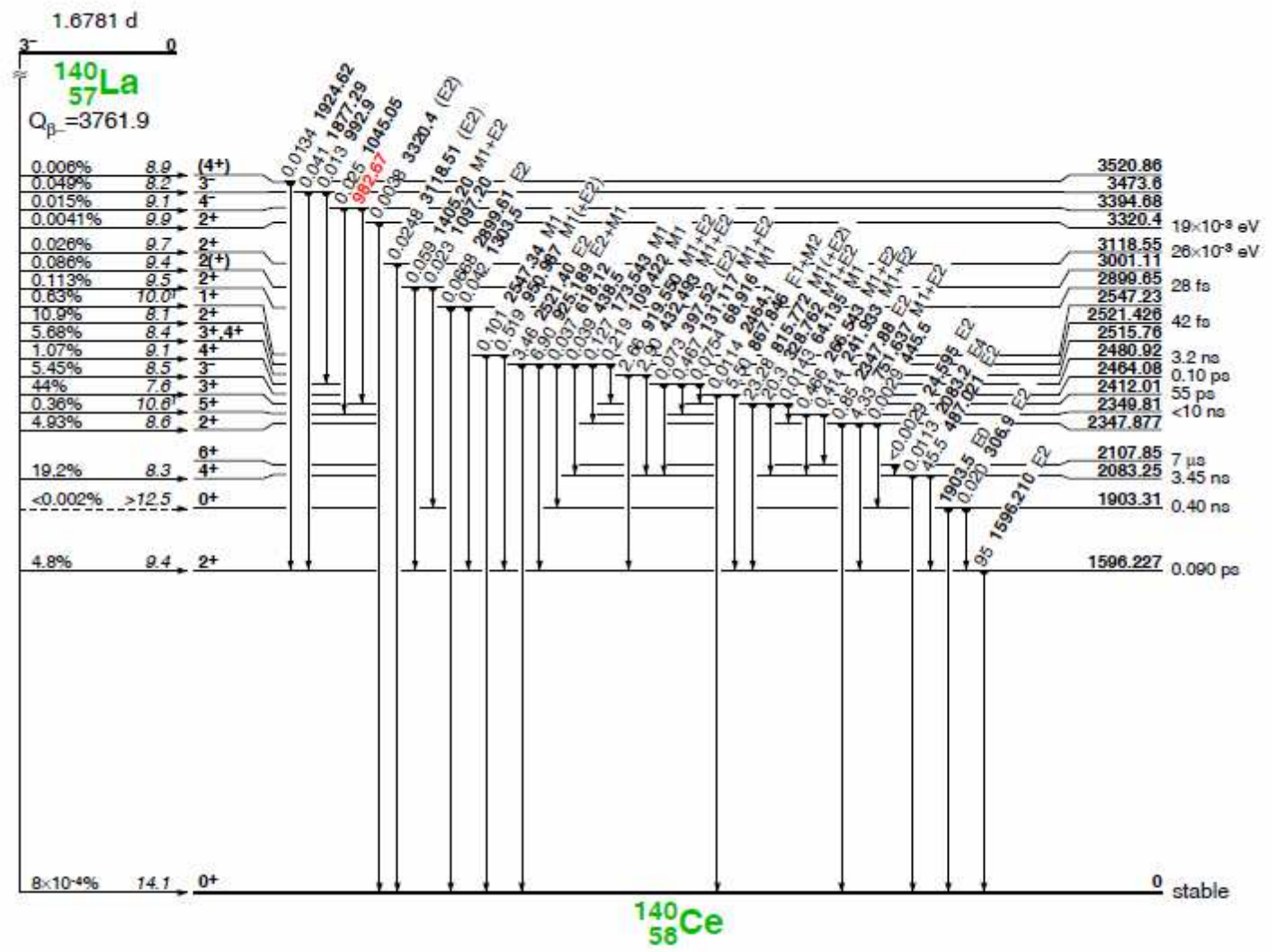

FIGURA 2.2 - Esquema de desexcitação do ${ }^{140} \mathrm{Ce}$ utilizado na determinação da concentração de La. 
No caso da determinação do lantânio pela NAA devem ser analisadas as transições gama de 1596, 815, 487 e $328 \mathrm{keV}$ oriundas da desexcitação do radionuclídeo ${ }^{140} \mathrm{Ce}$.

\subsubsection{Equação básica da NAA}

Quando submetido a um fluxo de nêutrons os átomos de uma determinada amostra podem capturar um nêutron e se tornarem radioativos. Contudo ao mesmo tempo em que o radioisótopo é formado, ele começa a decair, a taxa de decaimento é proporcional à meia vida do radioisótopo formado. Podese determinar a atividade de um radionuclídeo por meio da equação (1):

$$
\frac{d N_{y}}{d t}=\sigma_{x} \phi N_{x}-\lambda_{y} N_{y}
$$

Sendo:

$\sigma_{x}=$ Seção de choque para captura de nêutron;

$\phi=$ Fluxo de nêutrons;

$N_{x}=$ Número de átomos iniciais (núcleo alvo);

$\lambda_{y}=$ Constante de decaimento radioativo do radioisótopo formado;

$N_{y}=$ Número de átomos radioativos.

Considerando que em $\mathrm{t}=0$ o número de átomos radioativos $\left(N_{y}\right)$ é nulo, pode-se integrar a equação 1 no instante $t=0$ até o fim da irradiação. Por meio desta integração obtém-se a equação (2).

$$
A_{y}=\sigma_{x} \phi N_{x}\left(1-e^{\lambda_{y} t_{i}}\right)
$$

O número de átomos iniciais $\left(N_{x}\right)$ do núcleo a ser irradiado pode ser expresso em função da massa $(m)$.

$$
N_{x}=\frac{N_{0} \theta_{x} m_{t}}{M_{x}}
$$

Sendo $N_{0}$ a constante de Avogadro, $M_{x}$ a massa atômica e $\theta_{x}$ a abundância isotópica do elemento a ser ativado e $m_{t}$ é massa total do elemento.

Substituindo a equação (3) na equação (2) tem-se: 


$$
A_{y}=\frac{N \theta_{x} m_{t} \sigma_{x} \phi}{M_{x}}\left(1-e^{\lambda_{y} t_{i}}\right)
$$

A atividade induzida em um elemento por um fluxo de nêutrons é diretamente proporcional à massa do elemento presente na amostra, ao fluxo de nêutrons ao qual a amostra é submetida e à seção de choque para captura de nêutrons.

O fluxo de nêutrons de um reator nuclear pode ser dividido em diferentes faixas de energia: térmicos, epitérmicos e rápidos. A ativação de um elemento ocorre principalmente pelos nêutrons térmicos e epitérmicos (uma vez que a seção de choque de absorção de um nêutron na faixa de energia dos nêutrons rápidos é muito baixa). Sendo assim, deve ser aplicada uma correção na equação (4) pois os valores de fluxo de nêutrons térmicos e epitérmicos variam com a posição na qual as amostras são irradiadas e os valores de seção de choque térmica $\left(\sigma_{t h}^{x}\right)$ e epitérmica $\left(\sigma_{e p}^{x}\right)$ são diferentes para um determinado isótopo. Na irradiação com nêutrons térmicos e epitérmicos a equação (4) deve ser reescrita como:

$$
A_{y}=\frac{N_{0} \theta_{x} m_{t}}{M_{x}} \cdot\left(\sigma_{t h}^{x} \cdot \phi_{t h}+\sigma_{e p}^{x} \cdot \phi_{e p}\right) \cdot\left(1-e^{-\lambda_{y} t_{i}}\right)
$$

A atividade do radioisótopo, formado na reação $(n, \gamma)$, oriunda do decaimento $\beta$ do isótopo ativado pode ser medida experimentalmente utilizando equipamento apropriado, geralmente um detector de germânio hiperpuro (HPGe). Considerando $t_{i}$ como o tempo de decaimento da amostra, ou seja, o tempo decorrido entre o fim da irradiação e o início da contagem da amostra, a taxa de contagem em uma amostra é obtida por meio da equação (6) (De Soete et al., 1972):

$$
T=\frac{\varepsilon I_{\gamma} N_{0} m_{t} \theta_{x}}{M_{x}}\left(\sigma_{t h}^{x} \cdot \phi_{t h}+\sigma_{e p}^{x} \cdot \phi_{e p}\right) \cdot\left(1-e^{-\lambda t_{i}}\right)
$$

Onde $I_{\gamma}$ representa a intensidade da transição gama utilizada na análise. 
A determinação da concentração do elemento de interesse na amostra a ser analisada pode ser realizada pelo método comparativo (metodologia empregada neste trabalho). Este método consiste em irradiar simultaneamente a amostra que se deseja analisar e um padrão com massa conhecida do elemento que se deseja determinar a concentração. Neste caso as taxas de contagens da amostra e do padrão ( $T_{a}$ e $T_{p}$, respectivamente) podem ser obtidas por meio das equações (7) e (8):

$$
\begin{aligned}
& T_{0 a}=\frac{\varepsilon I_{\gamma} N_{0} m_{a} \theta_{x}}{M_{x}}\left(\sigma_{t h}^{x} \cdot \phi_{t h}+\sigma_{e p}^{x} \cdot \phi_{e p}\right) \cdot\left(1-e^{-\lambda t_{i}}\right) \\
& T_{0 p}=\frac{\varepsilon I_{\gamma} N_{0} m_{p} \theta_{x}}{M_{x}}\left(\sigma_{t h}^{x} \cdot \phi_{t h}+\sigma_{e p}^{x} \cdot \phi_{e p}\right) \cdot\left(1-e^{-\lambda t_{i}}\right)
\end{aligned}
$$

Sendo que os índices $a$ e $p$ se referem à amostra e padrão, respectivamente. Considerando que a amostra e padrão foram irradiados simultaneamente (posição de irradiação e mesmo instante), pode-se determinar a massa do elemento de interesse na amostra dividindo a equação (7) pela (8) e obtendo a relação dada por:

$$
m_{a}=\frac{T_{0 a} m_{p}}{T_{0 p}}
$$

A concentração do elemento de interesse $\left(C_{a}\right)$ na amostra pode ser obtida dividindo ambos os membros da equação (9) pela massa total da amostra:

$$
C_{a}=\frac{T_{0 a} m_{p}}{T_{0 p} M_{a}}
$$

Sendo $C_{a}=m_{a} / M_{a}$.

Devido à impossibilidade de realizar a aquisição de dados das taxas de contagens da amostra e do padrão ao mesmo tempo, deve ser aplicada uma correção. Pela lei de decaimento tem-se (Friedlander et al., 1981):

$$
T=T_{0} e^{-\lambda t_{d}}
$$

Aplicando esta correção para as taxas de contagem da amostra e do padrão na equação (9) tem-se: 


$$
C_{a}=\frac{T_{a} m_{p} e^{\lambda\left(t_{d a}-t_{d p}\right)}}{T_{p} M_{a}}
$$

Sendo $t_{d a}$ e $t_{d p}$ os tempo de decaimento da amostra e padrão, respectivamente. $T_{a}$ e $T_{p}$ são as taxas de contagens da amostra e padrão para tempos de decaimento $t_{d a}$ e $t_{d p}$, respectivamente.

A equação (12) é utilizada para o cálculo da determinação da concentração de um elemento em uma amostra que se deseja analisar.

\subsection{Fissão do urânio}

O processo de fissão do U foi descoberto em 1938 por O. Hahn e F. Strassmann (Tipler \& Llewellyn, 2001). Estes pesquisadores notaram que quando átomos de $U$ eram bombardeados por um fluxo de nêutrons térmicos ocorria a produção de elementos de massa atômica intermediária. Este processo de formação de elementos pela fissão do U está representado na equação (13):

$$
{ }^{235} U+n \rightarrow{ }^{236} U \rightarrow \text { produtos de fissão }+2 a 3 n
$$

A fissão do átomo de ${ }^{235} \mathrm{U}$ pode ser simétrica, quando $0{ }^{235} \mathrm{U}$ se divide em dois átomos com massas aproximadamente iguais; ou com maior probabilidade assimétrica, quando os átomos resultantes da fissão possuem massas diferentes. Na FIG.2.3 é apresentada a distribuição do número de massa dos fragmentos de fissão do ${ }^{235} \mathrm{U}$. 




FIGURA 2.3 - Distribuição do número de massa dos fragmentos resultantes da fissão do ${ }^{235} \mathrm{U}$ por nêutrons (Fonte: Tipler, 2001).

A atividade de um radionuclídeo proveniente da fissão do $U$ pode ser calculada utilizando a equação 14 :

$$
A_{y}^{U}=\frac{m_{U} a_{U} N_{0} f_{y}}{M_{U}} \cdot\left(\sigma_{t h}^{(n, f)} \cdot \phi_{t h}+\sigma_{e p}^{(n, f)} \cdot \phi_{e p}\right) \cdot\left(1-e^{-\lambda_{y} t_{i}}\right)
$$

Sendo:

$m_{U}=$ massa de $\mathrm{U}$ presente na amostra;

$a_{U}=$ abundância isotópica do ${ }^{235} \mathrm{U}$;

$M_{U}=$ massa atômica do U;

$f_{y}=$ rendimento de fissão cumulativo para o elemento de interesse;

$\sigma_{t h}^{(n, f)}=$ seção de choque térmica para fissão do ${ }^{235} \mathrm{U}$;

$\sigma_{e p}^{(n, f)}=$ seção de choque térmica para fissão do ${ }^{235} \mathrm{U}$.

Cabe falar sobre o rendimento de fissão cumulativo, esta variável representa o quanto um radionuclídeo é formado direta e indiretamente pela fissão do ${ }^{235} U$. Dos Santos \& Arezzo (1972) descrevem que o rendimento de fissão pode ser separado em duas categorias distintas: rendimento de fissão 
independente, que é a porcentagem do urânio que sofre fissão primária para o radionuclídeo; rendimento de fissão cumulativo, que é o rendimento de fissão independente do elemento de interesse somado aos rendimentos de fissão independentes dos elementos que sofrem decaimento para o nuclídeo de interesse. Estes autores utilizam para exemplificar o caso da formação do ${ }^{115} \mathrm{Ag}$ :

$$
{ }_{44}^{115} \mathrm{Ru} \stackrel{\beta^{-}}{\rightarrow}{ }_{45}^{115} \mathrm{Rh} \stackrel{\beta^{-}}{\rightarrow}{ }_{46}^{115} \mathrm{Pd} \stackrel{\beta^{-}}{\rightarrow}{ }_{47}^{115} \mathrm{Ag}
$$

Como exemplo o rendimento de fissão cumulativo da ${ }^{115} \mathrm{Ag}$ é obtido pela soma do rendimento independente de fissão da ${ }^{115} \mathrm{Ag}$ mais os rendimentos independentes de fissão dos produtos de fissão que formam a ${ }^{115} \mathrm{Ag}$.

O rendimento de fissão cumulativo é uma variável importante, uma vez que por meio deste parâmetro é possível determinar a quantidade total de um núcleo formado por meio de processo de fissão.

\subsection{Interferência devido à fissão do U}

$O$ problema da interferência dos produtos de fissão do ${ }^{235} \mathrm{U}$ na NAA ocorre quando um dos produtos de fissão do $U$ formado é o mesmo radioisótopo utilizado na quantificação da concentração do elemento de interesse.

O fator de interferência de fissão $(F)$ é definido como a razão entre a atividade específica do do radionuclídeo formado pela fissão do ${ }^{235} \mathrm{U}$ e a atividade específica do radionuclídeo utilizado na NAA, nas mesmas condições de irradiação:

$$
F=\frac{A_{y}^{U}}{A_{y}} \cdot \frac{m_{y}}{m_{U}}
$$

Sendo que $A_{y}$ representa a atividade do radionuclídeo utilizado na NAA para a determinação do elemento de interesse.

O fator de interferência determinado por meio da equação (15) é denominado na literatura como "fator de interferência experimental" (Park et al., 1993; Glascock et al., 1986; Al-Jobori et al., 1990), e pode ser obtido preparando padrões de $U$ e do elemento de interesse com massas conhecidas, irradiando junto estes padrões e utilizando um sistema de aquisição apropriado para a medida de atividade induzida nestes padrões. 
A determinação do fator de interferência devido à fissão do $U$ pode ser realizada utilizando o cálculo teórico de atividade específica nas equações (14) e (5) e dividindo a relação (14) pela (5).

$$
F=\frac{M_{y} \cdot a_{U} \cdot f_{y}\left[\sigma_{t h}^{(n, f)}+\left(\phi_{e p} / \phi_{t h}\right) \cdot \sigma_{e p}^{(n, f)}\right]}{M_{U} \cdot a_{y}\left[\sigma_{t h}^{(n, \gamma)}+\left(\phi_{e p} / \phi_{t h}\right) \cdot \sigma_{e p}^{(n, \gamma)}\right]}
$$

A determinação do fator de interferência por meio da equação (16) é denominada por vários autores como "fator de interferência teórico" (Park et al., 1993; Glascock et al., 1986; Al-Jobori et al., 1990), devido à possibilidade de utilização de parâmetros nucleares reportados na literatura para seu cálculo, exceto os dados de fluxos de nêutrons que dependem das condições nas quais as amostras são irradiadas.

Verifica-se pela análise da equação (16) que a magnitude de interferência provinda da fissão do $U$ em uma análise depende da concentração de $U$ na amostra, do rendimento de fissão cumulativo $(f)$, da seção de choque para a reação $n, f$ do ${ }^{235} \cup\left(\sigma^{(n, f)}\right)$, da abundância isotópica (De Soete et al., 1972), além de algumas características da fonte de nêutrons.

\subsection{Determinação dos fluxos de nêutrons}

\subsubsection{Distribuição energética do espectro de nêutrons em um reator de pesquisas}

A determinação do fator de interferência devido à fissão do $U$ pelo método teórico depende das condições de irradiação, mais precisamente da razão entre o fluxo de nêutrons térmicos e epitérmicos (conforme pode ser visto na equação 16), a qual varia em função da posição de irradiação no reator nuclear.

Os nêutrons em um reator nuclear de pesquisas apresentam energias em uma ampla faixa, variando de frações de eV até a ordem de MeV. Desta maneira é motivo de estudo a determinação da distribuição energética de nêutrons em um reator em bandas que abrangem certas faixas de energia. No 
caso de um reator nuclear de pesquisas o fluxo de nêutrons pode ser dividido em três faixas diferentes (Mariano, 2012):

- Nêutrons térmicos - caracterizada por nêutrons de baixa energia, com valor máximo de até $0,5 \mathrm{eV}$ (Bitelli, 1988). A distribuição energética destes nêutrons é descrita pela função de Maxwell-Boltzmann, pois estão em equilíbrio térmico com o meio moderador;

- Nêutrons epitérmicos - nêutrons com energias acima de $0,5 \mathrm{eV}$ até 0,5 $\mathrm{MeV}$;

- Nêutrons rápidos - nêutrons de fissão, com energias superiores à 0,5 MeV.

Na FIG. 2.4 é apresentado um espectro da distribuição energética dos nêutrons para um reator térmico.

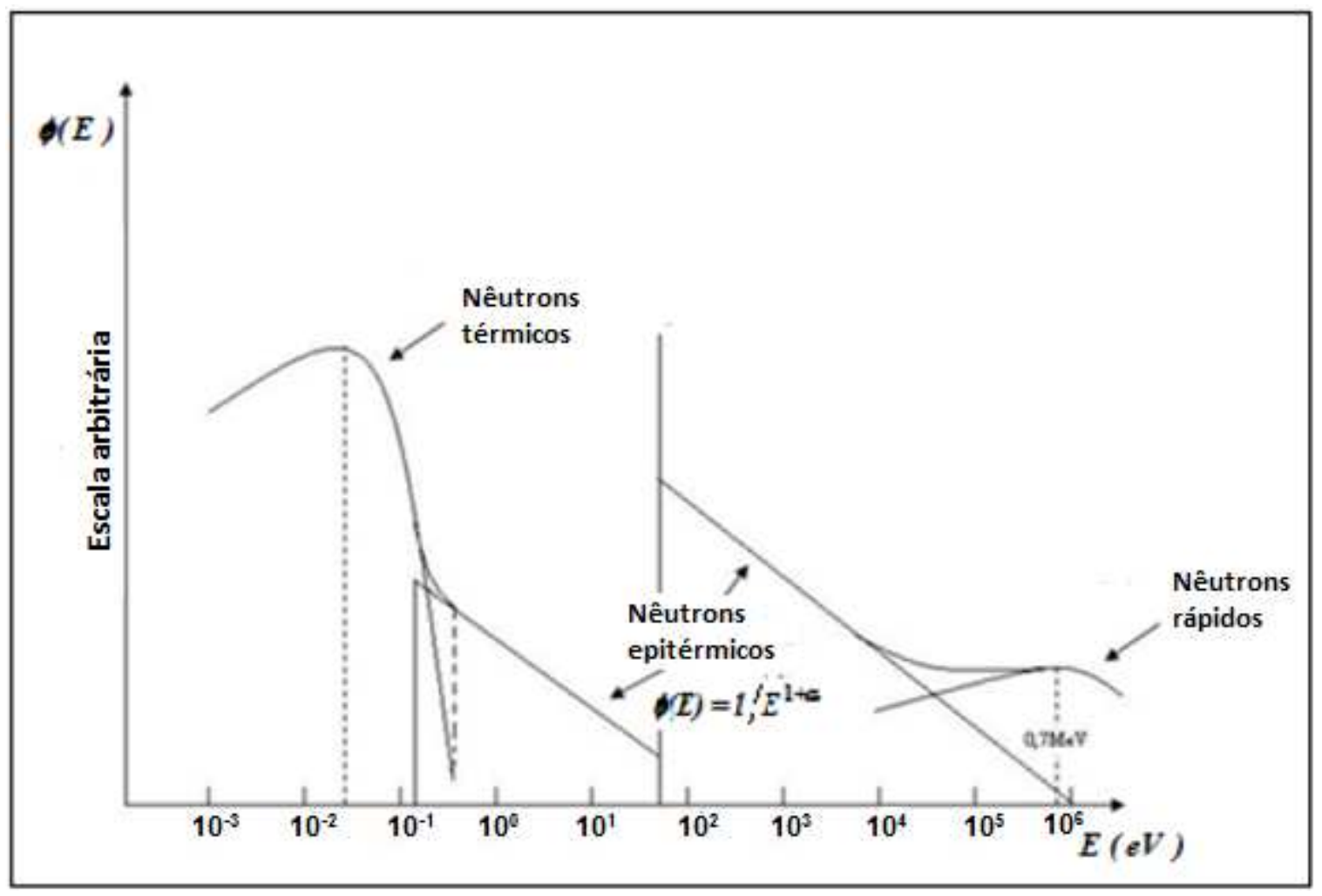

FIGURA 2.4 - Distribuição da densidade do fluxo de nêutrons em função da energia dos nêutrons (Fonte: Costa, 2007).

No reator nuclear IEA-R1 do IPEN-CNEN/SP, os nêutrons são produzidos em uma ampla faixa de energia que varia entre frações de eV até energias da ordem de alguns milhões de elétron-Volt (Koskinas, 1979). Nas proximidades do núcleo do reator grande parte dos nêutrons possuem alta energia, entretanto à medida que se distanciam do núcleo a energia desses nêutrons diminui devido às sucessivas colisões com o meio moderador que, no 
IEA-R1 é a água. Portanto a distribuição energética dos nêutrons varia em função da posição em que as amostras são irradiadas.

No presente trabalho foi feita a determinação do fluxo de nêutrons térmicos e epitérmicos para o cálculo do fator de interferência teórico na mesma posição onde foram irradiados os padrões sintéticos utilizados na determinação do fator de interferência experimental.

\subsubsection{Técnica da razão de cádmio}

A técnica da razão de cádmio é utilizada como um método de medida indireta do fluxo de nêutrons em reatores nucleares de pesquisa. Esta técnica apresenta a vantagem de causar pequenas perturbações no fluxo devido ao pequeno tamanho das folhas de ativação utilizadas (Bitelli, 1988).

Nesta técnica o material utlizado como monitor de fluxo deve possuir elevada seção de choque de ativação para a reação utilizada nas análises. $\mathrm{Na}$ região térmica onde ocorrem prefencialmente reações do tipo $(n, \gamma)$ a seção de choque para ativação deve possuir um comportamento do tipo $1 / \mathrm{v}$, ou seja, a seção de choque para ativação na região térmica deve ser inversamente proporcional a energia do nêutron incidente.

A determinação das magnitudes de fluxo de nêutrons térmicos e epitérmicos é realizada por meio da medida da atividade induzida no detector de ativação via espectroscopia gama , que no presente trabalho será uma liga de AuAl com $0,1 \%$ de Au.

A técnica da razão de cádmio consiste na irradiação simultânea de dois monitores de fluxo, no caso a liga de Au-Al, sendo um em uma cápsula de cádmio e o outro monitor sem a cápsula na mesma posição de irradiação. $\mathrm{O}$ isótopo ${ }^{113} \mathrm{Cd}$ apresenta elevada seção de choque para absorção de nêutrons térmicos, conforme mostrado na FIG. 2.5. 
Cd-113m1(n, $\gamma) C d-114$

$1.0000+00 *$ JEF -2.2

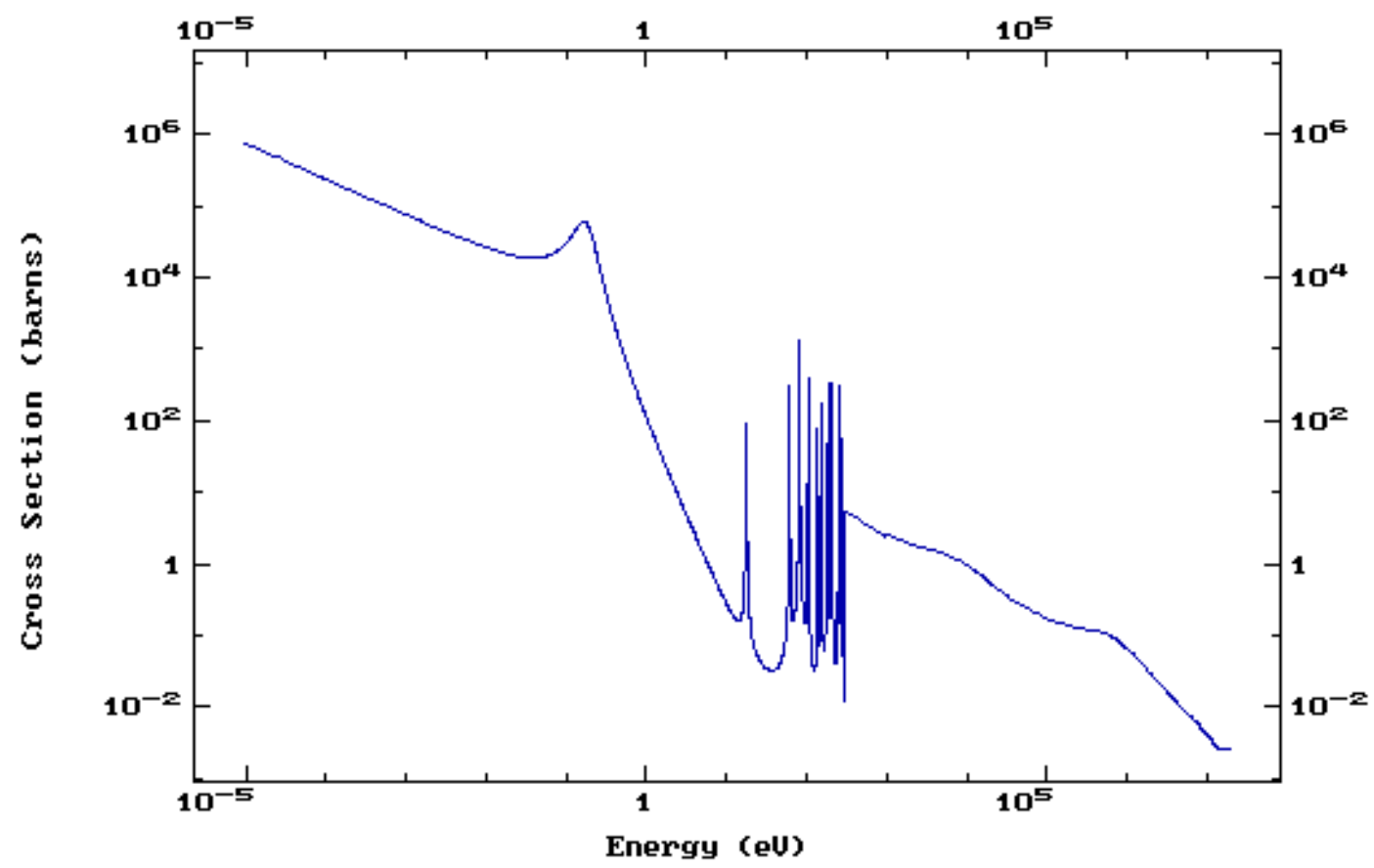

FIGURA 2.5 - Seção de choque para captura de nêutrons do ${ }^{113} \mathrm{Cd}$ em função da energia do nêutron incidente. Na região de energia $0,2 \mathrm{eV}$ verifica-se um brusco degrau, que normalmente é utilizado para definir o limite entre nêutron térmicos e epitérmicos.

Dessa forma, a atividade do monitor de fluxo envolto com cádmio será induzida em sua maioria apenas pelos nêutrons epitérmicos, ao passo que o monitor "nú" terá sua atividade induzida pelos fluxos térmico e epitérmico. Dessa forma a atividade do monitor sem a cápsula de cádmio é expressa por (Bitelli, 1988):

$$
A_{A u}=A_{t h}+A_{e p i}
$$

Sendo $A_{A u}$ a atividade do total do monitor de fluxo sem a cápsula de cádmio, $A_{t h}$ a atividade induzida pelo fluxo térmico e $A_{e p i}$ a atividade induzida pelo fluxo epitérmico (no monitor envolto por cádmio).

Embora $0{ }^{113} \mathrm{Cd}$ possua uma elevada seção de choque para a reação $(\mathrm{n}, \gamma)$, da ordem de $20600 \mathrm{~b}$, ele não é um filtro perfeito, pois parte dos nêutrons térmicos atravessam o cádmio, sendo assim deve-se aplicar uma correção denominada de "fator de cádmio" $\left(F_{C d}\right)$ : 


$$
A_{e p i}=A_{C d} \cdot F_{C d}
$$

Na qual $A_{C d}$ é a atividade medida do monitor de fluxo coberto pela cápsula de cádmio e $F_{C d}$ é o fator de cádmio que depende da espessura da cápsula utilizada.

Para determinar qual é a parcela da atividade induzida no monitor de fluxo nú, ou seja, devido ao fluxo térmico, utiliza-se a razão de cádmio (BITELLI, 1998):

$$
R=\left(\frac{A_{A u}}{A_{C d}}\right) \cdot \frac{m_{C d}}{m_{A u}}
$$

Sendo:

$A_{A u}=$ Atividade do monitor de fluxo sem a cápsula de $\mathrm{Cd}$;

$A_{C d}=$ Atividade do monitor de fluxo coberto com Cd;

$m_{C d}=$ Massa do monitor de fluxo coberto pela cápsula de $\mathrm{Cd}$;

$m_{A u}=$ Massa do monitor de fluxo sem a cápsula de Cd.

A atividade devido ao fluxo de neutrons térmicos é obtida substituindo a equação (19) na relação (17):

$$
A_{t h}=A_{A u}\left(1-\frac{F_{C d}}{R} \frac{m_{C d}}{m_{A u}}\right)
$$

Por fim, os valores de fluxo de nêutrons térmicos e epitérmicos podem ser obtidos utilizando as seguintes relações:

$$
\begin{gathered}
\phi_{n}^{t h}=\frac{A_{A u}\left(1-\frac{F_{C d}}{R} \frac{m_{C d}}{m_{A u}}\right) \cdot M_{A u}}{m_{A u} \cdot N_{0} \cdot \sigma_{t h}} \\
\phi_{n}^{e p i}=\frac{A_{A u}\left[1-\left(1-\frac{F_{C d}}{R} \frac{m_{C d}}{m_{A u}}\right)\right] \cdot M_{A u}}{m_{A u} \cdot N_{0} \cdot \sigma_{e p i}}
\end{gathered}
$$

Sendo $M_{A u}, \sigma_{t h}$ e $\sigma_{e p i}$ : massa atômica do ouro, seção de choque térmica do ouro para captura de nêutrons e integral de ressonância do ouro, 
respectivamente. O presente estudo utilizou ligas de Au-Al infinitamente diluídas e portanto foram desconsiderados efeitos de auto blindagem dos monitores de fluxo utilizados.

\section{REVISÃO DA LITERATURA}

A determinação dos valores dos fatores de interferência devido à fissão do $U$ tem sido objeto de estudo de vários pesquisadores, pois conforme recomendado por De Soete et al. (1972), em amostras que contenham alto teor de U pode ocorrer o problema de interferência nas análises pela NAA quando os radioisótopos utilizados nas análises coincidem com o produto de fissão.

lla et al. (1983) estudaram o problema das interferências dos produtos de fissão dos radioisótopos ${ }^{140} \mathrm{La},{ }^{141} \mathrm{Ce},{ }^{147} \mathrm{Nd}$ e ${ }^{153} \mathrm{Sm}$ e também fizeram a análise de algumas amostras. Os padrões utilizados na determinação dos fatores de interferência foram irradiados em um reator nuclear tipo piscina sob um fluxo de nêutrons de $1,5 \times 10^{13} \mathrm{~cm}^{-2} \cdot \mathrm{s}^{-1}$ localizado na McMaster University, Hamilton, Canadá.

Landsberger (1986) fez a determinação dos fatores de interferência para diversos produtos de fissão no reator nuclear McMaster sob um fluxo de nêutrons térmicos e epitérmicos de $5 \times 10^{12}$ e $2 \times 10^{11} \mathrm{~cm}^{-2} \cdot \mathrm{s}^{-1}$, respectivamente. Em outro trabalho Landsberger, 1989 realizou um trabalho comparativo entre os valores de fatores de interferência obtidos por diferentes autores.

Park et al. (1993) estudaram os fatores de interferência experimentais e teóricos dos radioisótopos ${ }^{95} \mathrm{Zr},{ }^{99} \mathrm{Mo},{ }^{103} \mathrm{Ru},{ }^{140} \mathrm{La},{ }^{141} \mathrm{Ce}$ e ${ }^{147} \mathrm{Nd}$. Estes autores apontam a necessidade de se determinar a concentração dos elementos citados acima com grande precisão em amostras de minerais e rochas em estudos petrogenéticos. As amostras dos elementos de interesse, $U$ e monitores de fluxo de Au-Al e Co-Al foram irradiadas em um reator nuclear tipo TRIGA por um período de $10 \mathrm{~h}$ sob um fluxo de nêutrons de $4 \times 10^{12} \mathrm{~cm}^{-2} \cdot \mathrm{s}^{-1}$.

Al-Jobori et al. (1990) alertam para o problema de interferências devido à fissão do $U$ na determinação de ETRs em matrizes geológicas. Estes autores determinaram os fatores de interferência para os radioisótopos ${ }^{141} \mathrm{Ce},{ }^{143} \mathrm{Ce},{ }^{140} \mathrm{La}$, ${ }^{147} \mathrm{Nd} \mathrm{e}{ }^{95} \mathrm{Zr}$ teoricamente e experimentalmente no núcleo do reator nuclear IRT- 
5000 irradiando padrões dos elementos de interesse e monitores de fluxo por um período de $5 \mathrm{~h}$. Os autores fazem um comparativo entre os valores obtidos para os fatores de interferência e outros valores reportados por outros pesquisadores.

O problema das interferências de produtos de fissão também foi estudado por Myamoto et al. (1999). Neste artigo os autores discutem sobre possíveis problemas que podem levar a resultados analíticos inconsistentes na NAA, e dentre esses problemas é citada a interferência devido aos produtos de fissão do U.Os autores realizaram a determinação dos fatores de interferência para os elementos ${ }^{141} \mathrm{Ce},{ }^{140} \mathrm{La},{ }^{99} \mathrm{Mo},{ }^{147} \mathrm{Nd}$ e ${ }^{95} \mathrm{Zr}$. Este artigo também apresenta resultados obtidos nas análises de alguns materiais de referência utilizando os fatores de correção determinados.

Glascock et al. (1986) alertam para a necessidade de determinação precisa da concentração de ETRs e $Z r$ em estudos de formação das rochas e sobre os erros obtidos nas concentrações em rochas graníticas devido à interferência de produtos de fissão. Estes pesquisadores determinaram os fatores de interferência teoricamente e experimentalmente para os elementos $\mathrm{Ba}, \mathrm{Ce}, \mathrm{La}$, $\mathrm{Mo}, \mathrm{Nd}, \mathrm{Sm}$ e Zr. Os padrões dos elementos de interesse e monitores de fluxo de Co e $\mathrm{Zr}$ foram irradiados juntos, por um período de $12 \mathrm{~h}$ no reator nuclear da Universidade de Missouri (MURR). Estes pesquisadores recomendam a utilização dos fatores de interferência determinados experimentalmente, uma vez que estes não dependem da razão entre fluxo de nêutrons e parâmetros nucleares reportados na literatura. Os fatores de interferência obtidos foram aplicados na determinação da concentração real dos elementos alvo do estudo para se verificar a magnitude da correção devida à fissão do $U$ em alguns MRCs. Martinho \& Freitas (1998) também estudaram a discrepância entre os valores obtidos por diferentes autores.

Vobecky (1979) fez a determinação dos fatores de interferência devido à fissão do U para os radioisótopos ${ }^{141} \mathrm{Ce},{ }^{99} \mathrm{Mo},{ }^{147} \mathrm{Nd},{ }^{103} \mathrm{Ru},{ }^{131} \mathrm{Te}$ e ${ }^{95} \mathrm{Zr}$. Este pesquisador atribui a disparidade dos valores obtidos para $0{ }^{99} \mathrm{Mo}$ entre diferentes pesquisadores em consequência da utilização de diferentes valores publicados de seção de choque e integral de ressonância. Este pesquisador chama a atenção em relação ao fator de interferência do ${ }^{140} \mathrm{La}$ ser devido à série isobárica do produto de fissão ${ }^{140} \mathrm{Ba}$. 
Kawabe et al. (1994) apresentam resultados comparativos entre as concentrações obtidas para alguns ETRs pelas técnicas de INAA e CPS-AES. Neste artigo, os autores mostram que na análise de um dos MRCs os resultados das concentrações obtidos pela INAA foram até 20 vezes maiores do que os resultados obtidos por CPS-AES, em virtude da alta concentração relativa entre $U$ e os ETRs analisados nesse estudo (para alguns elementos essa concentração relativa ficou na ordem de 10 vezes mais $U$ do que o ETR analisado). 


\section{MATERIAIS E MÉTODOS}

Nesta etapa serão descritos os procedimentos relacionados à confecção e irradiação dos padrões sintéticos utilizados para a determinação do fator de interferência experimental, preparação dos materiais de referência analisados neste trabalho, assim como os procedimentos envolvidos na determinação da razão entre fluxos de nêutrons epitérmicos e térmicos.

\subsection{Materiais}

Os principais materiais utilizados no presente trabalho foram as soluções padrões dos elementos alvo deste estudo, os materiais de referência certificados (MRCs), e ligas de Au-Al utilizadas como aferidores de fluxo de nêutrons.

\subsubsection{Materiais de referência certificados (MRCs)}

Foram utilizados MRCs a fim de se verificar a precisão e exatidão dos resultados obtidos nas análises das concentrações dos elementos certificados, e que são alvos deste estudo ( $\mathrm{Ce}, \mathrm{La}, \mathrm{Mo}, \mathrm{Nd}, \mathrm{Sm}$ e $\mathrm{Zr}$ ) e também para a verificação da magnitude da correção da concentração devido à aplicação dos fatores de interferência obtidos. Na TAB.4.1 São apresentados os materiais de referência utilizados.

TABELA 4.1- Materiais de referência utilizados neste trabalho.

\begin{tabular}{ccc}
\hline \multicolumn{1}{c}{ Nome } & Procedência* & Referência \\
\hline RM 8704 Buffalo River Sediment & NIST & NIST, 2008 \\
IAEA-SL-1 Lake Sediment & IAEA & IAEA, 1999 \\
BCR-677 Estuarine Sediment & IRMM & IRMM, 1999 \\
\hline $\begin{array}{l}\text { *NIST= National Institute of Standards and Technology; IAEA= International Atomic Energy Agency; IRMM= } \\
\text { Institute for Reference Material and Measurements. }\end{array}$ &
\end{tabular}

Os MRCs presentes na TAB 3.1 foram escolhidos tendo em vista a concentração de $U$, concentração dos elementos de interesse presentes e a disponibilidade destes MRCs para sua utilização.

\subsubsection{Aferidores de fluxo}

A determinação do fluxo de nêutrons térmicos e epitérmicos foi realizada utilizando uma liga de Au-Al com $0,1 \%$ de $A u$ como monitor de fluxo. Essas ligas foram fabricadas pelo Institute for Reference Materials and Measurements (IRMM-530R). 
As caixas de Cd utilizadas na determinação do fluxo de nêutrons foram confeccionadas utilizando as seguintes dimensões:

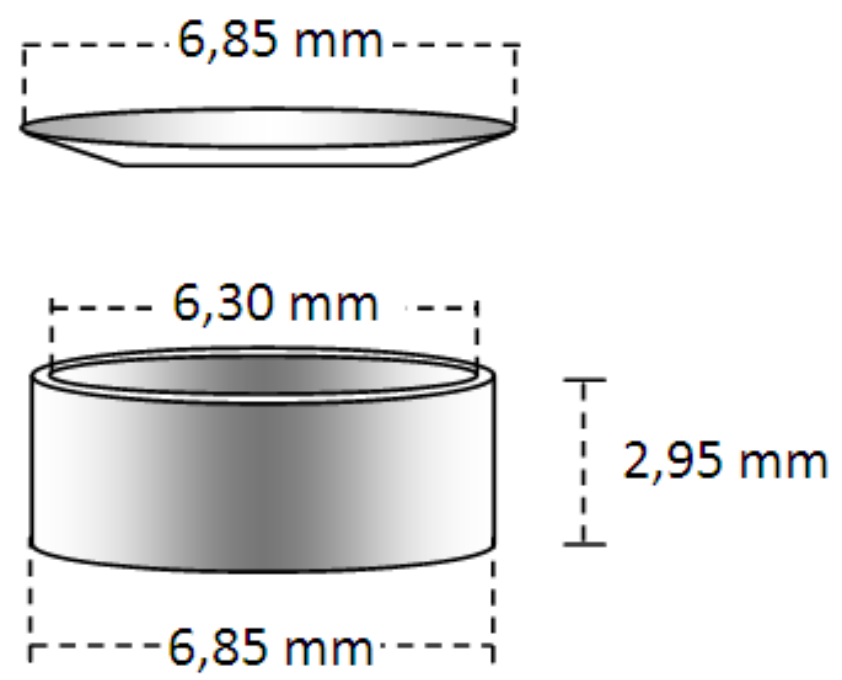

FIGURA 4.1 - Dimensões da caixa de Cd utilizada.

O fator de cádmio utilizado na determinação da razão dos fluxos de nêutrons epitérmicos e térmicos varia em função da espessura da caixa de Cd utilizada. No presente estudo a espessura da caixa de Cd utilizada foi de 0,5 $\mathrm{mm}$ que corresponde a um fator de cádmio de 1,098.

\subsection{Métodos}

Os fatores de interferência devido à fissão do $U$ foram determinados por meio de duas metodologias diferentes, denominadas por método teórico e método experimental.

$\checkmark$ Método Teórico: utilizando parâmetros nucleares e a razão entre o fluxo de nêutrons térmicos e epitérmicos, determinada experimentalmente;

$\checkmark$ Método Experimental: por meio da irradiação no reator nuclear de padrões de $\mathrm{U}$ e dos elementos $\mathrm{Ce}$, La, Mo, $\mathrm{Nd}$, Sm e $\mathrm{Zr}$, cujos radioisótopos formados sofrem interferências dos produtos de fissão do $U$.

$\mathrm{Na}$ análise dos MRCs foi empregada a técnica da análise por ativação com nêutrons instrumental, descrita no Capítulo 2.

\subsubsection{Preparação dos MRCs}

Foi realizada a determinação da perda de umidade dos MRCs utilizados neste estudo a fim de se obter os resultados analíticos expressos na 
base seca. Para tal foram pesados cerca de $200 \mathrm{mg}$ de cada um destes MRCs em pesa-filtros limpos utilizando uma balança da marca Shimadzu modelo AEL40SM com uma precisão de 0,01 mg. Em seguida estes pesa-filtros foram levados para a secagem em uma estufa de secagem e esterilização marca FANEM modelo $315 \mathrm{SE}$, por um período aproximado de 24 horas à temperatura de $105^{\circ} \mathrm{C}$. Após este período foram aferidas novamente as massas destes MRCs, a perda de umidade foi obtida pela diferença das massas dos materiais antes e após a secagem.

A perda de umidade dos materiais de referência IAEA-SL-1, RM 8704 e BCR-667 obtidas foram respectivamente 4,2\%, 0,7\% e 0,9\%.

Após a determinação da perda de umidade os materiais de referência foram pesados em invólucros de polietileno desmineralizado confeccionados com uma seladora elétrica e devidamente identificados.

\subsubsection{Preparação dos padrões sintéticos}

Para a determinação dos fatores de interferência experimentais e análise dos materiais de referência foram utilizadas soluções concentradas dos elementos alvo deste estudo ( $\mathrm{Ce}$, La, Mo, Nd, Sm, Zr e U) oriundas das empresas Spex Certi Prep EUA e Alfa Cesar. Estas soluções padrões foram previamente diluídas a fim de se obter as massas adequadas nos padrões confeccionados para irradiação.

Os padrões sintéticos diluídos dos elementos de interesse foram preparados pipetando-se $50 \mu \mathrm{L}$ destas soluções em tiras de papel filtro Whatman $\mathrm{n}^{\circ} 40 \mathrm{com}$ dimensões aproximadas de $1,8 \mathrm{~cm} \times 6,0 \mathrm{~cm}$, as quais foram colocadas em um dessecador contendo sílica para que a secagem acontecesse à temperatura ambiente, pelo período de 24 horas. A calibração da pipeta utilizada neste procedimento foi previamente verificada.

Após a secagem, as tiras de papel pipetadas foram dobradas com auxílio de pinça revestida com teflon. Em seguida estas tiras foram inseridas em invólucros de polietileno incolor previamente desmineralizados e selados com 0 uso de uma seladora elétrica. Na FIG. 4.2 é apresentada a foto dos padrões sintéticos devidamente codificados e a pinça revestida com teflon. 


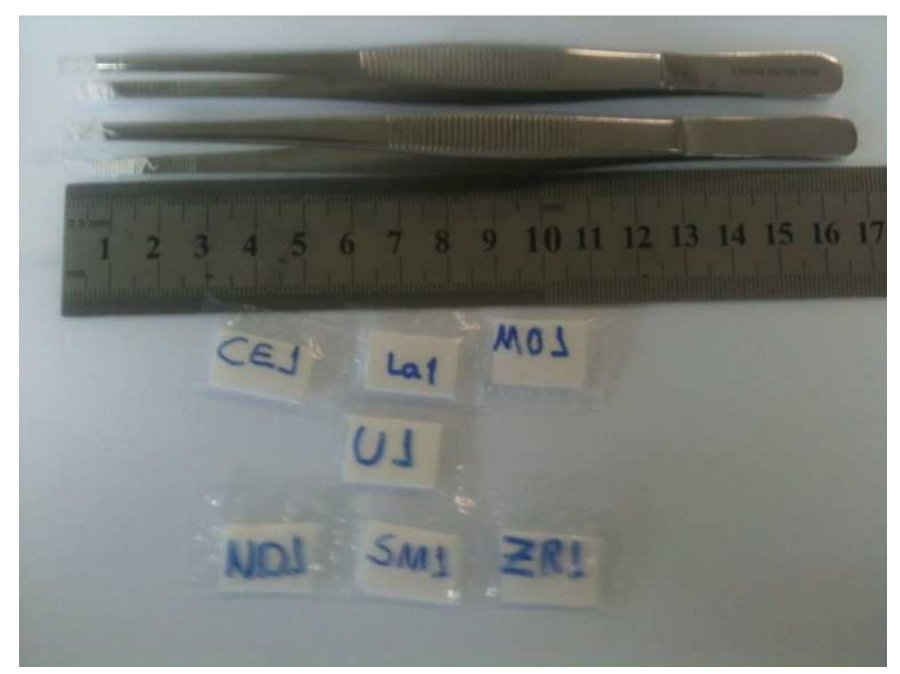

FIGURA 4.2 - Foto dos padrões sintéticos preparados e das pinças utilizadas.

$\mathrm{Na}$ TAB. 4.2 são apresentados os padrões sintéticos utilizados, os elementos de interesse presentes nesses padrões, sua concentração e sua massa total.

TABELA 4.2 - Concentração e massa dos elementos de interesse nos padrões sintéticos preparados.

\begin{tabular}{cccc}
\hline $\begin{array}{c}\text { Elemento no } \\
\text { padrão }\end{array}$ & Código & $\begin{array}{c}\text { Concentração do } \\
\text { elemento }\left(\mu \mathrm{mL}^{-1}\right)\end{array}$ & Massa (ng) \\
\hline Ce & CE1 & $159,7 \pm 0,5$ & $7984 \pm 161$ \\
La & LA1 & $39,9 \pm 0,1$ & $1996 \pm 40$ \\
Mo & MO1 & $120,4 \pm 0,4$ & $6018 \pm 122$ \\
Nd & ND1 & $200,2 \pm 0,6$ & $10010 \pm 202$ \\
Sm & SM1 & $200,2 \pm 0,6$ & $10010 \pm 20$ \\
Zr & ZR1 & $2000 \pm 0,6$ & $100000 \pm 2022$ \\
U & U1 & $200,6 \pm 0,6$ & $10030 \pm 203$ \\
\hline
\end{tabular}

Para o cálculo das incertezas das massas dos elementos pipetados nos padrões químicos foi acrescentado um erro relativo de $2 \%$ da massa total utilizada devido à incerteza da pipeta.

\subsubsection{Preparação dos monitores de fluxo}

A preparação dos monitores de fluxo consistiu na limpeza das ligas com álcool etílico, no corte e medida das massas por meio de uma balança da marca Shimadzu modelo AEL-40SM com uma precisão de 0,01 mg. Cada monitor utilizado na determinação dos fluxos possuiu uma massa total de 
aproximadamente $4 \mathrm{mg}$, após a pesagem os monitores de fluxo utilizados foram devidamente codificados e embrulhados em papel alumínio para evitar problemas de contaminação. Na FIG. 4.3 é mostrada a foto de um monitor de fluxo ao lado de uma régua.



FIGURA 4.3 - Dimensão dos monitores de fluxo utilizados.

\subsubsection{Determinação dos fatores de interferência experimentais}

A determinação dos fatores de interferência experimentais foi realizada irradiando-se os padrões sintéticos dos elementos de interesse e um padrão de $U$ dentro de um mesmo dispositivo de irradiação.

Os padrões sintéticos dos elementos de interesse foram embrulhados individualmente em uma folha de alumínio e posteriormente todos eles foram envolvidos em uma nova folha de alumínio. Em seguida, este conjunto contendo os padrões sintéticos foi colocado dentro de um dispositivo de irradiação denominado "coelho". Este procedimento foi adotado para garantir que as condições de irradiação fossem as mesmas para todos os padrões sintéticos.

Devido à ampla utilização na análise de materiais geológicos as irradiações para a determinação dos fatores de interferência foram realizadas na posição $14 \mathrm{~b}$ prateleira 3 , do reator IEA-R1, durante um período de 8 horas sob o fluxo total de nêutrons de $4,6 \times 10^{12} \mathrm{~cm}^{-2} \mathrm{~s}^{-1}$. No total, foram realizadas 18 irradiações dos padrões sintéticos. Na FIG 4.4 está representada um esquema da configuração do reator para se ter uma ideia da posição onde foram determinados os fatores de interferência. Na FIG. 4.5 está representado o esquema da 
sequência de eventos para a irradiação das amostras e padrões no reator nuclear e a tomada de dados.



FIGURA 4.4 - Configuração do reator IEA-R1 do IPEN-CNEN/SP. A posição 14B prateleira 3 (4⿳亠丷厂 coluna, $3^{a}$ linha) é onde as medidas foram realizadas .

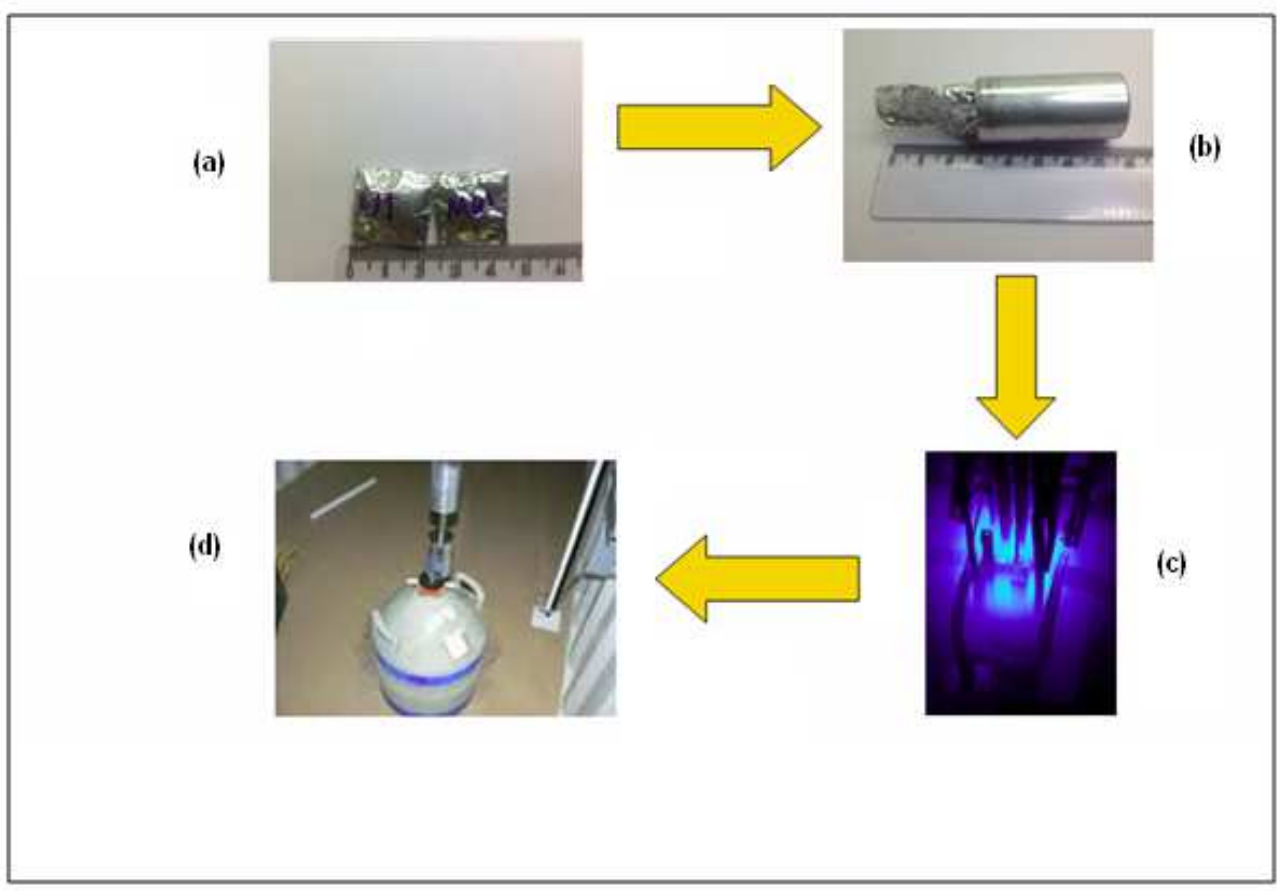

FIGURA 4.5 - Esquema de sequência da preparação e irradiação das amostras. (a) padrões embrulhados em folha de alumínio; (b) padrões inseridos no coelho; (c) irradiação no reator nuclear; (d) contagem das atividades. 
As amostras foram abertas após aproximadamente 6 dias de espera (ou decaimento), tempo em que a dose absorvida é baixa o suficiente para esse procedimento. Após a abertura do coelho, os padrões foram fixados individualmente em suportes de aço inoxidável, denominados "panelinhas", com o auxílio de pinças e fita gomada, conforme mostrado na FIG. 4.6.

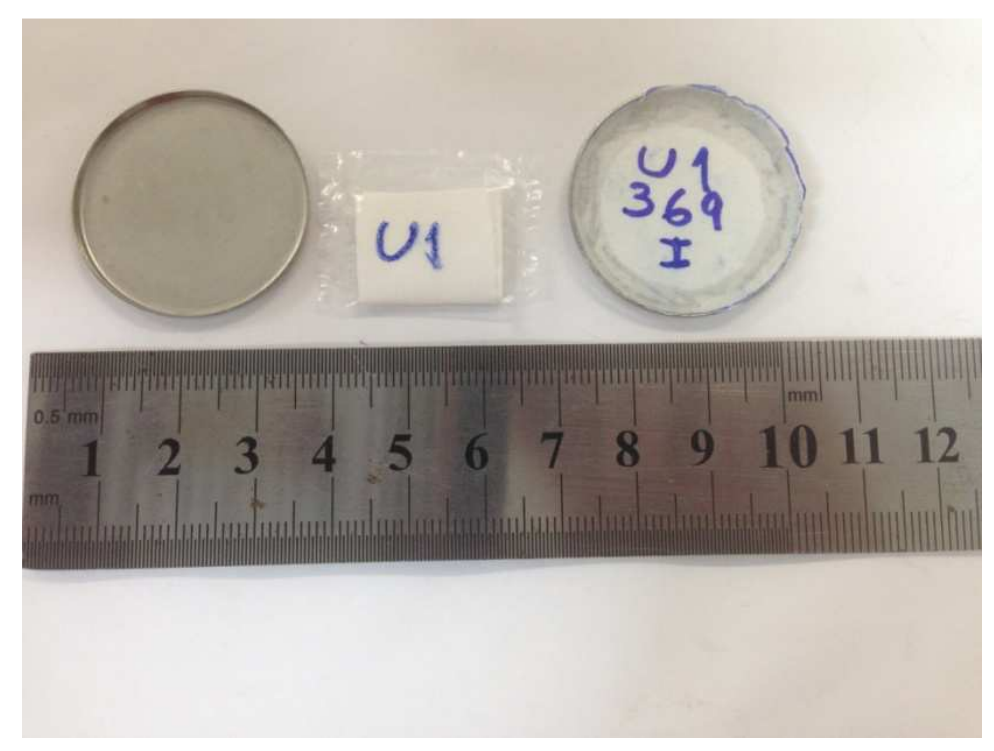

FIGURA 4.6 - Foto da amostra fixada no suporte de aço inoxidável.

As atividades das amostras foram medidas por meio das transições gamas características dos radioisótopos formados, em um detector de germânio hiperpuro modelo GC1930 com eficiência nominal de 30\% e resolução de 0,90 $\mathrm{keV}$ na energia de $122 \mathrm{keV}$ e 1,80 keV para energia de $1332 \mathrm{keV}$, acoplado a um processador digital de espectro DSA1000, ambos da marca Canberra. A análise do espectro das transições gama foi feita com o uso do software Canberra Genie 2000 versão 3.1 que fornece as taxas de contagens (cps) dos raios gamas analisados e seus respectivos desvios padrões.

As medições das atividades dos radioisótopos analisados foram realizadas em três tempos de decaimento diferentes: 6, 13 e 20 dias após a irradiação, a fim de mitigar o problema de interferências espectrais. Os tempos de contagem utilizados na aquisição de dados variaram entre 3600 e 10000 segundos para os padrões sintéticos a fim de se obter melhor estatística de contagens para as amostras com maior atividade, como no caso o $\mathrm{U}$. 
Foram utilizadas diferentes distâncias entre a fonte e o detector nas análises das atividades dos materiais de referência e padrões sintéticos a fim de minimizar problemas ocasionados por tempo morto elevado. A FIG.4.7 mostra as diferentes posições utilizadas nas aquisições de dados.

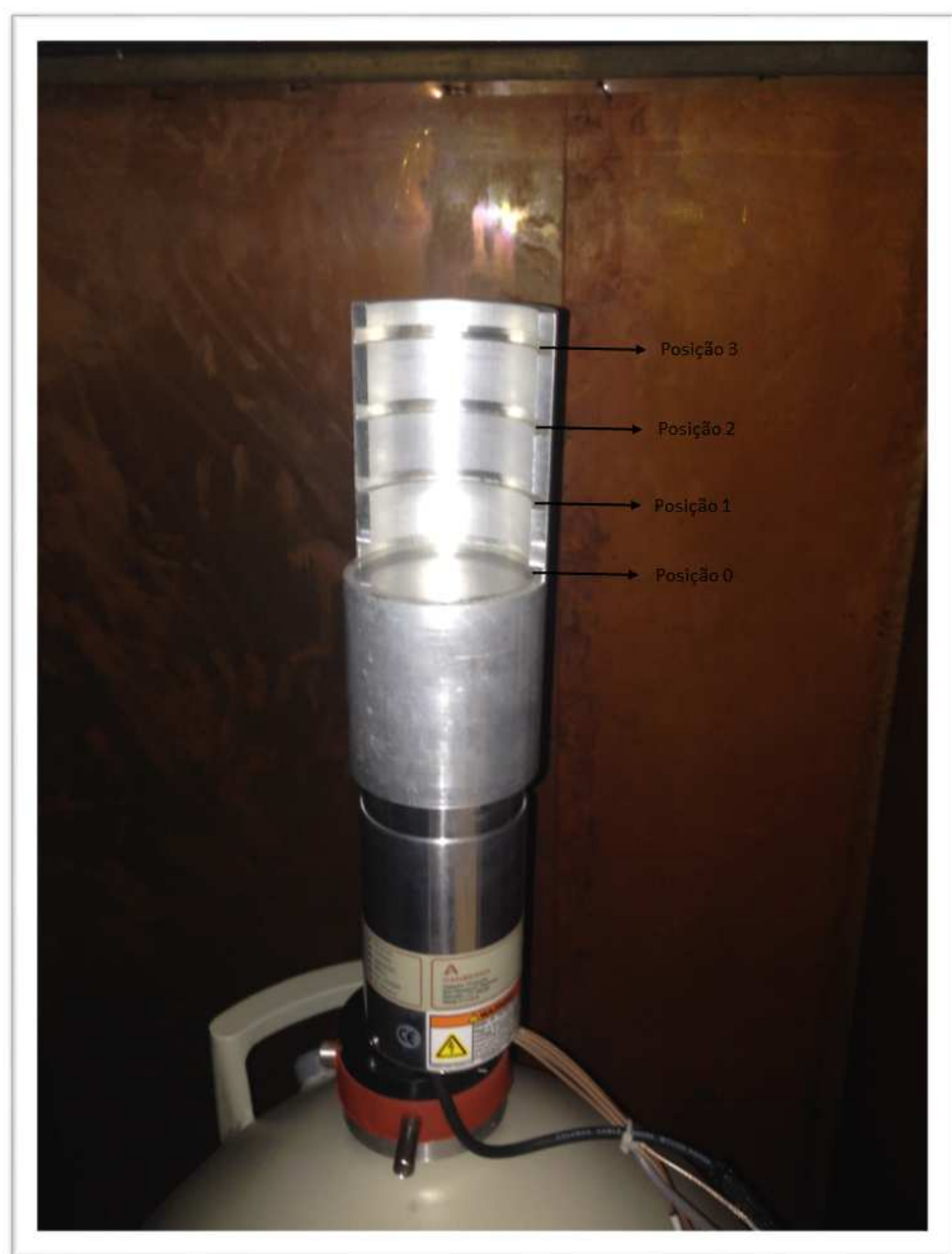

FIGURA 4.7 - Diferentes posições de contagem utilizadas na aquisição de dados.

As distâncias fonte-detector usadas, que variaram em função da atividade da amostra, foram de $0 \mathrm{~cm}, 3,5 \mathrm{~cm}, 7,0 \mathrm{~cm}$ e $10,5 \mathrm{~cm}$ aqui chamadas de posições $0,1,2$ e 3 respectivamente, representadas na FIG. 4.7 .

A identificação dos radioisótopos foi realizada por meio da energia, meia vida e intensidade das transições gamas. Na TAB. 4.3 são apresentadas as características nucleares dos radioisótopos analisados neste trabalho. 
TABELA 4.3 - Parâmetros nucleares dos radioisótopos utilizados na determinação das atividades (LNHB).

\begin{tabular}{ccccc}
\hline \multirow{2}{*}{ Elemento } & Radioisótopo & E $\boldsymbol{( k e V )}$ & Intensidade & $\begin{array}{c}\text { Meia vida } \\
\text { (d) }\end{array}$ \\
\hline \multirow{2}{*}{$\mathrm{Ce}$} & ${ }^{141} \mathrm{Ce}$ & $145,4433(14)^{*}$ & $0,4829(19)$ & $32,503(11)$ \\
& ${ }^{143} \mathrm{Ce}$ & $293,266(2)^{*}$ & $0,428(4)$ & $1,3766(2)$ \\
\hline \multirow{2}{*}{$\mathrm{La}$} & ${ }^{140} \mathrm{La}$ & $487,022(6)$ & $0,461(4)$ & $1,67850(17)$ \\
& ${ }^{140} \mathrm{La}$ & $328,761(4)$ & $0,208(3)$ & $1,67850(17)$ \\
& ${ }^{140} \mathrm{La}$ & $815,781(6)$ & $0,2372(12)$ & $1,67850(17)$ \\
& ${ }^{140} \mathrm{La}$ & $1596,203(13)^{*}$ & $0,9540(8)$ & $1,67850(17)$ \\
$\mathrm{Mo}$ & ${ }^{99} \mathrm{Mo}$ & $140,511(1)^{* a}$ & $0,896(17)$ & $2,7479(6)$ \\
& ${ }^{99} \mathrm{Mo}$ & $181,068(8)$ & $0,0601(11)$ & $2,7479(6)$ \\
& ${ }^{99} \mathrm{Mo}$ & $739,500(17)^{*}$ & $0,1212(15)$ & $2,7479(6)$ \\
\hline \multirow{2}{*}{$\mathrm{Nd}$} & ${ }^{147} \mathrm{Nd}$ & $91,105(2)$ & $0,284(18)$ & $10,987(11)$ \\
& ${ }^{147} \mathrm{Nd}$ & $531,016(22)^{*}$ & $0,127(9)$ & $10,987(11)$ \\
\hline \multirow{2}{*}{$\mathrm{Sm}$} & ${ }^{153} \mathrm{Sm}$ & $103,18012(17)$ & $0,2919(16)$ & $1,92855(5)$ \\
\hline & ${ }^{95} \mathrm{Zr}$ & $724,193(3)$ & $0,4427(22)$ & $64,032(6)$ \\
& ${ }^{95} \mathrm{Zr}$ & $756,729(12)^{*}$ & $0,5438(22)$ & $64,032(6)$ \\
\hline \multirow{2}{*}{$\mathrm{U}$} & ${ }^{239} \mathrm{~Np}$ & $106,125(2)$ & $0,259(3)$ & $2,356(3)$ \\
& ${ }^{239} \mathrm{~Np}$ & $228,183(1)$ & $0,1132(22)$ & $2,356(3)$ \\
& ${ }^{239} \mathrm{~Np}$ & $277,599(1)^{*}$ & $0,144(1)$ & $2,356(3)$ \\
\hline
\end{tabular}

*Transições gama recomendadas para análise por IAEA, 1990. ${ }^{\text {T}}$ Transição gama oriunda do ${ }^{99 \mathrm{~m}} \mathrm{Tc}$.

O cálculo dos fatores de interferência e a análise dos materiais de referência certificados foram realizadas utilizando as equações e procedimentos descritos nos itens 2.1 .2 e 2.4 .

\subsubsection{Determinação teórica dos fatores de interferência}

Os valores dos fatores de interferência determinados teoricamente dependem de alguns parâmetros nucleares característicos de cada reação envolvida na ativação do elemento de interesse (conforme visto na equação 15). Estes parâmetros nucleares são apresentados na TAB. 4.4. 
TABELA 4.4 - Parâmetros nucleares utilizados no cálculo do fator de interferência teórico.

\begin{tabular}{cccccc}
\hline Reação nuclear & $\begin{array}{c}\text { Abundância } \\
\text { isotópica } \\
\text { [Firestone, } \\
1996]\end{array}$ & $\begin{array}{c}\text { Massa } \\
\text { atômica }\end{array}$ & $\begin{array}{c}\sigma_{\text {Th flux }}(\mathrm{b}) \\
\text { [Mughabghab, } \\
\text { 2003] }\end{array}$ & $\begin{array}{c}\sigma_{\text {Epth flux }}(\mathrm{b}) \\
\text { [Mughabghab, } \\
\text { 2003] }\end{array}$ & $\begin{array}{c}\text { Rendimento } \\
\text { de fissão } \\
\text { cumulativa } \\
\text { [IAEA, 2012] }\end{array}$ \\
\hline${ }^{139} \mathrm{La}(n, \gamma){ }^{140} \mathrm{La}$ & 0,999088 & 138,905 & $9,04 \pm 0,04$ & $12,1 \pm 0,6$ & 0,062946 \\
${ }^{140} \mathrm{Ce}(n, \gamma){ }^{141} \mathrm{Ce}$ & 0,88449 & 140,116 & $0,58 \pm 0,02$ & $0,54 \pm 0,05$ & 0,0586 \\
${ }^{142} \mathrm{Ce}(n, \gamma){ }^{143} \mathrm{Ce}$ & 0,1108 & 140,116 & $0,97 \pm 0,02$ & $1,15 \pm 0,05$ & 0,0599 \\
${ }^{146} \mathrm{Nd}(n, \gamma){ }^{147} \mathrm{Nd}$ & 0,1719 & 144,24 & $1,41 \pm 0,05$ & $23,2 \pm 0,5$ & 0,02232 \\
${ }^{152} \mathrm{Sm}(n, \gamma){ }^{153} \mathrm{Sm}$ & 0,267 & 150,36 & $206 \pm 6$ & $2970 \pm 100$ & 0,001477 \\
${ }^{98} \mathrm{Mo}(n, \gamma){ }^{99} \mathrm{Mo}$ & 0,2413 & 95,94 & $0,137 \pm 0,02$ & $6,9 \pm 0,3$ & 0,06132 \\
${ }^{94} \mathrm{Zr}(n, \gamma){ }^{95} \mathrm{Zr}$ & 0,1738 & 91,224 & $0,0499 \pm 0,0024$ & $0,27 \pm 0,03$ & 0,06502 \\
${ }^{235} \mathrm{U}(n, f)$ & 0,0072 & 238,029 & $582,6^{[\mathrm{a}]}$ & $275^{[a]}$ & \\
\hline
\end{tabular}

a= Referência: https://www-nds.iaea.org/sgnucdat/a5.htm

Para a determinação dos fatores de interferência teóricos foram realizadas as determinações dos fluxos de nêutrons térmicos e epitérmicos na mesma posição onde os padrões sintéticos dos elementos de interesse foram irradiados.

A determinação do fluxo de nêutrons térmicos e epitérmicos consistiu na irradiação de 8 amostras de ligas de Au-Al por um período de $4 \mathrm{~h}$ na mesma posição 14b prateleira 3 onde foram irradiados os padrões sintéticos e materiais de referência.

As ligas de Au-Al foram irradiadas dentro de um mesmo dispositivo de irradiação, sendo um dos monitores "nú" e o outro dentro de uma cápsula de cádmio. A liga irradiada dentro da cápsula de cádmio foi envolvida em uma folha de alumínio para diminuir o risco de contaminação com o Cd da cápsula.

Foi mantida uma distância de aproximadamente $6 \mathrm{~cm}$ entre 0 monitor nú e a cápsula de Cd para minimizar problemas de sombreamento devido à alta seção de choque térmica para reação $(n, \gamma)$ do ${ }^{113} \mathrm{Cd}(20600 \mathrm{~b} \pm 400 \mathrm{~b})$. A foto do arranjo experimental utilizado na irradiação destes monitores de fluxo é mostrada na FIG. 4.8. 


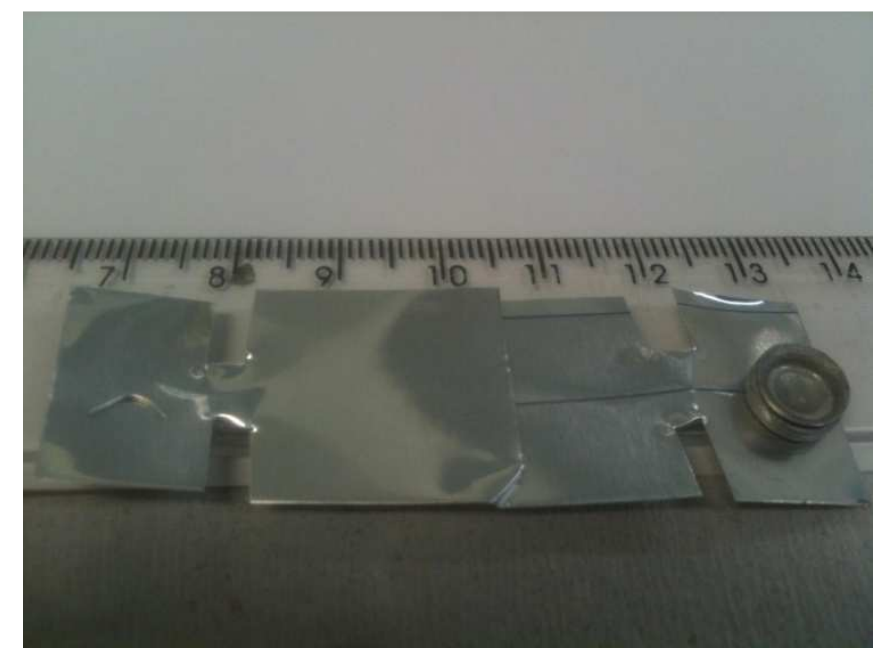

FIGURA 4.8 - Arranjo experimental montado para a irradiação dos monitores de fluxo.

As medições das atividades foram feitas por meio do mesmo sistema de detecção descrito no item 4.2.6, com tempo de decaimento de aproximadamente 6 dias usando a transição gama de $411 \mathrm{keV}$ do ${ }^{198} \mathrm{Au}$ (meia vida $=2,69 \mathrm{~d}$ ). Os tempos de contagem utilizados na aquisição de dados variaram entre 3600 e 5400 segundos.

O detector utilizado na análise da atividade dos monitores de fluxos foi previamente calibrado em relação à eficiência na energia de $411 \mathrm{keV}$ utilizando uma fonte calibrada de ${ }^{152}$ Eu cuja transição gama é de 411,115 keV e meia vida de 13,5 anos. A determinação da eficiência consistiu em realizar contagens desta amostra nas diferentes posições presentes na FIG. 4.7 com tempos de contagem de aproximadamente $3600 \mathrm{~s}$.

\subsubsection{Análise dos MRCs.}

Os MRCs foram primeiramente embrulhados individualmente em folha de alumínio, em seguida foram envoltos todos juntos em uma única folha de alumínio e colocados em um único dispositivo de irradiação, conforme mostrado na FIG. 4.9.

Este conjunto contendo todos os padrões e os MRCs foram irradiados na mesma posição 14b prateleira 3, do reator IEA-R1, por um período de 8 horas e sob o fluxo total de nêutrons $4,6 \times 10^{12} \mathrm{~cm}^{-2} \mathrm{~s}^{-1}$. Devido ao elevado número de padrões químicos necessários, só foi possível acomodar 2 MRCs por irradiação. A abertura do dispositivo de irradiação foi realizada também com tempo de decaimento de aproximadamente 6 dias após a irradiação. 

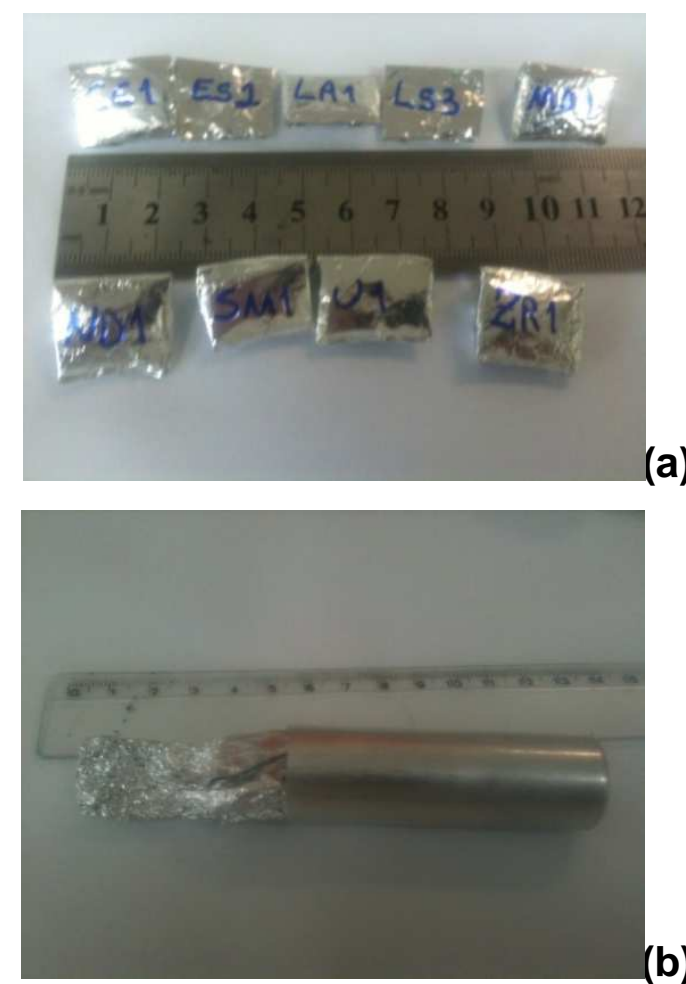

FIGURA 4.9 - (a) foto dos padrões e amostras envoltos individualmente em folha de alumínio; (b) foto do conjunto padrões e amostras dentro do dispositivo de irradiação.

As transições gamas utilizadas na determinação da concentração dos elementos alvo deste estudo foram as recomendadas pela IAEA, 1990, conforme mostrado na TAB. 4.3.

As taxas de contagens foram medidas pelo mesmo sistema de aquisição descrito no item 4.2.4 com tempos de decaimento que variaram entre 6 dias e 21 dias a fim de se evitar problemas de interferências de outros elementos presentes nas amostras analisadas. Os tempos de contagem foram de $50000 \mathrm{~s}$ para melhorar a estimativa do erro nas taxas de contagens.

\subsubsection{Análise estatística dos dados}

Os resultados obtidos para os fatores de interferência experimental foram analisados por 4 métodos estatísticos diferentes, a saber: utilizando a média aritmética (MA), Média ponderada com $1 / \sigma^{2}(\mathrm{MP})$, Método dos Resíduos Normalizados (MRN) e o teste de Rajeval (RJ). As descrições dessas metodologias seguem nas subseções a seguir. 


\subsubsection{Média aritmética}

A média aritmética para uma distribuição de dados não agrupados é calculada utilizando a seguinte expressão (Mann, 2004):

$$
\bar{x}=\frac{\sum x}{N}
$$

Onde $\bar{x}$ representa a média aritmética, $\sum x$ representa a somatória dos dados experimentais e $N$ é o tamanho da população.

O desvio padrão da média aritmética pode ser calculado utilizando a seguinte expressão:

$$
\sigma_{\bar{x}}=\sqrt{\frac{\sum(x-\bar{x})^{2}}{N-1}} \cdot \frac{1}{\sqrt{N}}
$$

A determinação do valor do fator de interferência calculado por meio da média aritmética e do desvio da média apresenta a desvantagem de não utilizar informações sobre as incertezas obtidas nas diferentes medidas. Para uma análise mais aprimorada dos resultados obtidos utilizou-se no presente trabalho outros tratamentos estatísticos que serão descritos neste capítulo.

\subsubsection{Média ponderada com $1 / \sigma^{2}$}

Esta técnica pode ser utilizada quando pretende-se determinar a média de uma mesma grandeza física (Lyons, 1986). Por está técnica o valor da média é obtida utilizando a seguinte equação:

$$
\bar{x}=\sum\left(x_{i} / \sigma_{i}^{2}\right) / \sum\left(1 / \sigma_{i}^{2}\right)
$$

Sendo que $x_{i}$ e $\sigma_{i}$ representam o valor medida $i$ e a incerteza associada à medida $i$, respectivamente.

O desvio padrão da média neste caso é calculado utilizando a equação (26):

$$
\frac{1}{\sigma^{2}}=\sum\left(1 / \sigma_{i}^{2}\right)
$$

Esta maneira de se calcular a média e o desvio padrão apresentam a vantagem em relação à primeira metodologia na medida em que são considerados os valores das incertezas envolvidas em cada medida, e desta 
forma são extraídas mais informações das medidas individuais no cálculo da média. Contudo esta metodologia apresenta a desvantagem de que valores experimentais com baixo desvio padrão podem influenciar fortemente no valor da média.

\subsubsection{Método dos Resíduos Normalizados}

O cálculo da média e seu desvio pelo Método dos Resíduos Normalizados (MRN) é realizado utilizando as equações (24) e (26), ou seja, os valores obtidos são ponderados em função de $1 / \sigma_{i}^{2}$. Contudo, esta técnica normaliza os erros experimentais de forma que um dado valor $x_{i}$ cuja incerteza associada é $\sigma_{i}$ não tenha peso maior que $50 \%$ no cálculo da média, por isso é denominada Método dos Resíduos Normalizados (James et al, 1986; Macmahon et al., 2004).

A análise dos resíduos é realizada utilizando a equação (27):

$$
R_{i}=\sqrt{\frac{w_{i} W}{W-w_{i}}} \cdot\left(x_{i}-\bar{x}\right)
$$

Sendo $\bar{x}$ a média ponderada com $1 / \sigma_{i}^{2}$ que é dada por $\bar{x}=\sum x_{i} w_{i} / W$, $w_{i}=1 / \sigma_{i}^{2}$ e $W=\sum w_{i}$.

Utilizando a equação (28) é estipulado um valor máximo para os resíduos $\left(R_{0}\right)$ em função do número de medidas $(N)$.

$$
R_{0}=\sqrt{1,8 \cdot \ln (N)+2.6}
$$

Nesta técnica, se o módulo de valor de resíduo de um ponto experimental $\left(R_{i}\right)$ for maior que o valor calculado de resíduo $R_{0}$, os valores de $R_{i}$ que excedem $R_{0}$ são ajustado. Para cada ponto ajustado de $R_{i}$ é calculada uma nova média até que a todos os valores de $R_{i}$ sejam menores que o valor de $R_{0}$.

\subsubsection{Técnica de Rajeval}

A técnica de Rajeval é semelhante ao Método dos Resíduos Normalizados na medida em que os valores das incertezas são ajustados a fim de que pontos discrepantes com menores incertezas não tenham peso demasiado no cálculo da média. Contudo, esta técnica apresenta a vantagem da realização de teste de outliers antes da realização da análise dos resíduos, para que estes valores sejam ignorados nos cálculos. O teste de outliers é realizado utilizando a equação (29): 


$$
y_{i}=\frac{x_{i}-\bar{x}_{A i}}{\sqrt{\sigma_{i}^{2}+\sigma_{A i}^{2}}}
$$

Sendo $\bar{x}_{A i}$ a média aritmética dos dados experimentais desconsiderando o valor $x_{i}$ que se deseja verificar a validade e $\sigma_{A i}^{2}$ é o desvio da média aritmética desconsiderando a incerteza $\sigma_{i}^{2}$.

Valores de módulo $y_{i}$ até 1,96 são considerados críticos a um nível de significância de $5 \%$. Contudo, nesta técnica são considerados outliers valores de módulo de $y_{i}$ maiores do que $3 \times 1,96$.

Em seguida os valores restantes que são submetidos a um teste de consistência utilizando a equação (30):

$$
z_{i}=\frac{x_{i}-\bar{x}}{\sqrt{\sigma_{i}^{2}+\sigma_{w}^{2}}}
$$

O desvio central é calculado pela diferença absoluta entre as probabilidades obtidas pelo valor de $z_{i}$ e 0,5 . Este valor obtido é comparado com um valor crítico, que é determinado pela seguinte relação:

$$
0,5^{N} /(N-1)
$$

Esta relação tem validade desde que $N$ seja maior do que 2 (Rajput \& Mahon, 1992).

Os valores de desvio central que são maiores do que o valor crítico calculado são considerados inconsistentes e tem suas incertezas ajustadas pela seguinte relação:

$$
\sigma_{i}^{\prime}=\sqrt{\sigma_{i}^{2}+\sigma_{w}^{2}}
$$

Para cada análise de consistência dos valores pelo teste $z$, quando necessários são realizados ajustes das incertezas $\sigma_{i}^{\prime}$ de modo que todos os valores de desvio central sejam menores do que o desvio crítico. 


\section{RESULTADOS E DISCUSSÃO}

Neste capítulo são apresentados os resultados obtidos dos fatores de interferência devido à fissão do $U$ determinados experimentalmente e teoricamente, assim como os resultados obtidos nas análises dos MRCs.

As análises dos resultados obtidos tanto para os fatores de interferência quanto para os MRCs foram realizadas utilizando os seguintes testes estatísticos, a saber: média aritmética (MA), média ponderada com $1 / \sigma^{2}(\mathrm{MP})$, método dos resíduos normalizados (MRN) e o teste de Rajeval (RJ).

\subsection{Espectroscopia gama}

A espectroscopia gama dos padrões sintéticos foi realizada utilizando o sistema de aquisição descrito no capítulo 4.2.4. Os valores de incertezas e taxas de contagens (cps) utilizados nas determinações dos fatores de interferência experimentais e nas análises dos MRCs foram aqueles fornecidos pelo software Genie 2000 versão 3.1. Foi feita ainda uma análise mais detalhada dos espectros dos para verificar a presença de possíveis interferências e também analisar os resultados fornecidos pelo software Genie 2000.

Os espectros apresentados nas figuras 5.1 até a figura 5.5 foram obtidos com os dados de uma única irradiação e mantendo uma mesma geometria de contagem, neste caso a aquisição de dados dos padrões sintéticos foi feita na posição 1 (representada na FIG. 4.7). Nestes espectros foram destacadas a regiões das transições gama utilizadas neste trabalho. 


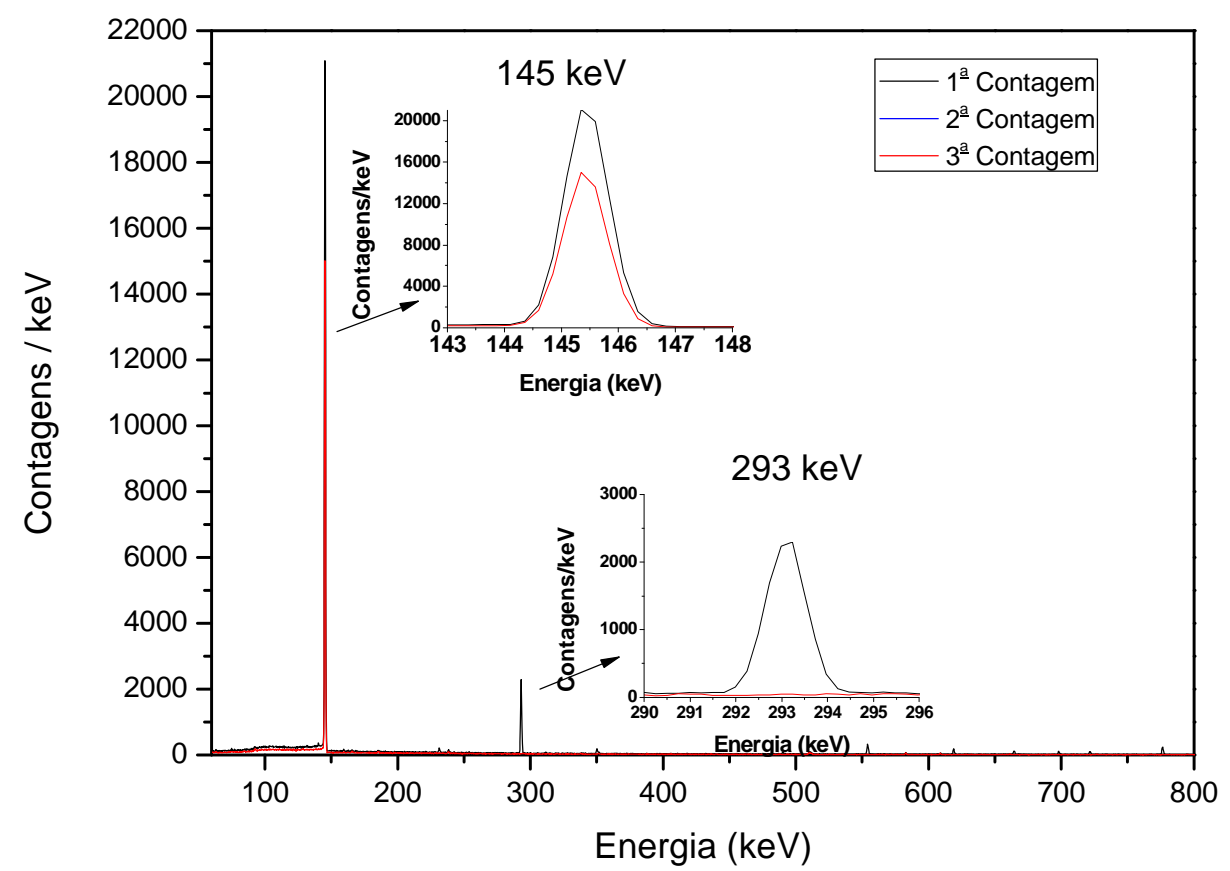

FIGURA 5.1 - Espectro do padrão sintético de Ce para diferentes tempos de decaimento.

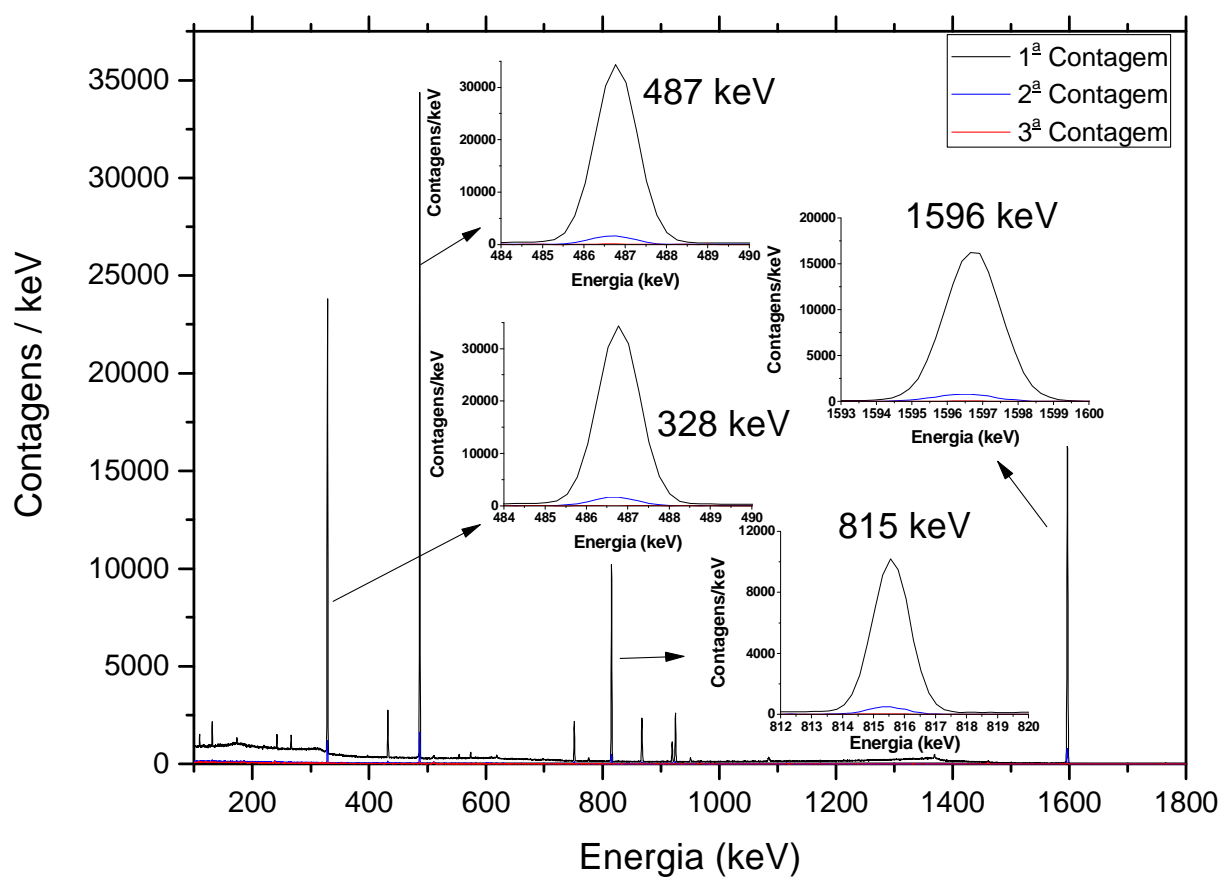

FIGURA 5.2 - Espectro do padrão sintético de La para diferentes tempos de decaimento. 


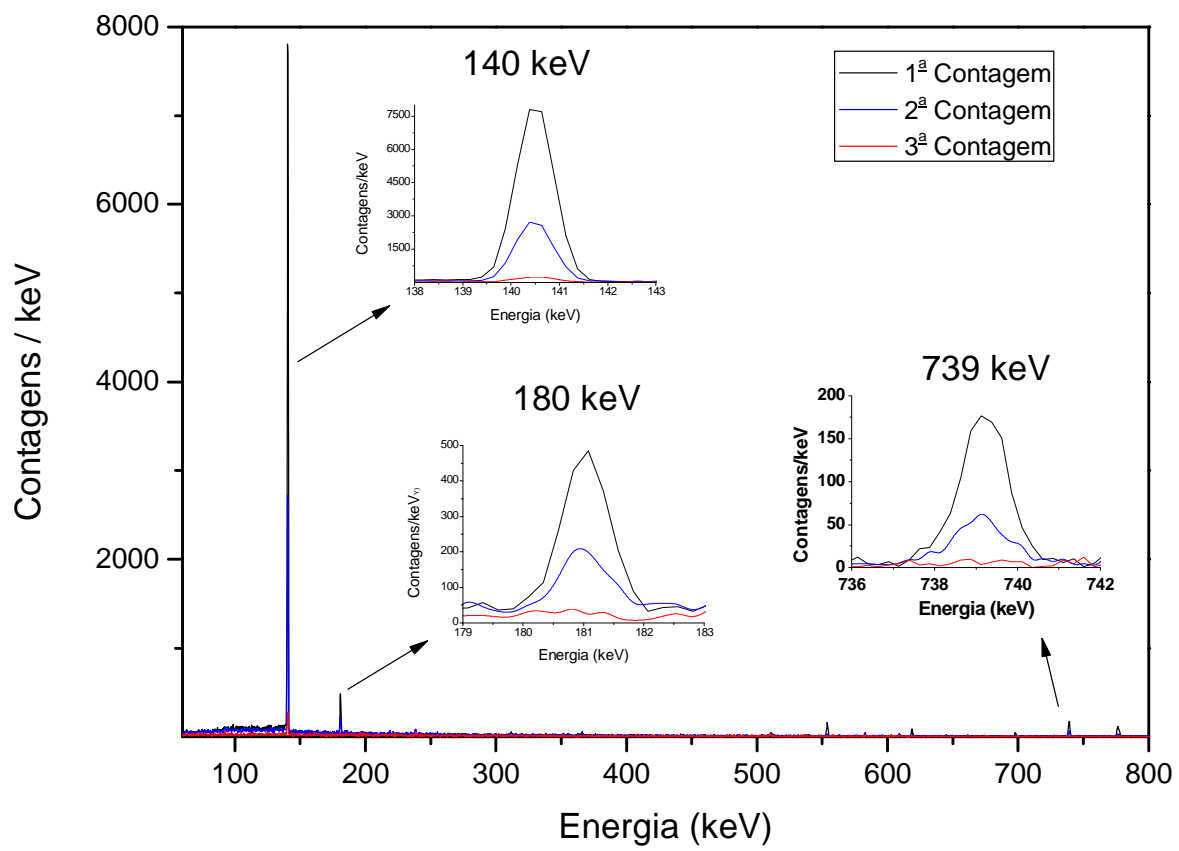

FIGURA 5.3 - Espectro do padrão sintético de Mo para diferentes tempos de decaimento.

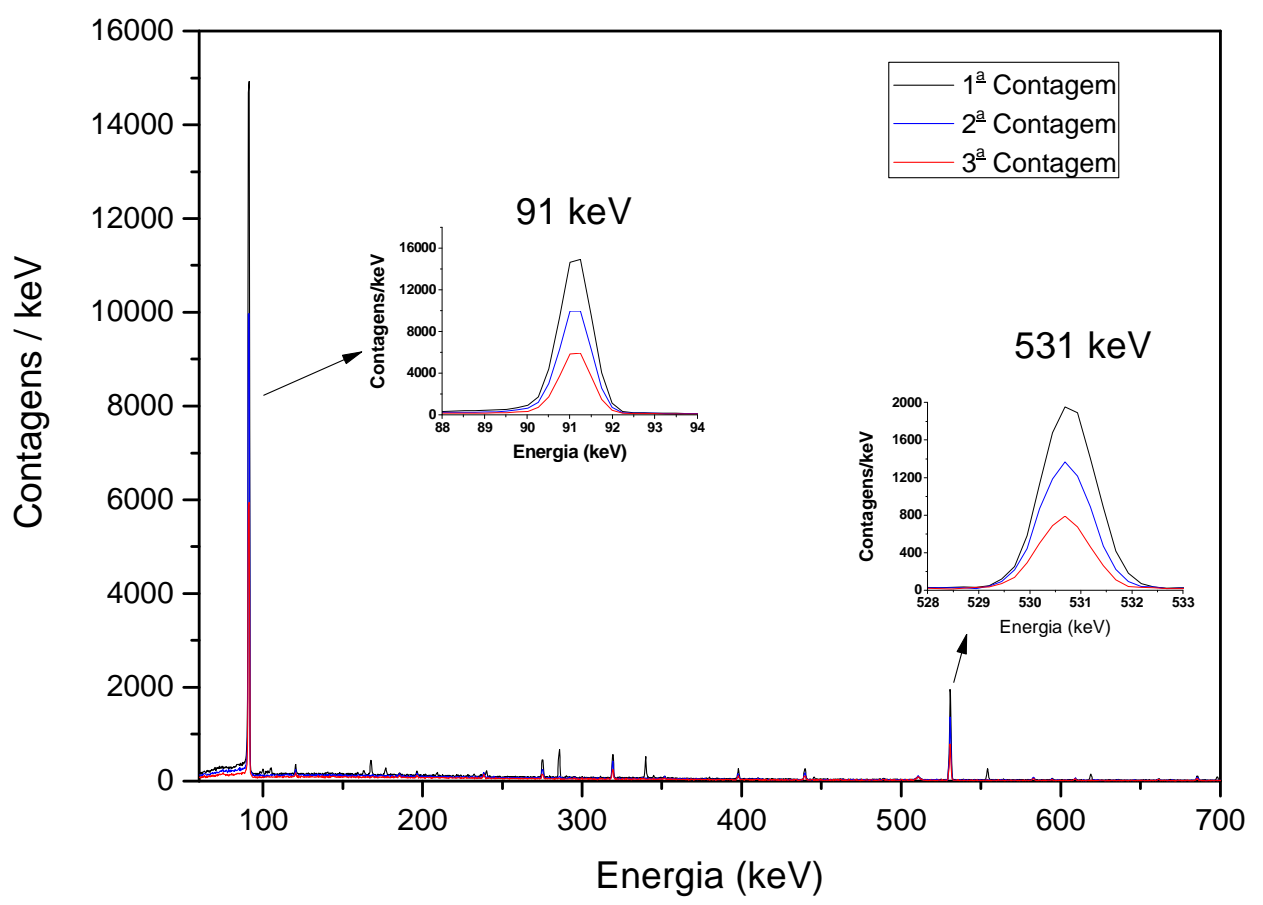

FIGURA 5.4 - Espectro do padrão sintético de Nd para diferentes tempos de decaimento. 




FIGURA 5.5 - Espectro do padrão sintético de Zr para diferentes tempos de decaimento.

Nestes padrões sintéticos analisados as transições gama característica de cada radioisótopo não apresentaram problemas de interferência, como pode ser verificado nos gráficos apresentados. Foi feita a verificação dos resultados do ajuste usando o software IDEFIX e os resultados foram compatíveis, portanto nos cálculos dos fatores de interferência foram utilizados os valores fornecidos pelo software Genie 2000.

Pela análise dos espectros destes padrões verificou-se a presença de $\mathrm{Br}$, visto que foram constatadas as transições gama características do radioisótopo ${ }^{82} \mathrm{Br}\left(t_{1 / 2}=35,3 \mathrm{~h}\right)$. A presença deste elemento não prejudicou as análises uma vez que as transições gama do radioisótopo ${ }^{82} \mathrm{Br}$ não coincidem com as transições gama utilizadas neste trabalho.

No caso do espectro dos padrões de $U$ foram feitos 3 gráficos para os diferentes tempos de decaimento utilizados nas análises. 


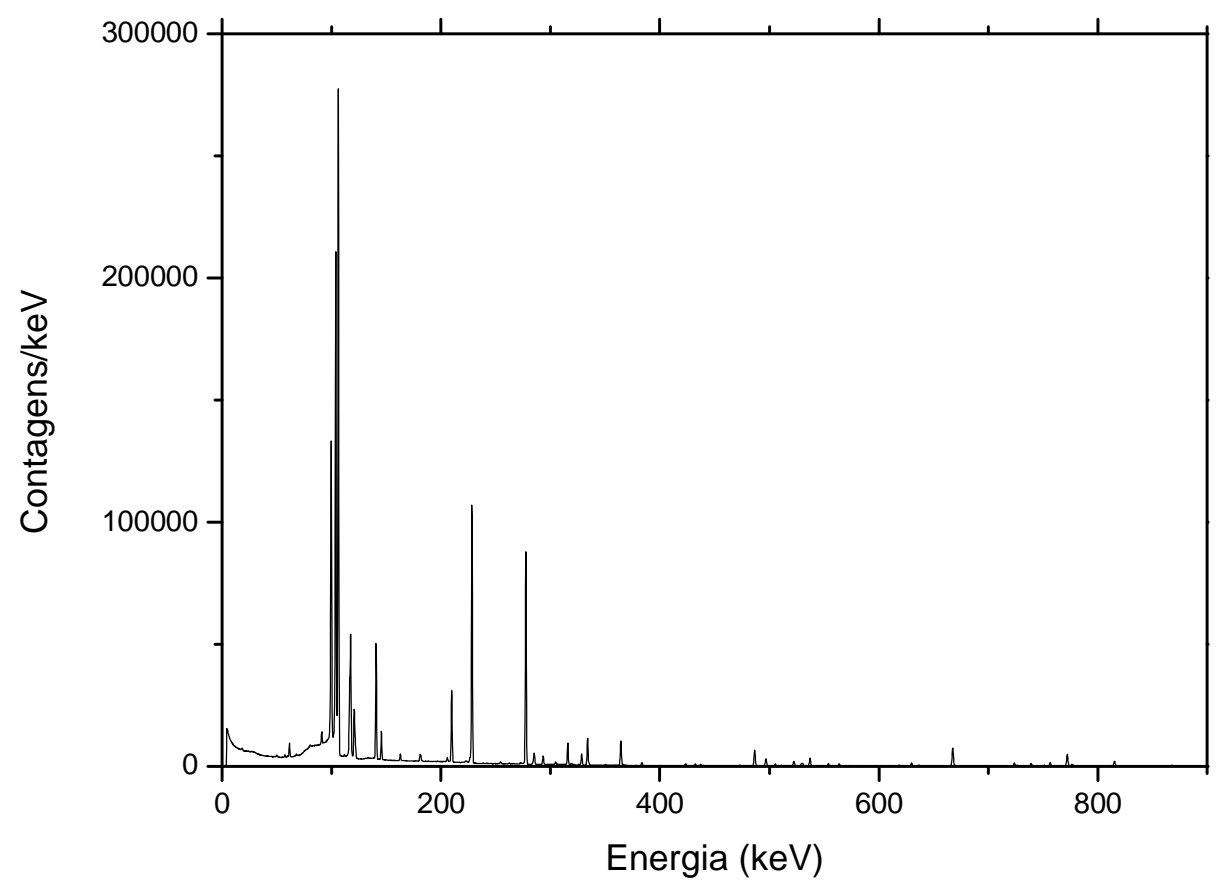

FIGURA 5.6 - Espectro do padrão sintético de U obtido com 7 dias de tempo de decaimento.

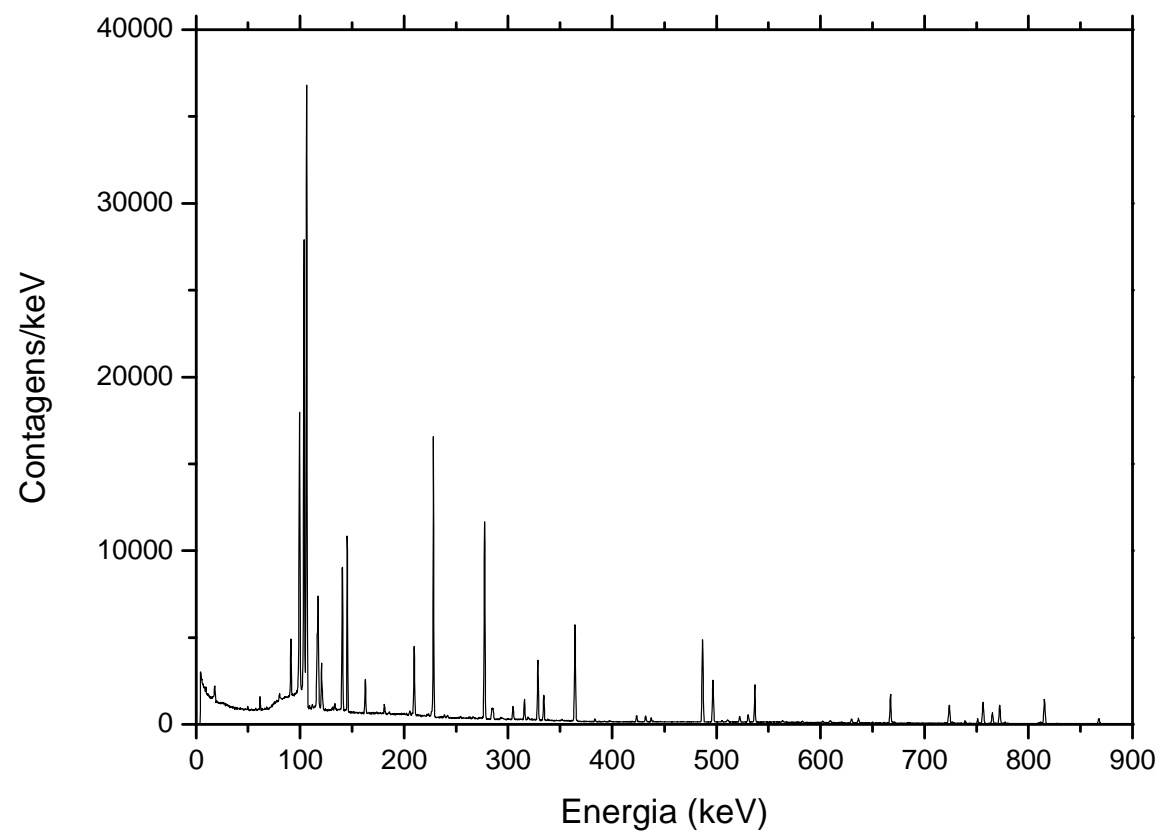

FIGURA 5.7 - Espectro do padrão sintético de U obtido com 14 dias de tempo de decaimento. 


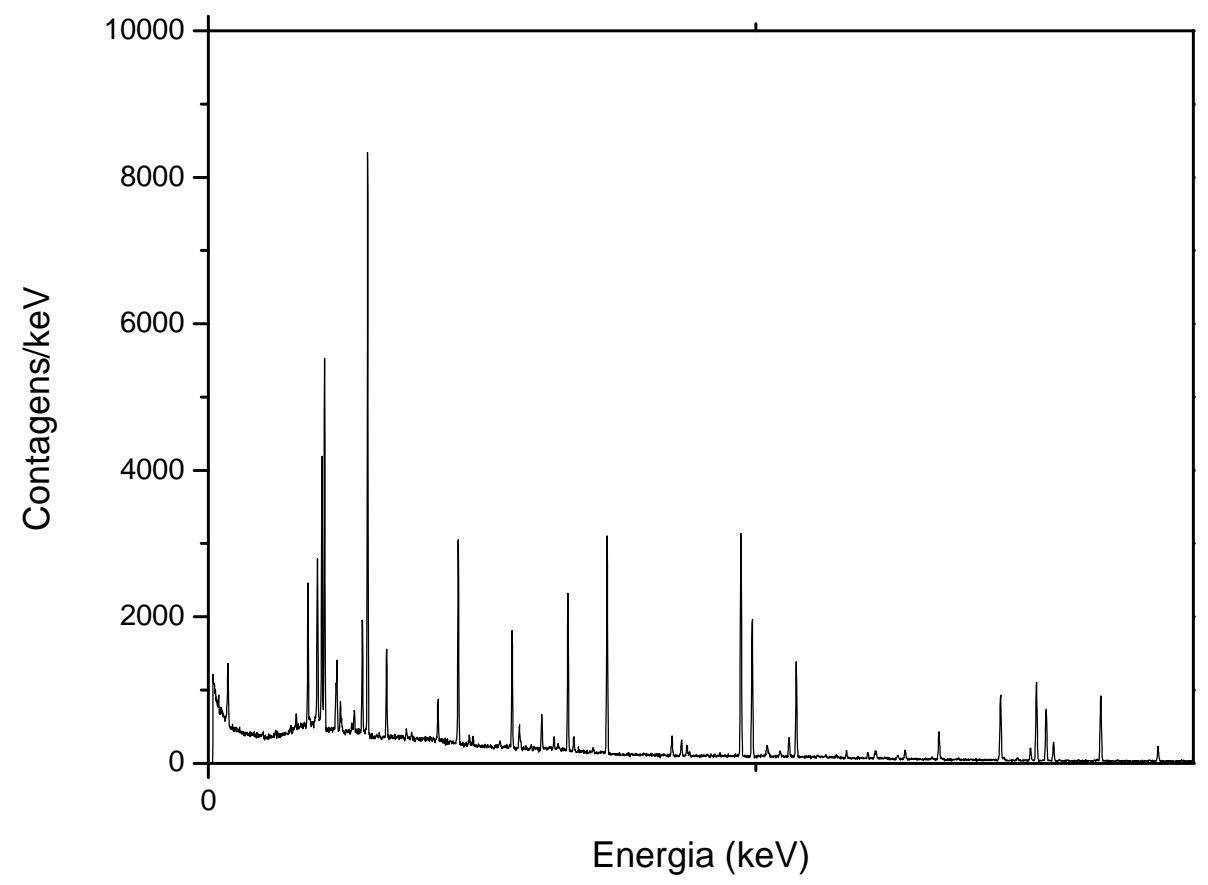

FIGURA 5.8 - Espectro do padrão sintético de U obtido com 20 dias de tempo de decaimento.

$\mathrm{Na}$ região de energia de aproximadamente $100 \mathrm{keV}$ verifica-se que o número de eventos diminui bastante entre a primeira e terceira contagens, isso ocorre em virtude de que nessa região temos as transições gama de 103 e 106 keV que são do ${ }^{153} \mathrm{Sm}$ e ${ }^{239} \mathrm{~Np}$ cujas meias vida são 1,9 e 2,3 dias, respectivamente.

Foram feitos os gráficos de espectro de energia para a primeira contagem do $U$ para diferentes faixas de energia para se realizar a análise de possíveis interferências espectrais das transições gama utilizadas. 




FIGURA 5.9 - Transições gama (entre 50 e $400 \mathrm{keV}$ ) do padrão de U utilizadas nas análises para 7 dias de tempo de decaimento.

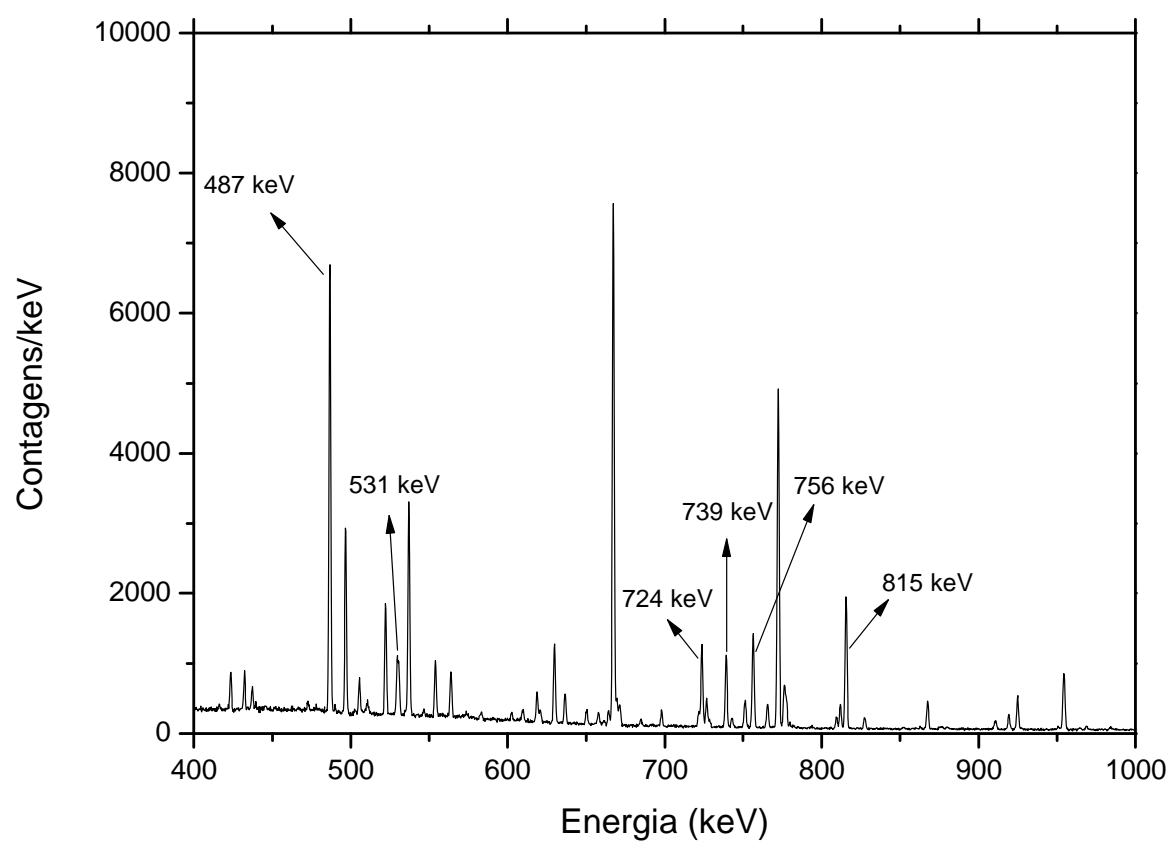

FIGURA 5.10 - Transições gama (entre 400 e $1000 \mathrm{keV}$ ) do padrão de U utilizadas nas análises para 7 dias de tempo de decaimento. 
Pela análise das FIGs. 5.9 e 5.10 verifica-se que mesmo para menores tempos de decaimento, quando o espectro é mais denso, os espectros foram bem ajustados e não foi constatado problemas de interferências das transições gama utilizadas, e dessa forma também optou-se por utilizar os resultados fornecidos pelo programa Genie 2000.

\subsection{Fatores de interferência determinados experimentalmente}

Foram realizadas um total de 18 irradiações dos padrões sintéticos de $\mathrm{Ce}, \mathrm{La}, \mathrm{Mo}, \mathrm{Nd}, \mathrm{Sm}, \mathrm{Zr}$ e U com a finalidade de se determinar experimentalmente os valores dos fatores de interferência devido à fissão do U. Estes fatores foram determinados por meio do procedimento experimental descrito no item 3.2.4 desta dissertação e utilizando a equação (15) do item 2.3.

Na TAB. 5.1 são apresentados os valores dos fatores de interferência determinados experimentalmente com seus desvios padrões juntamente com os valores reportados por outros pesquisadores para comparação.

TABELA 5.1 - Fatores de interferência determinados experimentalmente neste trabalho e valores reportados por outros pesquisadores.

\section{Fatores de Interferência $\left(\mathrm{mg} \mathrm{kg}^{-1}\right)$}

\begin{tabular}{|c|c|c|c|c|c|c|}
\hline \multirow[b]{2}{*}{ RADIONUCLÍDEO } & \multirow[b]{2}{*}{$\begin{array}{c}\mathrm{E} \gamma \\
(\mathrm{keV})\end{array}$} & & & & & \\
\hline & & $\begin{array}{c}\text { Este } \\
\text { Trabalho }\end{array}$ & $\begin{array}{c}\text { Al- } \\
\text { Jobori } \\
\text { et al. } \\
(\mathbf{1 9 9 0})\end{array}$ & $\begin{array}{c}\text { Park } \\
\text { et al. } \\
(1993)\end{array}$ & $\begin{array}{c}\text { Gouveia } \\
\text { et al. } \\
(\mathbf{1 9 8 7})\end{array}$ & $\begin{array}{c}\text { Glascock et } \\
\text { al. (1986) }\end{array}$ \\
\hline${ }^{141} \mathrm{Ce}$ & $145,44 *$ & $\begin{array}{c}0,262 \pm \\
0,002\end{array}$ & 0,3 & $\begin{array}{c}0,296 \pm \\
0,017\end{array}$ & $\begin{array}{c}0,274 \pm \\
0,012\end{array}$ & $0,287 \pm 0,008$ \\
\hline${ }^{143} \mathrm{Ce}$ & $293,27^{*}$ & $\begin{array}{c}1,241 \pm \\
0,016\end{array}$ & 1,38 & - & - & $1,35 \pm 0,04$ \\
\hline${ }^{140} \mathrm{La}$ & 328,76 & $\begin{array}{c}(2,392 \pm \\
0,015) 10^{-} \\
3 \cdot \alpha\end{array}$ & 0,0018 & - & - & - \\
\hline${ }^{140} \mathrm{La}$ & 487,021 & $\begin{array}{c}(2,392 \pm \\
0,015) 10^{-} \\
\quad 3 \cdot \alpha\end{array}$ & 0,0018 & - & - & $\begin{array}{c}(0,0028 \pm \\
0,0002)^{*} \alpha\end{array}$ \\
\hline${ }^{140} \mathrm{La}$ & 815,77 & $\begin{array}{c}(2,392 \pm \\
0,015) 10^{-} \\
3 \cdot \alpha\end{array}$ & 0,0018 & - & - & - \\
\hline${ }^{140} \mathrm{La}$ & $1596,21^{*}$ & $(2,392 \pm$ & 0,0018 & - & - & - \\
\hline
\end{tabular}


Fatores de Interferência $\left(\mathrm{mg} \mathrm{kg}^{-1}\right)$

\begin{tabular}{|c|c|c|c|c|c|c|}
\hline \multirow[b]{2}{*}{ RADIONUCLÍDEO } & \multirow[b]{2}{*}{$\begin{array}{c}\mathbf{E} \gamma \\
(\mathbf{k e V})\end{array}$} & \multicolumn{5}{|c|}{ Fatores de Interferência $\left(\mathrm{mg} \mathrm{kg}^{-1}\right)$} \\
\hline & & $\begin{array}{c}\text { Este } \\
\text { Trabalho }\end{array}$ & $\begin{array}{c}\text { Al- } \\
\text { Jobori } \\
\text { et al. } \\
(\mathbf{1 9 9 0})\end{array}$ & $\begin{array}{l}\text { Park } \\
\text { et al. } \\
(\mathbf{1 9 9 3 )}\end{array}$ & $\begin{array}{c}\text { Gouveia } \\
\text { et al. } \\
(\mathbf{1 9 8 7})\end{array}$ & $\begin{array}{c}\text { Glascock et } \\
\text { al. (1986) }\end{array}$ \\
\hline & & $\begin{array}{c}0,015) 10^{-} \\
3 \cdot \alpha\end{array}$ & & & & \\
\hline${ }^{9} \mathrm{Mo}$ & 739,5 & $\begin{array}{c}2,022 \pm \\
0,033\end{array}$ & - & $\begin{array}{c}1,36 \pm \\
0,19\end{array}$ & - & $1,39 \pm 0,05$ \\
\hline${ }^{147} \mathrm{Nd}$ & 91,1 & $\begin{array}{c}0,206 \pm \\
0,003\end{array}$ & 0,22 & $\begin{array}{c}0,251 \pm \\
0,013\end{array}$ & $\begin{array}{c}0,219 \pm \\
0,009\end{array}$ & $0,21 \pm 0,01$ \\
\hline${ }^{153} \mathrm{Sm}$ & 103,18 & - & - & - & - & - \\
\hline${ }^{95} \mathrm{Zr}$ & 724,2 & $\begin{array}{c}10,05 \pm \\
0,08\end{array}$ & 7,3 & - & - & - \\
\hline${ }^{95} \mathrm{Zr}$ & $756,73^{*}$ & $\begin{array}{c}10,05 \pm \\
0,08\end{array}$ & 7,3 & $\begin{array}{c}11,7 \pm \\
0,10\end{array}$ & $10,5 \pm 0,4$ & $11,3 \pm 0,2$ \\
\hline
\end{tabular}

$\alpha=\left(\boldsymbol{e}^{\mathbf{0 . 3 5 8 4 t _ { d }}}-\mathbf{1}\right)$, sendo $t_{d}$ o tempo de decaimento em dias, ${ }^{*}=$ transições gama recomendadas.

A TAB. 5.1 mostra que os fatores de interferência determinados em distintos laboratórios podem ser diferentes, em virtude da dependência de características das instalações de irradiação, mais precisamente da razão entre os fluxos de nêutrons térmicos e epitérmicos, a qual varia em função do reator e em função das diferentes posições de irradiação em um mesmo reator nuclear.

O procedimento experimental adotado por Al-Jobori et al. (1990), consistiu na irradiação dos padrões sintéticos dos elementos estudados por eles por um período de $5 \mathrm{~h}$ no núcleo do reator nuclear tipo piscina IRT-500 cuja potência é de $5 \mathrm{MW}$. A diferença entre os valores apresentados por Al-Jobori et al. (1990) e neste estudo é devido aos valores da razão entre fluxos de nêutrons epitérmicos e térmicos ser diferente dos valores obtidos neste trabalho. Al-Jobori et al. (1990) apresentou os seguintes valores de $\phi_{e p} / \phi_{t h}=0,015 e 0,025$, o valor encontrado neste trabalho foi de 0,01357 .

Park et al. (1993) realizaram as irradiações dos padrões sintéticos por um período de $10 \mathrm{~h}$ em um reator nuclear tipo Triga. Esses autores relatam apenas o valor do fluxo de nêutrons térmicos $\left(\phi_{t h}=4 \cdot 10^{12} \mathrm{~cm}^{2} \cdot \mathrm{s}^{-1}\right)$.

As irradiações dos padrões sintéticos dos elementos pesquisados por Gouveia et al. (1987) foram realizadas por um período de 70 h no RPI Nuclear 
Reactor (Sacavém). O valor de $\phi_{e p} / \phi_{t h}$ encontrado por eles foi de 0,015 . Os valores dos fatores de interferência obtidos por Gouveia et al. (1987) ficaram próximos dos valores obtidos neste estudo, isso se deve em razão dos valores de $\phi_{e p} / \phi_{t h}$ nesses trabalhos serem próximos.

Glascock et al. (1986) irradiaram os padrões sintéticos dos elementos presentes na TAB. 5.1 por um período de $12 \mathrm{~h}$ no University of Missouri Research Reactor (MURR) em um sistema giratório com velocidade de 9 voltas por hora. $\mathrm{O}$ valor de $\phi_{e p} / \phi_{t h}$ obtido por eles foi de 0,020 . Pela análise da TAB 5.1 verifica-se que os valores dos fatores de interferência obtidos neste estudo e os valores reportados por Glascock et al. (1986) são diferentes, isto em virtude da diferença entre a razão de fluxo nêutrons epitérmicos e térmicos obtida nos dois trabalhos.

A seguir serão discutidos os resultados obtidos para estes fatores de interferência individualmente e como foram estabelecidos os resultados apresentados na TAB. 5.1.

\subsubsection{Fator de interferência experimental obtido para o ${ }^{141} \mathrm{Ce}$}

$\mathrm{Na}$ determinação do fator de interferência experimental do ${ }^{141} \mathrm{Ce}$ (meia vida de $32,5 \mathrm{~d}$ ) foi utilizada a transição gama de $145 \mathrm{keV}$, recomendada pela IAEA devido à sua alta intensidade de 48,2\% (IAEA, 1990).

Em cada irradiação foram realizadas até 3 séries de contagens em diferentes tempos de decaimento para a determinação do fator de interferência. Foram obtidos no total 48 valores de fatores de interferência por meio das medidas realizadas pelos diferentes tempos de decaimento, o que representa 16 procedimentos de irradiação.

Os valores dos fatores de interferência apresentaram uma variação de $0,196 \pm 0,010$ como valor mínimo até $0,287 \pm 0,004$, entretanto o valor de 0,196 \pm 0,010 foi descartado pois houve contaminação devido ao vazamento de uma amostra de solo que foi irradiada juntamente os padrões sintéticos pipetados, dessa maneira os resultados analíticos ficaram comprometidos. Na FIG. 5.1 é apresentado um gráfico da dispersão dos valores obtidos em cada uma das determinações dos fatores de interferência para o ${ }^{141} \mathrm{Ce}$. 


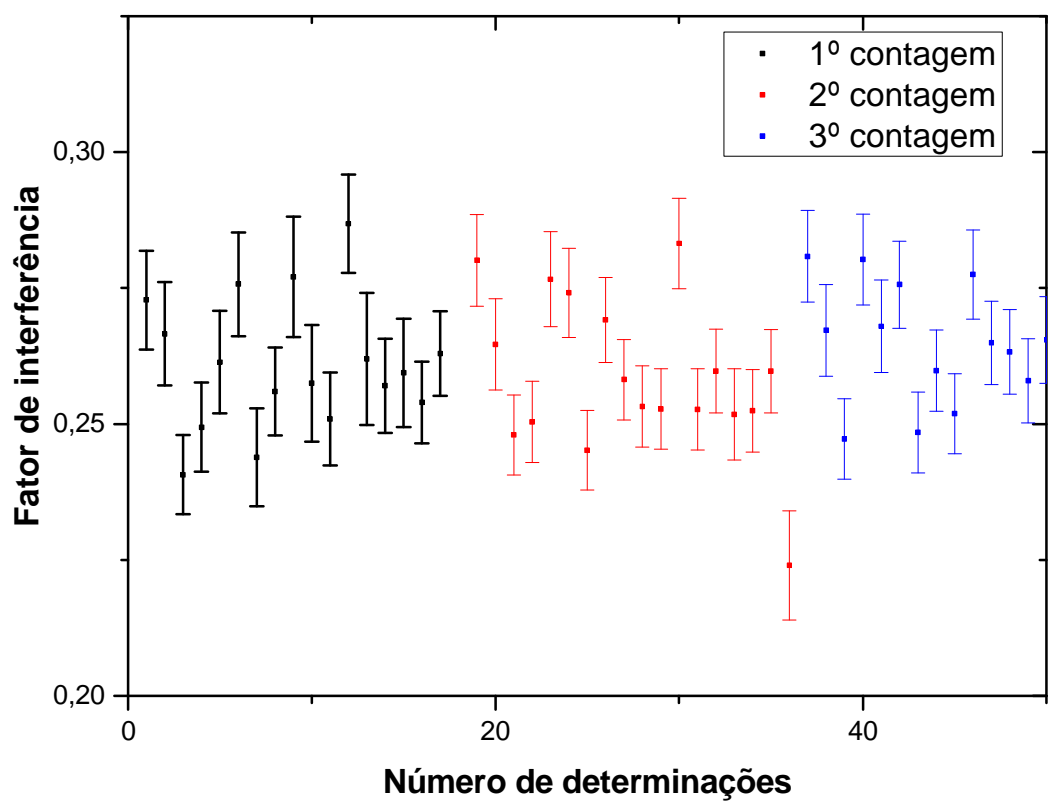

FIGURA 5.11 - Valores dos fatores de interferência obtidos para o ${ }^{141} \mathrm{Ce}$ em diferentes tempos de decaimento.

Como pode ser visto na FIG. 5.11, os valores dos fatores de interferência estão agrupados em uma mesma região, entretanto um dos valores obtidos, 0,224 $\pm 0,010$, ficou menor que os demais valores.

Na TAB. 5.2 são apresentados os valores dos fatores de interferência obtidos para $0{ }^{141} \mathrm{Ce}$ pelos diferentes tratamentos estatísticos utilizados neste trabalho.

TABELA 5.2 - Valores obtidos para os fatores de interferência do ${ }^{141} \mathrm{Ce}(\mathrm{em} \mathrm{mg}$ $\mathrm{kg}^{-1}$ ) utilizando diferentes tratamentos estatísticos.

\begin{tabular}{ccccccc}
\hline & & & \multicolumn{3}{c}{ TRATAMENTO ESTATíSTICO } \\
\cline { 4 - 7 } Contagem & Transição & $\mathbf{N}$ & $\mathbf{M A m} \pm \mathbf{D P}$ & $\mathbf{M P} \pm \mathbf{D P}$ & $\mathbf{M R N} \pm \mathbf{D P}$ & \multirow{2}{*}{$\mathbf{R J} \pm \mathbf{D P}{ }^{(\mathbf{a})}$} \\
\hline Primeira & $145 \mathrm{keV}$ & 17 & $0,261 \pm 0,003$ & $0,259 \pm 0,002$ & $0,259 \pm 0,003$ & $0,259 \pm 0,002$ \\
Segunda & $145 \mathrm{keV}$ & 17 & $0,261 \pm 0,003$ & $0,259 \pm 0,002$ & $0,259 \pm 0,003$ & $0,258 \pm 0,002$ \\
Terceira & $145 \mathrm{keV}$ & 13 & $0,265 \pm 0,003$ & $0,264 \pm 0,002$ & $0,264 \pm 0,003$ & $0,265 \pm 0,002$ \\
Todas & $145 \mathrm{keV}$ & 47 & $0,262 \pm 0,002$ & $0,261 \pm 0,001$ & $0,261 \pm 0,002$ & $0,260 \pm 0,001$ \\
\hline
\end{tabular}

$\mathbf{N}=$ número de determinações; $\mathbf{a}=$ outliers.

Verifica-se na TAB. 5.2 que os fatores de interferência obtidos para o ${ }^{141} \mathrm{Ce}$ utilizando os 4 tratamentos estatísticos diferentes apresentam valores próximos com pequenas variações entre os resultados obtidos utilizando dados da primeira e segunda contagens, contudo verifica-se que que os fatores de 
interferência obtidos na terceira contagem, com tempo de decaimento de aproximadamente 21 dias terceira contagens, foram ligeiramente maiores devido a ocorrência de alguns fatores de interferência apresentarem valores mais elevados.

Optou-se, nas análises dos materiais de referência, por considerar o valor de 0,262 \pm 0,002 fornecido pela média aritmética de todos os dados de todas as contagens como o valor do fator de interferência devido à fissão do $U$ para o caso do ${ }^{141} \mathrm{Ce}$, visto que a meia vida deste radioisótopo é de $32,5 \mathrm{~d}$ e portanto a atividade na terceira contagem (com aproximadamente 21 dias de decaimento) ainda é adequada para a realização das medidas.

\subsubsection{Fator de interferência experimental obtido para $0{ }^{143} \mathrm{Ce}$}

Para o cálculo do fator de interferência experimental devido à fissão do $\mathrm{U}$ para $0{ }^{143} \mathrm{Ce}$ foram utilizados os resultados obtidos na primeira contagem (com aproximadamente 5 dias de decaimento) e alguns dados da segunda contagem (com aproximadamente 10 dias de decaimento). Em virtude da meia vida do ${ }^{143} \mathrm{Ce}$ ser de apenas 1,326 dias (IAEA, 1990) não foi realizada a determinação do fator de interferência para este radioisótopo com os dados obtidos na terceira contagem (com aproximadamente $21 \mathrm{~d}$ de decaimento).

No cálculo fator de interferência para este radioisótopo utilizou-se a transição gama de $293 \mathrm{keV}$, cuja intensidade é de 42,8\% (IAEA, 1990). O gráfico da FIG 5.12 apresenta a dispersão dos valores obtidos para o fator de interferência do ${ }^{143} \mathrm{Ce}$. 


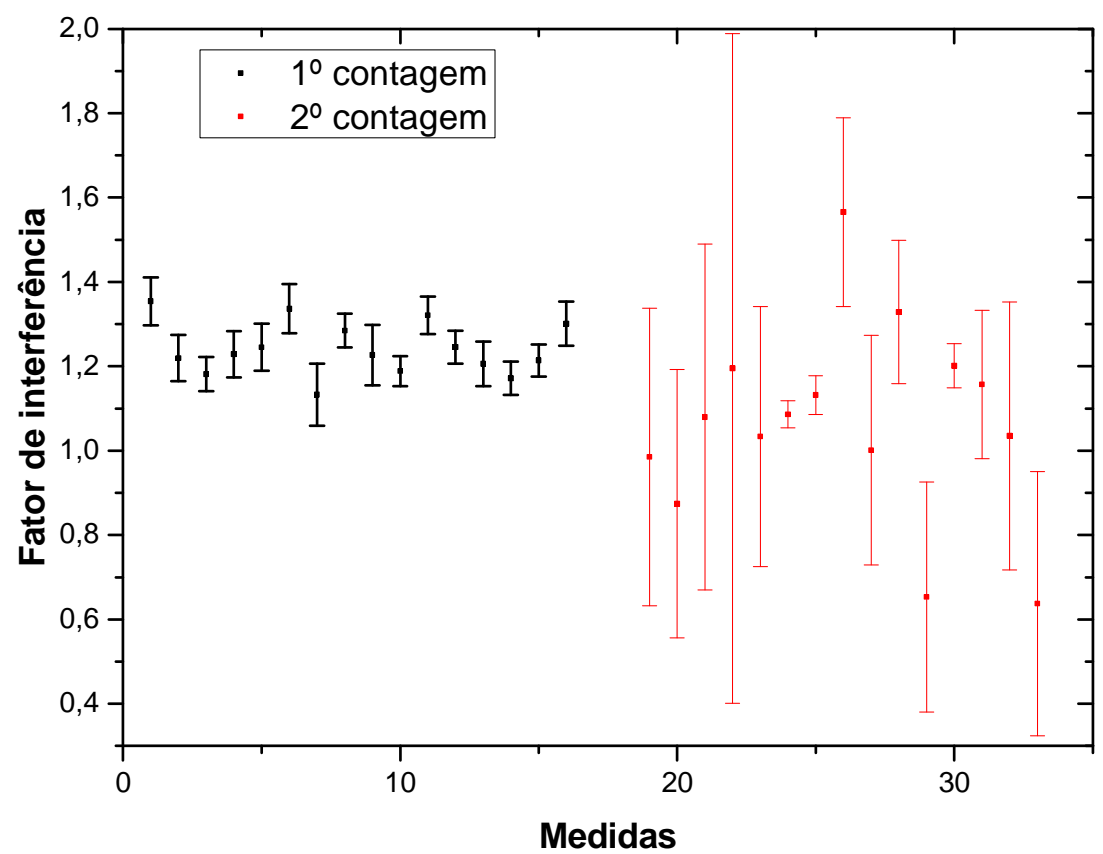

FIGURA 5.12 - Valores dos fatores de interferência obtidos para o ${ }^{143} \mathrm{Ce}$ em diferentes tempos de decaimento.

Os resultados apresentados na FIG. 5.12 mostram que alguns valores de fatores de interferência apresentaram desvios padrões mais elevados, isto porque estes valores foram obtidos pelos dados da segunda contagem, ou seja, com tempo de decaimento de aproximadamente 10 dias, quando a atividade do radioisótopo ${ }^{143} \mathrm{Ce}$ era baixa.

Verifica-se pela análise do gráfico da FIG 5.12 que alguns valores dos dados da segunda contagem apresentaram valores inferiores aos demais, esses pontos são: $0,63 \pm 0,31 ; 0,65 \pm 0,27$. Aplicando o teste de Rajeval esses pontos não foram considerados como sendo outliers e portanto foram utilizados nos cálculo do valor médio pelos 4 tratamentos estatísticos utilizados neste estudo.

Na TAB. 5.3 são apresentados os valores dos fatores de interferência obtidos para o ${ }^{143} \mathrm{Ce}$ utilizando os quatro tratamentos estatísticos. 
TABELA 5.3 - Valores obtidos para os fatores de interferência do ${ }^{143} \mathrm{Ce}$ (em mg $\mathrm{kg}^{-1}$ ) utilizando diferentes tratamentos estatísticos.

\begin{tabular}{ccccccc}
\hline & & \multicolumn{4}{c}{ Tratamento Estatístico } \\
\cline { 3 - 7 } Contagem & $\begin{array}{c}\text { Transição } \\
\text { gama (keV) }\end{array}$ & $\mathbf{N}$ & $\mathbf{M A} \pm \mathbf{D P}$ & $\mathbf{M P} \pm \mathbf{D P}$ & $\mathbf{M R N} \pm \mathbf{D P}$ & $\mathbf{R J} \pm \mathbf{D P}{ }^{(\mathbf{a})}$ \\
\hline Primeira & 293 & 16 & $1,241 \pm 0,016$ & $1,236 \pm 0,012$ & $1,236 \pm 0,012$ & $1,236 \pm 0,012$ \\
Segunda & 293 & 15 & $1,064 \pm 0,061$ & $1,120 \pm 0,022$ & $1,120 \pm 0,022$ & $1,120 \pm 0,022$ \\
Todas & 293 & 31 & $1,156 \pm 0,034$ & $1,211 \pm 0,010$ & $1,218 \pm 0,014$ & $1,221 \pm 0,010^{(2)}$ \\
\hline $\mathbf{N}=$ número de determinações; $\mathbf{a}=$ outiliers. & & & &
\end{tabular}

$\mathbf{N}=$ número de determinações; $\mathbf{a}=$ outiliers.

Utilizando os dados da segunda contagem, os valores dos fatores de interferência obtidos pelas 4 metodologias ficaram um pouco mais baixos do que os valores obtidos na primeira contagem e com erros mais altos, conforme pode ser verificado pela análise da TAB. 5.3. Isto ocorreu em virtude da segunda contagem ser realizada com aproximadamente 10 dias de tempo de decaimento, ou seja, já se passaram em torno de 7 meias vidas do radioisótopo ${ }^{143} \mathrm{Ce}$, e consequentemente o erro obtido nas taxas de contagens foram maiores.

Verifica-se pela análise da TAB. 5.3 que o valor obtido pela média aritmética utilizando os dados da segunda contagem ficou menor que os valores obtidos pelas outras metodologias, isto ocorreu em virtude da utilização dos valores $0,64 \pm 0,31$ e 0,65 $\pm 0,27$ terem sido utilizados no cálculo.

Neste radioisótopo também foi utilizado na análise dos materiais de referência o valor fornecido pela média aritmética como o fator de interferência para $0{ }^{143} \mathrm{Ce}$ no entanto aqui só foram considerados dados obtidos na primeira contagem $(1,241 \pm 0,016)$, isto porque os dados da primeira contagem são mais precisos em relação aos demais, devido à baixa meia vida deste radioisótopo quando a segunda contagem foi realizada.

\subsubsection{Fator de interferência experimental obtido para $0^{140} \mathrm{La}$}

A obtenção do fator de interferência para $0{ }^{140} \mathrm{La}$ é considerada um caso especial de determinação, isto porque o ${ }^{140} \mathrm{La}$ é formado de duas maneiras distintas na fissão do U:

1) Pelo decaimento $\beta$ - do produto de fissão ${ }^{140} \mathrm{Ba}$ cuja meia vida é de $12,75 \mathrm{~d}$ (conforme mostrado na FIG. 5.13); 


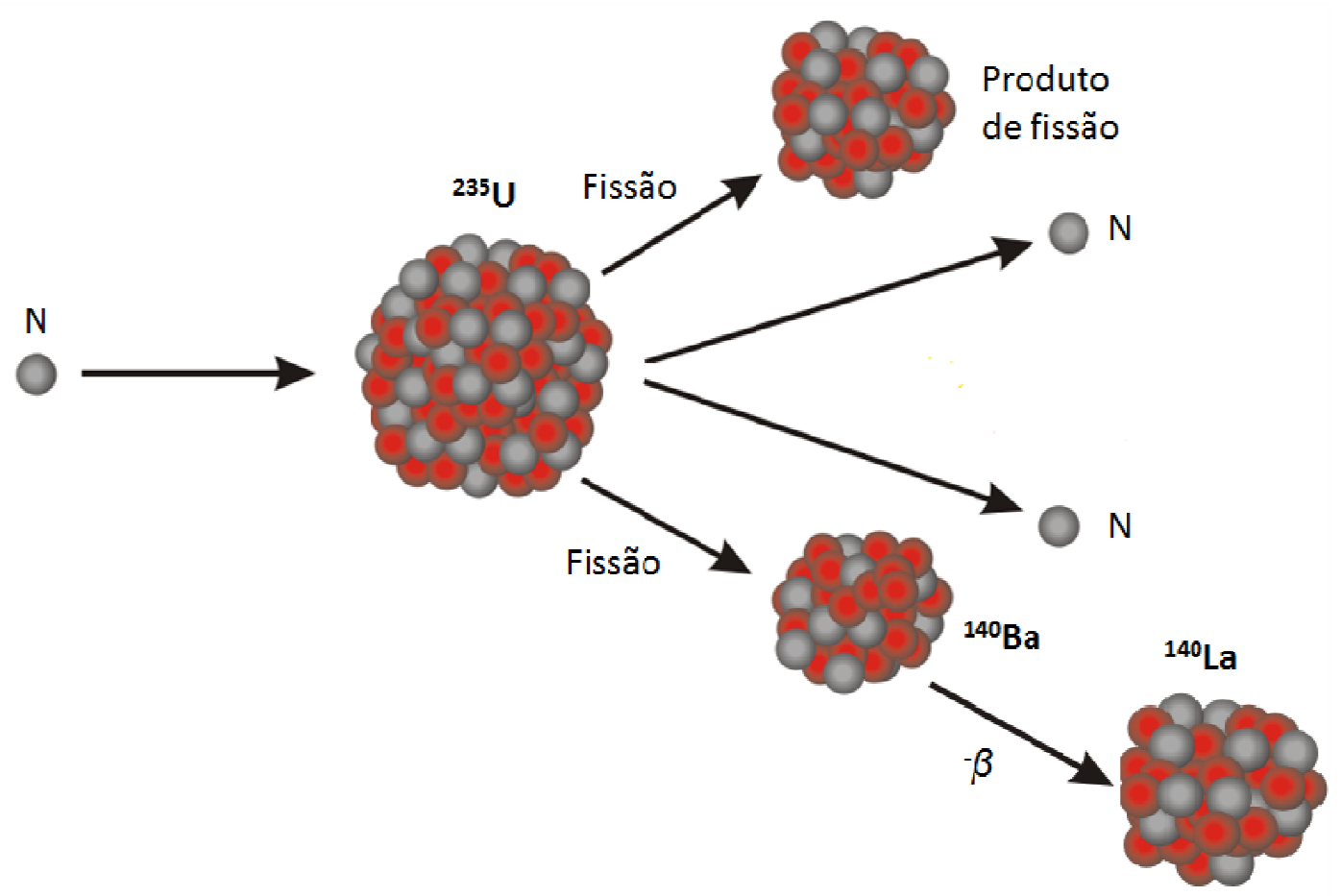

FIGURA 5.13 - Formação do ${ }^{140}$ La pelo decaimento do produto de fissão ${ }^{140} \mathrm{Ba}$.

2) Pela fissão direta do ${ }^{235} \mathrm{U}$ para o ${ }^{140} \mathrm{La}$.

A formação direta do ${ }^{140} \mathrm{La}$ a partir da fissão do ${ }^{235} \mathrm{U}$ é muito pequena, pois o rendimento de fissão independente para este elemento é da ordem de $0,00052 \pm 0,00019$, ao passo que o rendimento de fissão cumulativa do ${ }^{140} \mathrm{Ba}$ é de $6,314 \pm 0,095$, ou seja a maior parte do ${ }^{140}$ La formado pela fissão do ${ }^{235} U$ é oriunda do decaimento do ${ }^{140} \mathrm{Ba}$.

Considerando que o ${ }^{140} \mathrm{La}$ é formado pela fissão do ${ }^{235} \mathrm{U}$ e também pelo decaimento $\beta^{-}$do ${ }^{140} \mathrm{Ba}$ a equação (15) utilizada na determinação do fator de interferência experimental será dada por:

$$
F^{L a}(t)=\underbrace{\frac{\lambda_{B a}}{\lambda_{L a}-\lambda_{B a}} \cdot \frac{N_{0(n, f)}^{B a}}{N_{0(n, \gamma)}^{L a}}}_{k} \cdot\left(e^{\lambda_{L a} t_{d}} \cdot e^{-\lambda_{B a} t_{d}}-1\right)+\underbrace{\frac{N_{0(n, f)}^{L a}}{N_{0(n, \gamma)}^{L a}}}_{c}
$$

Sendo $t_{d}$ o tempo de decaimento; $N_{0(n, f)}^{B a}$ e $N_{0(n, f)}^{L a}$ são os números de átomos de ${ }^{140} \mathrm{Ba}$ e ${ }^{140} \mathrm{La}$ formados pela fissão do $U$ e $\lambda_{B a}$ e $\lambda_{L a}$ são as constantes de decaimento do ${ }^{140} \mathrm{Ba}$ e ${ }^{140} \mathrm{La}$, respectivamente e $N_{0(n, \gamma)}^{L a}$ é o número de átomos de ${ }^{140}$ La formados pela captura neutrônica. 
Na determinação do fator de interferência do ${ }^{140} \mathrm{La}$ o parâmetro $c$ pode ser considerado nulo, uma vez que a formação do ${ }^{140} \mathrm{La}$ pela fissão direta do $\mathrm{U}$ é mais do que 10 mil vezes menor do que a formação do ${ }^{140} \mathrm{Ba}$. Portanto na determinação do fator de interferência do ${ }^{140} \mathrm{La}$ a equação (33) foi reduzida a seguinte relação:

$$
F^{L a}(t)=k \cdot\left(e^{\lambda_{L} t_{d}} \cdot e^{-\lambda_{B} t_{d}}-1\right)
$$

Sendo que o parâmetro $k$ está relacionado com a razão entre a quantidade de ${ }^{140} \mathrm{Ba}$ formado pela fissão do $\mathrm{U}$ e a quantidade de ${ }^{140} \mathrm{La}$ formado pela captura. Assumindo essas considerações, a constante $k$, presente na equação (34), pode ser determinada experimentalmente realizando medidas do fator de interferência em diferentes tempos de decaimento.

$O$ fator de interferência para o ${ }^{140} \mathrm{La}$ foi determinado experimentalmente utilizando as transições gama de $328 \mathrm{keV}, 487 \mathrm{keV}, 815 \mathrm{keV}$ e $1596 \mathrm{keV}$, sendo que a última é a mais intensa com $95,40 \%$ (IAEA, 1990).

$\mathrm{Na}$ FIG. 5.14 é apresentado um gráfico de dispersão dos valores obtidos para a constante $k$ da relação (34), estes valores foram obtidos utilizando os fatores de interferência determinados para as 4 transições gama citadas acima, resultando na obtenção de 159 dados experimentais.

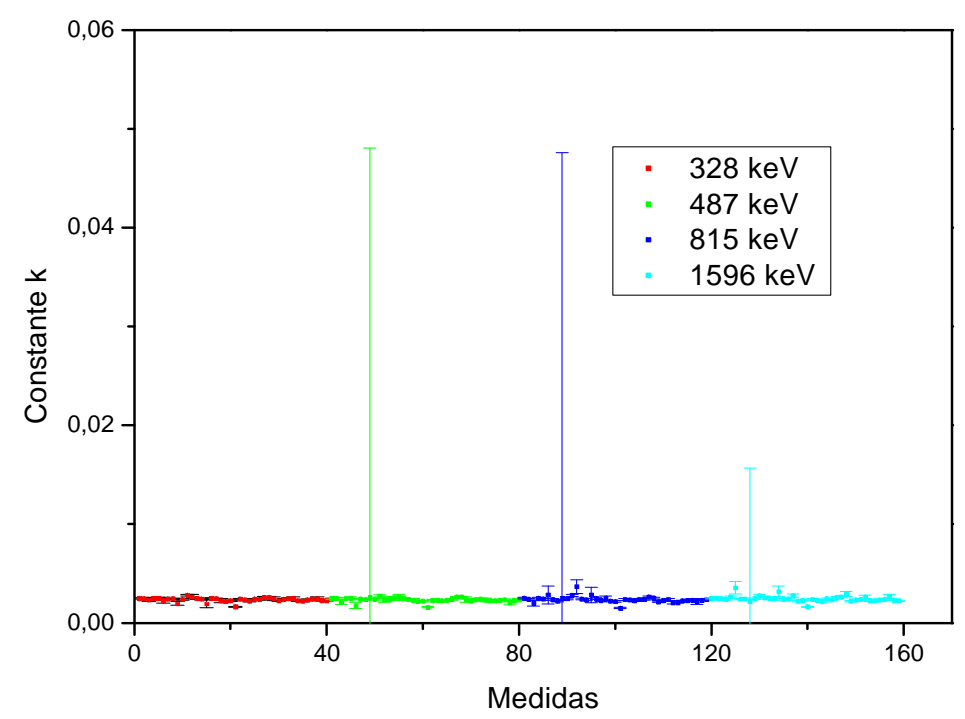

FIGURA 5.14 - Dispersão dos valores experimentais obtidos para a constante $\mathrm{k}$ do ${ }^{140} \mathrm{La}$. 
Verifica-se pela análise do gráfico da FIG. 5.14 que alguns valores obtidos para a constante $k$ possuem desvios elevados. O teste de Rajeval considerou dois pontos como outliers.

O valor da constante $k$ foi determinado experimentalmente realizando as medidas de fatores de interferência para diferentes tempos de decaimento isolando a constante $k$ presente na equação (34). Na TAB. 5.4 são apresentados os valores da constante $k$ obtidos para o ${ }^{140}$ La por meio os diferentes tratamentos estatísticos utilizados no presente estudo.

TABELA 5.4 - Valores obtidos para a constante $\boldsymbol{k}$ do ${ }^{140} \mathrm{La}\left(\mathrm{em} \mathrm{mg} \mathrm{kg}{ }^{-1}\right.$ ) utilizando diferentes tratamentos estatísticos.

\begin{tabular}{|c|c|c|c|c|c|c|}
\hline \multirow[b]{2}{*}{ Contagem } & \multirow[b]{2}{*}{$\begin{array}{c}\text { Transição } \\
\text { gama } \\
\text { (keV) }\end{array}$} & \multirow[b]{2}{*}{$\mathbf{N}$} & \multicolumn{4}{|c|}{ Tratamento estatístico } \\
\hline & & & $\mathbf{M A} \pm \mathbf{D P}$ & $\mathrm{MP} \pm \mathrm{DP}$ & $\mathrm{MRN} \pm \mathrm{DP}$ & $\mathbf{R J} \pm \mathbf{D P} \mathbf{p}^{(\mathbf{a})}$ \\
\hline todas & 328 & 40 & $(2,367 \pm 0,032) \times 10^{-3}$ & $(2,352 \pm 0,013) \times 10^{-3}$ & $(2,381 \pm 0,021) \times 10^{-3}$ & $(2,380 \pm 0,014) \times 10^{-3(1)}$ \\
\hline todas & 487 & 40 & $(2,346 \pm 0,034) \times 10^{-3}$ & $(2,318 \pm 0,014) \times 10^{-3}$ & $(2,365 \pm 0,021) \times 10^{-3}$ & $(2,361 \pm 0,015) \times 10^{-3(1)}$ \\
\hline todas & 815 & 39 & $(2,388 \pm 0,051) \times 10^{-3}$ & $(2,302 \pm 0,015) \times 10^{-3}$ & $(2,343 \pm 0,023) \times 10^{-3}$ & $(2,348 \pm 0,016) \times 10^{-3(1)}$ \\
\hline todas & 1596 & 40 & $(2,467 \pm 0,049) \times 10-3$ & $(2,351 \pm 0,013) \times 10^{-3}$ & $(2,387 \pm 0,023) \times 10^{-3}$ & $(2,390 \pm 0,014) \times 10^{-3(1)}$ \\
\hline todas & $\begin{array}{c}328487 \\
8151596\end{array}$ & 159 & $(2,392 \pm 0,015) \times 10^{-3}$ & $(2,333 \pm 0,007) \times 10^{-3}$ & $(2,372 \pm 0,011) \times 10^{-3}$ & $(2,371 \pm 0,007) \times 10^{-3(2)}$ \\
\hline
\end{tabular}

$\mathbf{N}=$ número de determinações; $\mathbf{a}=$ outliers.

Pela análise da TAB. 5.4 verifica-se que os valores obtidos da constante $k$ pelas diferentes transições gama sofreram poucas variações quando comparados entre si, isto é de se esperar, pois conforme visto na equação (15) a magnitude da interferência não depende da transição gama utilizada na análise, ou seja, se não há interferências espectrais os valores obtidos por diferentes transições gama devem ser iguais.

O valor da constante $k$ obtido utilizando todas as transições gama e a média aritmética foi usado na análise dos MRCs $(2,392 \pm 0,015) \times 10^{-3}$.

Assim como nos demais produtos de fissão estudados, o fator de interferência devido à fissão do $U$ para o ${ }^{140} \mathrm{La}$ foi determinado para diferentes tempos de decaimento em cada irradiação realizada. A variação do fator de interferência para $0{ }^{140} \mathrm{La}$ em função do tempo de decaimento está apresentada na FIG. 5.15. 




FIGURA 5.15 - Variação do fator de interferência do ${ }^{140} \mathrm{La}\left(\mathrm{em} \mathrm{mg} \mathrm{kg}^{-1}\right) \mathrm{em}$ função do tempo de decaimento.

O valor da constante $k$ presente na equação (33) foi determinado realizando um ajuste dos pontos experimentais (excluindo os outliers), conforme pode ser observado na FIG. 5.15. O valor obtido por esta metodologia foi de $0,00231 \pm 0,00002$ e fica muito próximo do valor obtido pela média aritimética $0,00239 \pm 0,00002$.

Foi determinado o valor da constante $c$ presente na equação (33), que representa a quantidade de ${ }^{140} \mathrm{La}$ formada a partir da fissão direta do $U$ para este radioisótopo. O valor obtido para essa constante foi de $(1,39 \pm 0,01) \times 10^{-6}$, com isso pode-se concluir que a formação direta de ${ }^{140} \mathrm{La}$ pela fissão do $U$ é muito pequena quando comparada com a formação devido ao decaimento do ${ }^{140} \mathrm{Ba}$, na ordem de dez mil vezes menor.

\subsubsection{Fator de interferência obtido experimentalmente para o ${ }^{99} \mathrm{Mo}$}

$\mathrm{O}$ fator de interferência para o ${ }^{99}$ Mo pode ser determinado por meio das taxas de contagens obtidas para as suas 3 transições gama: $140 \mathrm{keV}, 181 \mathrm{keV}$ e $739 \mathrm{keV}$, conforme apresentado na TAB. 3.3, sendo que a transição de $739 \mathrm{keV}$ é a recomendada pela IAEA (1990). 
Quando a determinação do fator de interferência é feita pela transição gama de $140 \mathrm{keV}$ deve-se ter o cuidado em relação ao tempo de decaimento, pois esta transição é proveniente do ${ }^{99 \mathrm{~m}}$ Tc cuja meia vida é de $6,01 \mathrm{~h}$, portanto é necessário esperar o ${ }^{99 \mathrm{~m}} \mathrm{Tc}$ atingir o equilíbrio radioativo (aproximadamente $22 \mathrm{~h}$ ) para realizar as medições de atividades por meio desta transição.

Os valores dos fatores de interferência obtidos nas análises de todas as transições gama do ${ }^{99}$ Mo estão presentes no gráfico da FIG. 5.16 para análise da dispersão dos pontos.

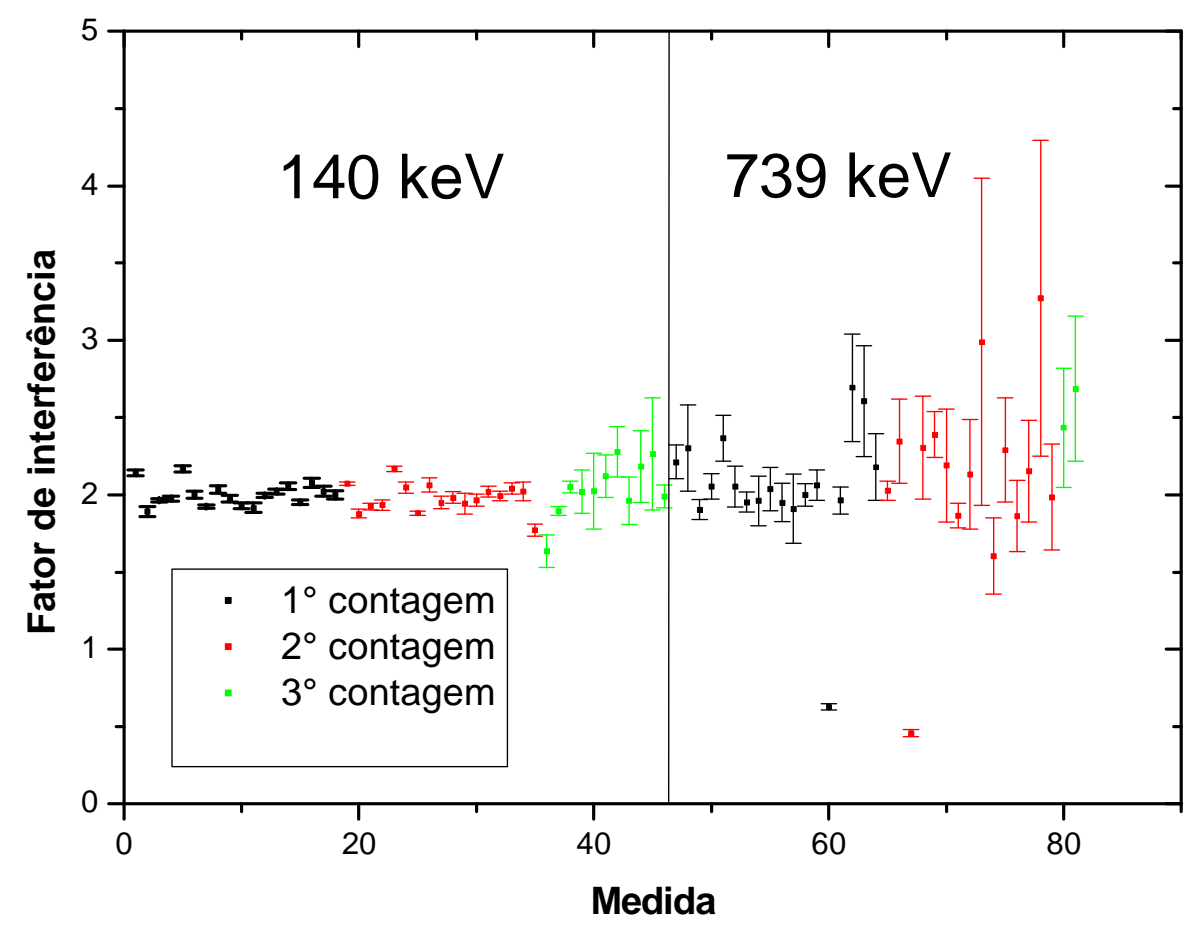

FIGURA 5.16 - Valores dos fatores de interferência obtidos para o ${ }^{99} \mathrm{Mo} \mathrm{em}$ diferentes tempos de decaimento.

Pela análise do gráfico presente na FIG. 5.16 verifica-se que os valores dos fatores de interferência obtidos pela transição gama de $140 \mathrm{keV}$ do ${ }^{99 \mathrm{~m}} \mathrm{Tc}$ (intensidade 89,06 \%), que estão localizados à esquerda, apresentam valores de desvio padrão menores em virtude da alta intensidade desta transição gama do decaimento do ${ }^{99 \mathrm{~m}} \mathrm{Tc}$.

Devido à baixa intensidade da transição gama de $181 \mathrm{keV}(6,08 \%)$ os resultados obtidos experimentalmente para os fatores de interferência não foram 
satisfatórios, e portanto foram descartados do cálculo do fator de interferência para o ${ }^{99} \mathrm{Mo}$.

Na TAB. 5.5 são apresentados os valores dos fatores de interferência obtidos para o ${ }^{99} \mathrm{Mo}$ utilizando os diferentes tratamentos estatísticos.

TABELA 5.5 - Valores obtidos para os fatores de interferência do ${ }^{99} \mathrm{Mo}$ (em mg $\mathrm{kg}^{-1}$ ) utilizando diferentes tratamentos estatísticos.

\begin{tabular}{ccccccc}
\hline & & & \multicolumn{4}{c}{ ANÁLISE ESTATÍSTICA } \\
\cline { 5 - 7 } Contagem & $\begin{array}{c}\text { Transição gama } \\
(\mathbf{k e V})\end{array}$ & $\mathbf{N}$ & $\mathbf{M A} \pm \mathbf{D P}$ & $\mathbf{M P} \pm \mathbf{D P}$ & $\mathbf{M R N} \pm \mathbf{D P}$ & $\mathbf{R J} \pm \mathbf{D P}^{(\mathbf{a})}$ \\
\hline primeira & 140 & 18 & $2,000 \pm 0,019$ & $1,999 \pm 0,017$ & $1,999 \pm 0,017$ & $2,000 \pm 0,017^{(1)}$ \\
segunda & 140 & 17 & $1,971 \pm 0,024$ & $1,971 \pm 0,018$ & $1,965 \pm 0,024$ & $2,025 \pm 0,040^{(1)}$ \\
terceira & 140 & 11 & $2,063 \pm 0,043$ & $1,967 \pm 0,034$ & $1,967 \pm 0,034$ & $2,019 \pm 0,029$ \\
primeira & 739 & 18 & $2,074 \pm 0,072$ & $2,005 \pm 0,035$ & $2,005 \pm 0,035$ & $2,006 \pm 0,035^{(1)}$ \\
segunda & 739 & 15 & $2,02 \pm 0,17$ & $1,218 \pm 0,039$ & $2,02 \pm 0,10$ & $1,972 \pm 0,055^{(1)}$ \\
todas & 140,739 & 79 & $2,022 \pm 0,033$ & $1,921 \pm 0,010$ & $1,980 \pm 0,013$ & $1,985 \pm 0,011^{(2)}$ \\
\hline $\mathbf{N}=$ número de determinações; a $\mathbf{a}=$ outliers. & & & & &
\end{tabular}

Verifica-se pela análise da TAB. 5.5 que os valores obtidos para o fator de interferência usando a transição $739 \mathrm{keV}$, pela média ponderada das $1^{\circ}$ e $2^{\circ}$ contagens, foram inferiores aos demais valores obtidos, isto ocorreu devido à presença de dois valores obtidos na primeira e segunda contagem estarem abaixo dos demais valores e com baixo erro, interferindo desta maneira na média ponderada com $1 / \sigma^{2}$.

Para este radioisótopo considerou-se o fator de interferência obtido utilizando a média aritmética, por meio dos dados das transições gama de 140 $\mathrm{keV}$ e $739 \mathrm{keV}$ e das três contagens $(2,022 \pm 0,033)$, uma vez que as intensidades dessas transições são maiores do que a de $180 \mathrm{keV}$ e os desvios associados às taxas de contagens obtidas para as transições gama de 140 e $739 \mathrm{keV}$ foram inferiores do que os desvios do fotopico da transição de $180 \mathrm{keV}$.

\subsubsection{Fator de interferência experimental obtido para $0^{147} \mathrm{Nd}$}

$\mathrm{O}$ fator de interferência do ${ }^{147} \mathrm{Nd}$ foi determinado utilizando as taxas de contagens para as transições gama de 91 e $531 \mathrm{keV}$ em 3 deferentes tempos de decaimento em cada uma das 18 irradiações realizadas. A FIG. 5.17 apresenta um gráfico com a dispersão dos valores dos fatores de interferência obtidos por meio das três contagens em cada irradiação. 


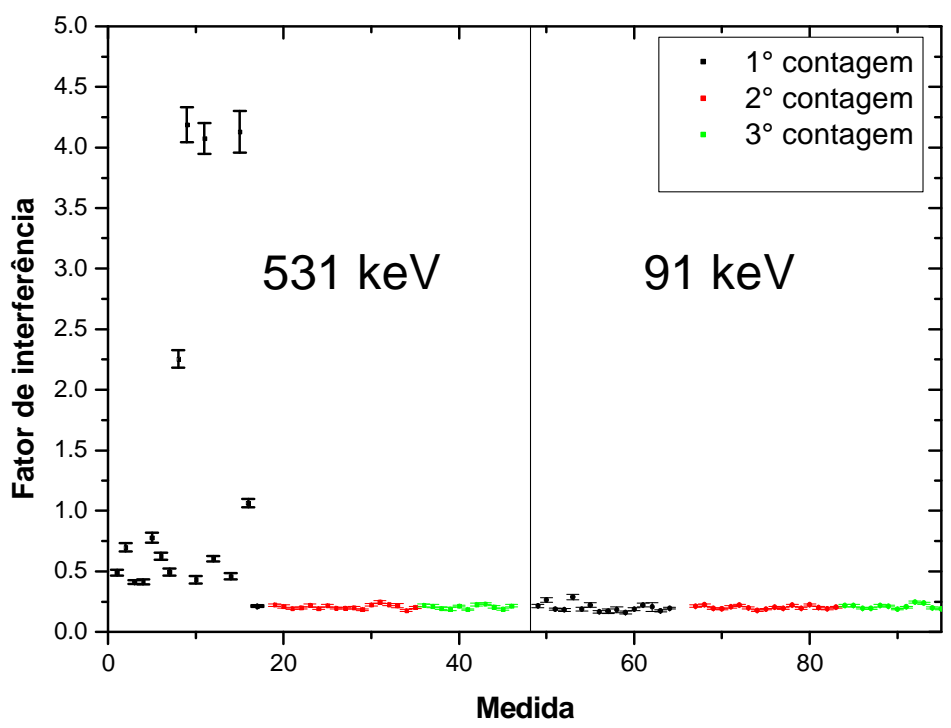

FIGURA 5.17 - Valores dos fatores de interferência obtidos para o ${ }^{147} \mathrm{Nd}$ em diferentes tempos de decaimento.

A FIG. 5.17 mostra que os valores dos fatores de interferência na região localizada à esquerda do gráfico são mais elevados do que os demais fatores. Isto decorre devido ao fato que nesta região citada estão presentes os fatores de interferência determinados na primeira contagem (com aproximadamente 5 dias de tempo de decaimento) pelo fotopico em $531 \mathrm{keV}$. Neste fotopico ocorre a interferência espectral de outro produto de fissão $0{ }^{133} \mathrm{I}$, cujas características nucleares são apresentadas na TAB. 5.6.

TABELA 5.6 - Características nucleares do ${ }^{133} \mathrm{I}$.

\begin{tabular}{|c|c|c|c|c|}
\hline Radioisótopo & $\begin{array}{c}\text { Transição gama } \\
(\mathrm{keV})\end{array}$ & Intensidade (\%) & Meia vida (h) & $\begin{array}{l}\text { Rendimento de } \\
\text { fissão (\%) }\end{array}$ \\
\hline${ }^{133} \mathrm{I}$ & 529,87 & 87 & 20,8 & $6,59 \pm 0,11$ \\
\hline
\end{tabular}

A meia vida do ${ }^{147} \mathrm{Nd}$ é de $10,98 \mathrm{~d}$, portanto para a determinação do fator de interferência devido à fissão do $U$ para o ${ }^{147} \mathrm{Nd}$ pelo fotopico em $531 \mathrm{keV}$ é possível esperar um tempo de decaimento adequado para que a atividade do ${ }^{133}$ I não interfira nas medições do fotopico em $531 \mathrm{keV}$ do ${ }^{147} \mathrm{Nd}$. No presente estudo foi verificado que a partir da segunda contagem (com aproximadamente 10 dias de tempo de decaimento) os valores dos fatores de interferência não sofreram mais esta influência do ${ }^{133} \mathrm{I}$. 
No gráfico da FIG. 5.18 estão apresentados os fatores de interferência obtidos com os dados da primeira contagem em função do tempo de decaimento, e por meio da análise deste gráfico verificou-se que a interferência do ${ }^{133}$ I diminui com o tempo de decaimento.

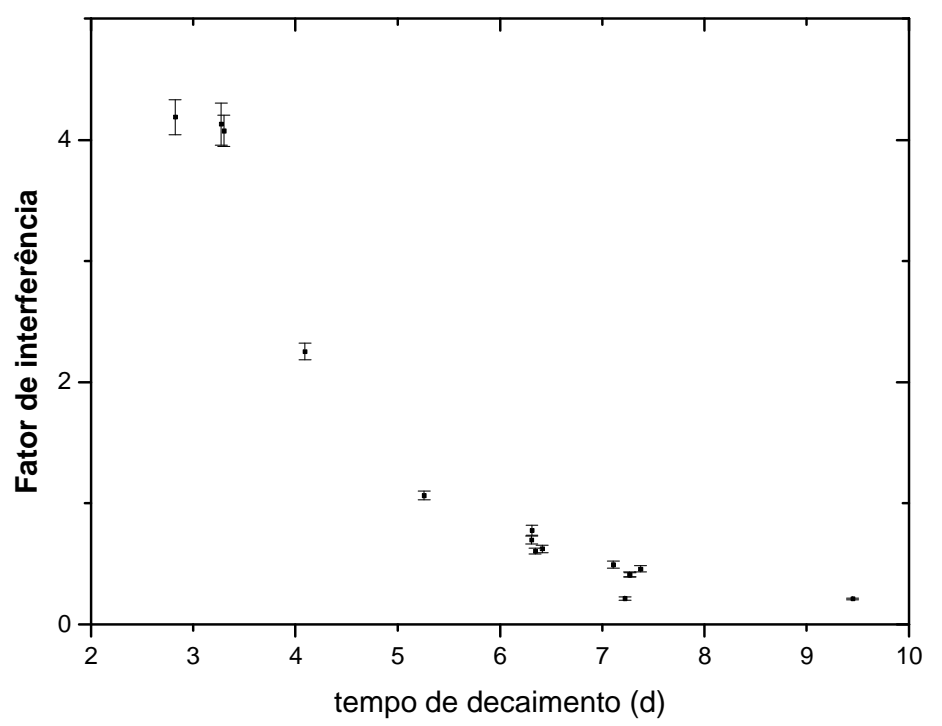

FIGURA 5.18 - Variação do fator de interferência para o ${ }^{147} \mathrm{Nd}$ utilizando o fotopico em $531 \mathrm{keV}$ em função do tempo de decaimento utilizando dados das primeiras contagens.

$\mathrm{Na}$ TAB. 5.7 são apresentados os valores dos fatores de interferência obtidos para o ${ }^{147} \mathrm{Nd}$ utilizando a Média Aritmética (MA), a Média Ponderada com $1 / \sigma^{2}$ (MP), Método dos Resíduos Normalizados (MRN) e o teste de Rajeval (RJ) de todas as transições gama citadas acima.

TABELA 5.7 - Valores obtidos para os fatores de interferência do ${ }^{147} \mathrm{Nd}$ utilizando diferentes transições gama.

\begin{tabular}{|c|c|c|c|c|c|c|}
\hline \multirow[b]{2}{*}{ Contagem } & \multirow[b]{2}{*}{$\begin{array}{c}\text { Transiçãa } \\
\text { gama (keV) }\end{array}$} & \multirow[b]{2}{*}{$\mathbf{N}$} & \multicolumn{4}{|c|}{ Tratamento estatístico } \\
\hline & & & $\mathbf{M A} \pm \mathbf{D P}$ & MP \pm & $\mathrm{MRN} \pm \mathrm{DP}$ & $\mathbf{R J} \pm \mathbf{D} \mathbf{P}^{(\mathbf{a})}$ \\
\hline primeira & 91 & 17 & $0,201 \pm 0,009$ & $0,192 \pm 0,003$ & $0,189 \pm 0,005$ & $0,190 \pm 0,003$ \\
\hline segunda & 91 & 17 & $0,203 \pm 0,003$ & $0,200 \pm 0,002$ & $0,202 \pm 0,003$ & $0,200 \pm 0,002$ \\
\hline terceira & 91 & 13 & $0,211 \pm 0,005$ & $0,208 \pm 0,002$ & $0,206 \pm 0,004$ & $0,206 \pm 0,002$ \\
\hline primeira & 531 & 17 & $1,63 \pm 0,46$ & $0,406 \pm 0,005$ & $0,504 \pm 0,030$ & $0,458 \pm 0,010^{(1)}$ \\
\hline segunda & 531 & 17 & $0,208 \pm 0,004$ & $0,205 \pm 0,002$ & $0,204 \pm 0,004$ & $0,204 \pm 0,002$ \\
\hline terceira & 531 & 11 & $0,209 \pm 0,005$ & $0,206 \pm 0,003$ & $0,209 \pm 0,005$ & $0,209 \pm 0,003$ \\
\hline todas & $91 *$ e $531 *$ & 78 & $0,206 \pm 0,003$ & $0,203 \pm 0,001$ & $0,202 \pm 0,002$ & $0,202 \pm 0,001$ \\
\hline
\end{tabular}

$\mathbf{N}=$ número de determinações; $\mathbf{a}=$ outliers; ${ }^{*}=$ Descartado os pontos da primeira contagem do fotopico em $531 \mathrm{keV}$. 
Como esperado, a média aritmética do fator de interferência obtido com dados da primeira contagem (tempo de decaimento de aproximadamente 5 dias) no fotopico em $531 \mathrm{keV}$ foi em geral superior aos valores obtidos pelos demais tratamentos estatísticos devido à interferência do ${ }^{133}$, conforme verificado na TAB. 5.7.

Examinando os dados da TAB. 5.7 verifica-se que os fatores de interferência obtidos na primeira contagem pelo fotopico em $91 \mathrm{keV}$ apresentaram valores ligeiramente inferiores do que os obtidos nas demais contagens. Os resultados mostram que utilizando os dados da segunda e terceira contagens do fotopico em $91 \mathrm{keV}$, os valores dos fatores de interferência obtidos usando os 4 tratamentos estatísticos foram bastante similares.

Landsberger (1986), recomenda que a determinação do fator de interferência devido à fissão do $U$ para o ${ }^{147} \mathrm{Nd}$ utilizando a transição gama de 91 $\mathrm{keV}$ seja realizada com contagens efetuadas com um tempo de decaimento de aproximadamente 4 semanas, para evitar o problema de interferências espectrais nesta região de baixa energia.

Diante do exposto, o valor do fator de interferência para $0{ }^{147} \mathrm{Nd}$ aplicado na análise dos MRCs foi o obtido aplicando a média aritmética nos resultados das duas transições gama e desconsiderando os dados das primeiras contagens $(0,206 \pm 0,003)$.

\subsubsection{Fator de interferência experimental obtido para o ${ }^{153} \mathrm{Sm}$}

A análise do ${ }^{153} \mathrm{Sm}$ pode ser feita via fotopico em $69,67 \mathrm{keV}$, cuja intensidade é de 4,85\% (IAEA, 1990), contudo devido à baixa intensidade e aos efeitos secundários nesta região espectral o fotopico em $69 \mathrm{keV}$ não foi detectado nas análises dos espectros do $\mathrm{U}$, e portanto o fator de interferência experimental para este radioisótopo foi obtido pela transição gama de $103 \mathrm{keV}$.

A determinação do fator de interferência para $0{ }^{153} \mathrm{Sm}$ pode ser considerada como um outro caso especial, porque a transição gama de $103 \mathrm{keV}$ utilizada na determinação do fator de interferência para este radioisótopo sofre interferência espectral de raios $X$ provenientes do processo de conversão interna no ${ }^{239} \mathrm{Pu}$, particularmente $\mathrm{o}$ raio $\mathrm{X} \quad K \alpha_{1}$ de energia $103 \mathrm{keV}$ (http://www.kayelaby.npl.co.uk/atomic and nuclear physics/4 2/4 2 1.html).

Foi verificado que esta interferência aumenta com o tempo de decaimento, uma vez que os fatores obtidos com dados das primeiras contagens 
ficam em média por volta de 0,0456 $\pm 0,0002$ ao passo que os fatores de interferência obtidos com dados das terceiras contagens apresentam média com valores de aproximadamente $0,114 \pm 0,003$.

Esse aumento dos fatores de interferência para $0^{153} \mathrm{Sm}$ estão mais evidentes na FIG. 5.19, onde são apresentados os valores dos fatores obtidos em função do tempo de decaimento.

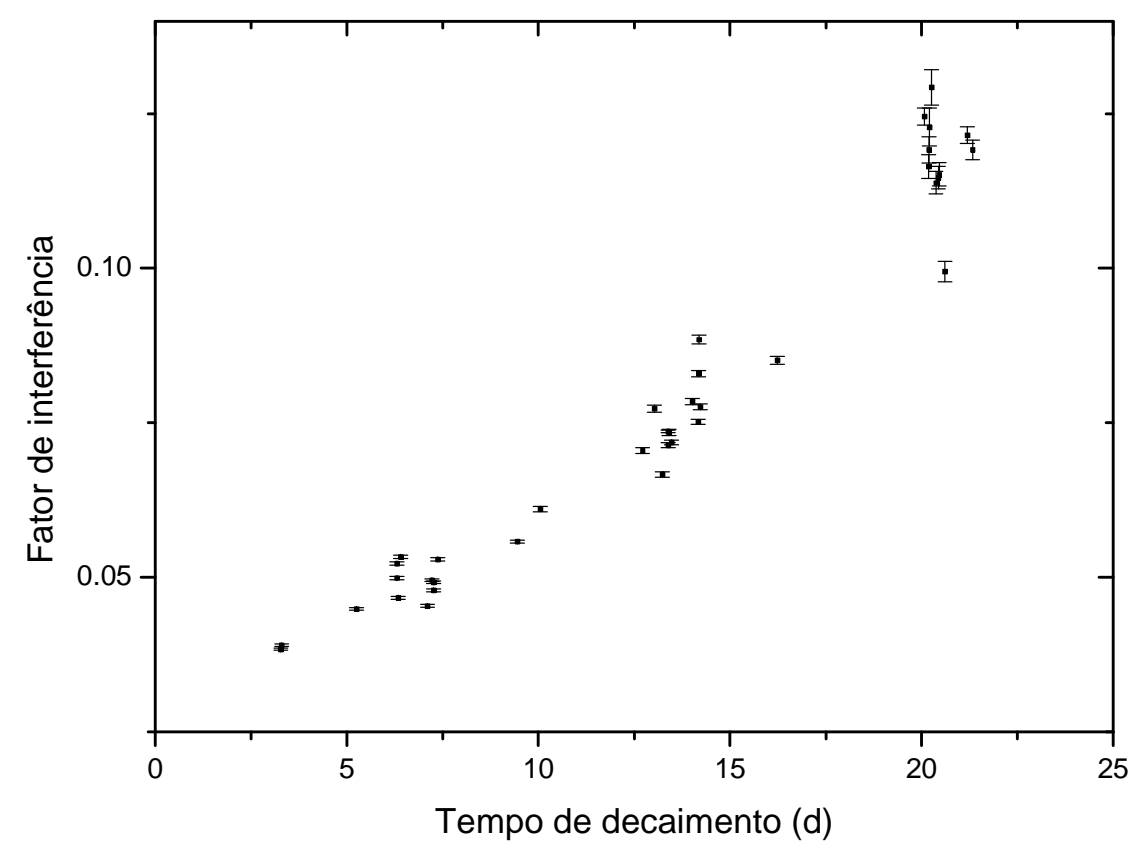

FIGURA 5.19 - Fatores de interferência obtidos para o ${ }^{153} \mathrm{Sm}$ em função do tempo de decaimento.

Como já dito, o problema da interferência de raios $X$ do ${ }^{239} \mathrm{Pu}$ ocorre devido ao decaimento do ${ }^{239} \mathrm{~Np}$ (meia vida de 2,36 dias) produto do decaimento $\beta^{-}$ do ${ }^{239} \mathrm{U}$ formado pela captura neutrônica do ${ }^{238} \mathrm{U}$ do padrão de $\mathrm{U}$ irradiado. A meia vida do ${ }^{153} \mathrm{Sm}$ é de 1,93 dias, portanto não há possibilidade de se esperar tempo adequado para que esta interferência não ocorra mais.

$\mathrm{Na}$ TAB. 5.8 são apresentados os valores dos fatores de interferência obtidos para o ${ }^{153} \mathrm{Sm}$ utilizando a transição gama de $103 \mathrm{keV}$. 
TABELA 5.8 - Valores obtidos para os fatores de interferência do ${ }^{153} \mathrm{Sm}$ utilizando a transição gama de $103 \mathrm{keV}$.

\begin{tabular}{ccccccc}
\hline & & \multicolumn{5}{c}{ Tratamento estatístico } \\
\cline { 4 - 7 } Contagem & $\begin{array}{c}\text { Transição } \\
\text { gama (keV) }\end{array}$ & $\mathbf{N}$ & $\mathbf{M A} \pm \mathbf{D P}$ & $\mathbf{M P} \pm \mathbf{D P}$ & $\mathbf{M R N} \pm \mathbf{D P}$ & $\mathbf{R J}^{2} \pm \mathbf{D P}^{(\mathbf{a})}$ \\
\hline primeira & 103 & 17 & $0,0467 \pm 0,0013$ & $0,0455 \pm 0,0003$ & $0,0472 \pm 0,0009$ & $0,0477 \pm 0,0005$ \\
segunda & 103 & 17 & $0,0680 \pm 0,0043$ & $0,0386 \pm 0,0004$ & $0,0713 \pm 0,0013$ & $0,0718 \pm 0,0007^{(1)}$ \\
terceira & 103 & 13 & $0,1136 \pm 0,0036$ & $0,1068 \pm 0,0010$ & $0,1165 \pm 0,0021$ & $0,1184 \pm 0,0013^{(1)}$ \\
todas & 103 & 47 & $0,0729 \pm 0,0044$ & $0,0354 \pm 0,0002$ & $0,0713 \pm 0,0016$ & $0,0506 \pm 0,0004^{(18)}$ \\
\hline \multicolumn{2}{c}{$\mathbf{N}=$ número de medidas; $\mathbf{a}=$ outliers } & & &
\end{tabular}

Verificou-se que os fatores de interferência obtidos pelos 4 tratamentos estatísticos aumentaram entre a primeira e terceira contagens. No caso da análise de Rajeval utilizando todas as contagens foram rejeitados 18 pontos, mostrando que o fator de interferência varia fortemente com o tempo de decaimento. Quando a análise de Rajeval foi realizada para um único tempo de decaimento apenas 1 ponto na segunda e terceira contagens foram considerados outliers.

Isso mostra uma impossibilidade de determinação experimental do fator de interferência devido à fissão do $U$ para $0{ }^{153} \mathrm{Sm}$. Entretanto foi verificado neste trabalho que o fator de interferência apresenta valores aproximados quando as contagens dos padrões de $\mathrm{U}$ e $\mathrm{Sm}$ são realizadas em mesmos tempos de decaimento.

Portanto devido à impossibilidade de se quantificar a contribuição dos raios $\mathrm{X}$ proveniente do ${ }^{239} \mathrm{~Np}$, recomenda-se que o analista determine um fator de interferência para $0^{153} \mathrm{Sm}$ com o mesmo tempo de decaimento em que se deseja determinar a concentração deste elemento na sua amostra de interesse. Conforme visto no gráfico da FIG 5.19 o fator de interferência do ${ }^{153} \mathrm{Sm}$ aumenta com o tempo de decaimento, portanto recomenda-se que as análises sejam feitas com tempo de decaimento de até 6 dias a fim de se ter uma menor interferência devida aos raios $\mathrm{X}$ e ${ }^{153} \mathrm{Sm}$ oriundo da fissão do ${ }^{235} \mathrm{U}$.

Foi verificado que $0{ }^{153} \mathrm{Sm}$ sofre interferência espectral do radioisótopo ${ }^{153} \mathrm{Gd}\left(t_{1 / 2}=241,6 d\right)$ cuja transição gama é de 103,2 keV (IAEA, 1990), este radioisótopo não é formado pela fissão do $U$, contudo nas determinações de concentração de Sm pela INAA o analista deve se certificar em relação a presença de Gd em sua amostra para evitar esse tipo de interferência.

\subsubsection{Fator de interferência experimental obtido para $0{ }^{95} \mathrm{Zr}$}

A determinação do $\mathrm{Zr}$ pela INAA também pode ser realizada pela reação ${ }^{96} \mathrm{Zr}(n, \gamma){ }^{97} \mathrm{Zr}$, entretanto a determinação de $\mathrm{Zr}$ por esta reação em 
amostras ricas em U apresenta algumas desvantagens segundo Martinho (1998), a saber:

1) A abundância isotópica do ${ }^{96} \mathrm{Zr}(2,8 \%)$ é menor do que a abundância isotópica do ${ }^{94} \mathrm{Zr}(17,38 \%)$;

2) $O$ valor do fator de interferência devido à fissão do $U$ para $0^{97} \mathrm{Zr}$ é maior do que o valor do fator de interferência para $0{ }^{95} \mathrm{Zr}$, ou seja a interferência do ${ }^{97} \mathrm{Zr}$ é maior.

Perante o exposto optou-se no presente estudo fazer a determinação do fator de interferência devido à fissão do $\mathrm{U}$ para $0^{95} \mathrm{Zr}$ em detrimento ao ${ }^{97} \mathrm{Zr}$.

No caso da determinação do fator de interferência devido à fissão do ${ }^{235} \mathrm{U}$ para $0{ }^{95} \mathrm{Zr}$ (meia vida 64 dias) foram realizadas 18 irradiações, e em cada irradiação as contagens foram realizadas para 3 diferentes tempos de decaimento. As transições gama utilizadas na determinação do fator de interferência para este radioisótopo foram as de $724 \mathrm{keV}$ e $756 \mathrm{keV}$, cujas intensidades são 44,15\% e 54,50\%, respectivamente (IAEA, 1990).

A FIG. 5.20 apresenta os fatores de interferência devido à fissão do ${ }^{235} \mathrm{U}$ para ${ }^{95} \mathrm{Zr}$ obtidos nas diferentes irradiações e em diferentes tempos de decaimento.

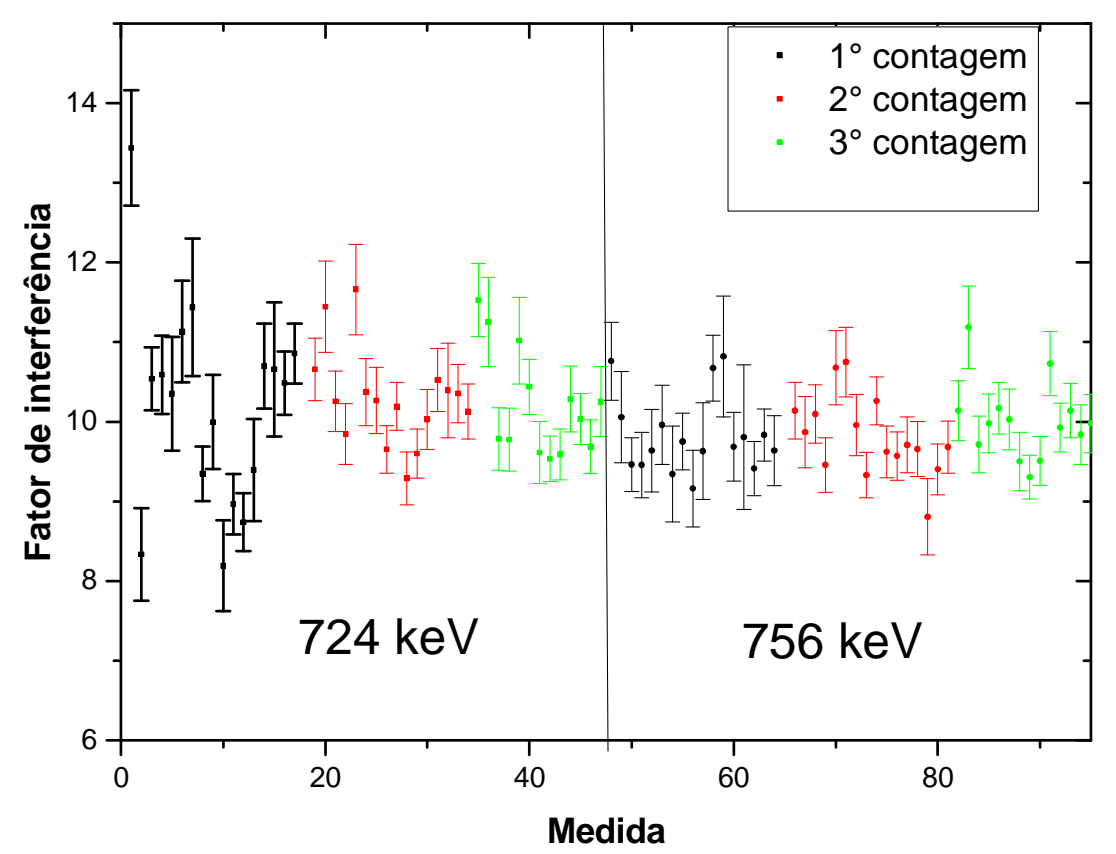

FIGURA 5.20 - Valores obtidos para o fator de interferência para o ${ }^{95} \mathrm{Zr}$ em diferentes tempos de decaimento. 
Os valores dos fatores de interferência para $0{ }^{95} \mathrm{Zr}$ apresentaram valores entre 8,19 $\pm 0,52$ e 13,44 0,62. Este fato pode ser explicado em virtude do ${ }^{94} \mathrm{Zr}$ possuir um alta razão entre seção de choque epitérmica e seção de choque térmica, e como pode ser visto na equação (16) quanto maior for esta razão maior será a variação do fator de interferência em função da razão entre fluxos de nêutrons térmicos e epitérmicos.

$\mathrm{Na}$ TAB. 5.9 são apresentados os valores dos fatores de interferência obtidos para o ${ }^{95} \mathrm{Zr}$ para as transições gama de 724 e $756 \mathrm{keV}$.

TABELA 5.9 - Valores obtidos para os fatores de interferência do ${ }^{95} \mathrm{Zr}$ utilizando as transições gama de 724 e $756 \mathrm{keV}$.

\begin{tabular}{|c|c|c|c|c|c|c|}
\hline \multicolumn{3}{|c|}{$\begin{array}{l}\text { DESCRIÇÃO DA } \\
\text { METODOLOGIA }\end{array}$} & \multicolumn{4}{|c|}{ ANÁLISE ESTATÍSTICA } \\
\hline Contagem & $\begin{array}{c}\text { Transição } \\
\text { gama (keV) }\end{array}$ & $\mathbf{N}$ & $\mathrm{MA} \pm \mathrm{DP}$ & $\mathrm{MP} \pm \mathrm{DP}$ & $\mathrm{MRN} \pm \mathrm{DP}$ & $\mathbf{R J} \pm \mathbf{D} \mathbf{P}^{(\mathbf{a})}$ \\
\hline primeira & 724 & 17 & $10,19 \pm 0,32$ & $9,94 \pm 0,12$ & $9,94 \pm 0,24$ & $10,25 \pm 0,14$ \\
\hline segunda & 724 & 16 & $10,29 \pm 0,15$ & $10,13 \pm 0,10$ & $10,13 \pm 0,13$ & $10,13 \pm 0,10^{(1)}$ \\
\hline terceira & 724 & 14 & $10,17 \pm 0,18$ & $10,01 \pm 0,10$ & $9,98 \pm 0,15$ & $9,94 \pm 0,10$ \\
\hline primeira & 756 & 16 & $9,84 \pm 0,13$ & $9,78 \pm 0,11$ & $9,78 \pm 0,11$ & $9,75 \pm 0,11$ \\
\hline segunda & 756 & 16 & $9,81 \pm 0,13$ & $9,77 \pm 0,09$ & $9,77 \pm 0,09$ & $9,76 \pm 0,09^{(1)}$ \\
\hline terceira & 756 & 14 & $10,01 \pm 0,13$ & $9,92 \pm 0,10$ & $9,92 \pm 0,10$ & $10,92 \pm 0,10$ \\
\hline todas & 724756 & 93 & $10,05 \pm 0,08$ & $9,93 \pm 0,04$ & $9,92 \pm 0,06$ & $9,92 \pm 0,04^{(2)}$ \\
\hline
\end{tabular}

segunda contagem das transições gama de 724 e $756 \mathrm{keV}$ foram 67,06 \ 0,02 e $78,00 \pm 0,60$, respectivamente. Os fatores de interferência obtidos na primeira e terceira contagens deste mesmo padrão foram consistentes.

Para o cálculo do fator de interferência utilizando todos os resultados das transições gama de $724 \mathrm{keV}$ e $756 \mathrm{keV}$ os outliers citados acima foram excluídos.

No caso deste radioisótopo considerou-se que o fator de interferência obtido aplicando a média aritmética por meio das transições gama de 724 keV e $756 \mathrm{keV}(10,05 \pm 0,08)$ o mais apropriado, uma vez que ambas as transições apresentam intensidades elevadas e valores aproximados de fator de interferência quando comparados individualmente.

\subsection{Balanço das incertezas dos fatores experimentais}

Com o intuito de verificar qual o peso das incertezas dos diversos parâmetros usados no cálculo dos fatores de interferência experimentais obtidos, foi feito o balanço das incertezas dos fatores para cada isótopo. Na TAB 5.10 são 
apresentados esses resultados. Foi considerada nos cálculos de incerteza desses fatores experimentais o erro da razão entre fluxos nêutrons epitérmicos e térmicos, uma vez que mudanças desta razão durante a irradiação podem provocar variações nos fatores interferência obtidos experimentalmente.

TABELA 5.10 - Balanço das incertezas envolvidas na determinação do fator de interferência experimental.

Balanço do peso das fontes de erros (\%)

\begin{tabular}{ccccccc}
\hline Radioisótopo & Energia & $\begin{array}{c}\text { Atividade } \\
\text { do produto } \\
\text { de fissão }\end{array}$ & $\begin{array}{c}\text { Atividade } \\
\text { do elemento }\end{array}$ & $\begin{array}{c}\text { Massa do } \\
\text { elemento }\end{array}$ & Massa do U & Fluxo \\
\hline${ }^{141} \mathrm{Ce}$ & 145,44 & 21 & 3 & 38 & 38 & 0,05 \\
${ }^{143} \mathrm{Ce}$ & 293,27 & 24 & 35 & 20 & 20 & 0,04 \\
${ }^{140} \mathrm{La}$ & 487,021 & 12 & 2 & 43 & 43 & 0,03 \\
${ }^{140} \mathrm{La}$ & 328,76 & 13 & 4 & 42 & 42 & 0,03 \\
${ }^{140} \mathrm{La}$ & 815,77 & 20 & 6 & 37 & 37 & 0,03 \\
${ }^{140} \mathrm{La}$ & 1596,21 & 9 & 3 & 44 & 44 & 0,03 \\
${ }^{99} \mathrm{Mo}$ & 140,51 & 2 & 11 & 29 & 29 & 30,01 \\
${ }^{99} \mathrm{Mo}$ & 739,5 & 3 & 91 & 2 & 2 & 3,29 \\
${ }^{147} \mathrm{Nd}$ & 91,1 & 79 & 1 & 9 & 9 & 1,43 \\
${ }^{147} \mathrm{Nd}$ & 531,01 & 54 & 13 & 16 & 16 & 2,45 \\
${ }^{153} \mathrm{Sm}$ & 103,18 & 0,4 & 0,4 & 50 & 50 & 0,86 \\
${ }^{95} \mathrm{Zr}$ & 724,2 & 18 & 44 & 19 & 19 & 0,00 \\
${ }^{95} \mathrm{Zr}$ & 756,73 & 18 & 38 & 22 & 22 & 0,74 \\
\hline
\end{tabular}

Verifica-se pela análise da TAB. 5.10 que os pesos dos parâmetros utilizados nos cálculos dos fatores de interferência experimentais variam bastante quando é feita a comparação entre diferentes radioisótopos.

Foi realizado também o cálculo do peso da incerteza proveniente do erro da meia vida dos radioisótopos utilizados, este erro não foi considerado uma vez que ficaram da ordem de $10^{-6} \%$ no budget das incertezas.

\subsection{Fatores de interferência determinados teoricamente}

Neste item são apresentados os valores obtidos para os fatores de interferência determinados teoricamente, assim como os valores obtidos na determinação da razão entre o fluxo de nêutrons térmicos e epitérmicos na mesma posição em que foram os fatores de interferência devido à fissão do $U$ foram obtidos experimentalmente.

\subsubsection{Determinação da razão entre fluxo de nêutrons epitérmicos e térmicos}

Conforme já mencionado nesta dissertação, os fatores de interferência devido à fissão do $U$ dependem da razão entre os fluxos de nêutrons epitérmicos 
e térmicos. Estes valores foram determinados por meio de 8 irradiações de monitores de fluxo.

A condição ideal para a determinação dos fatores de interferência teóricos seria que o parâmetro $\phi_{e p} / \phi_{t h}$ fosse constante durante a irradiação, uma vez que se espera que estes fatores de interferência não sofram variações. Entretanto foi verificado que os valores obtidos para este parâmetro sofreram uma variação de 0,0044 \pm 0,0003 até um máximo de 0,0163 \pm 0,0010.

Para a identificação de possíveis outliers foi aplicado o teste de Rajeval aos valores obtidos por meio das 8 irradiações destes monitores de fluxo. Os valores obtidos por meio da Média Aritmética (MA), Média Ponderada com $1 / \sigma^{2}$ (MP), Método dos Resíduos Normalizados (MRN) e o método de Rajeval estão presentes na TAB. 5.11.

TABELA 5.11 - Valores obtidos para a razão do entre os fluxos de nêutrons térmicos e epitérmicos na posição $14 \mathrm{~b}$ prateleira 3 do reator IEA-R1.

\begin{tabular}{lcccc}
\hline Razão & MA \pm DP & MP \pm DP & MRN \pm DP & RJ \pm DP \\
\hline$\phi_{e p} / \phi_{t h}$ & $(1,301 \pm 0,074) \times 10^{-2}$ & $(1,227 \pm 0,012) \times 10^{-2}$ & $(1,361 \pm 0,034) \times 10^{-2}$ & $(1,357 \pm 0,022) \times 10^{-2}$ \\
\hline
\end{tabular}

O teste de Rajeval detectou o valor de 0,0044 \pm 0,0003 como sendo um outlier, este valor foi excluído dos cálculos realizados para o valor de fluxo médio. O valor de $(1,357 \pm 0,022) \times 10^{-2}$ resultante do teste de Rajeval foi o valor da razão de $\phi_{e p} / \phi_{t h}$ utilizado para a determinação dos fatores de interferência teóricos neste estudo.

\subsubsection{Fatores de interferência teóricos}

A determinação dos fatores de interferência teóricos foi realizada substituindo na equação (16) a razão entre $\phi_{e p} / \phi_{t h}$ obtida na mesma posição em que os padrões sintéticos foram irradiados, e substituindo os parâmetros nucleares presentes na TAB. 4.4. Os valores obtidos para os fatores de interferência teóricos seguem na TAB. 5.12 juntamente com os valores obtidos experimentalmente para comparação. 
TABELA 5.12 - Fatores de interferência da fissão do U determinados teoricamente e experimentalmente.

\begin{tabular}{ccc}
\hline Radionuclídeo & FATOR TEÓRICO & $\begin{array}{c}\text { FATOR } \\
\text { EXPERIMENTAL }\end{array}$ \\
\hline${ }^{141} \mathrm{Ce}$ & $0,280 \pm 0,007$ & $0,262 \pm 0,002$ \\
${ }^{143} \mathrm{Ce}$ & $1,354 \pm 0,009$ & $1,241 \pm 0,016$ \\
${ }^{140} \mathrm{La}$ & $0,0168 \pm 0,0002$ & $(2,392 \pm 0,015) 10^{-3} \cdot \alpha$ \\
${ }^{99} \mathrm{Mo}$ & $1,873 \pm 0,125$ & $1,022 \pm 0,033$ \\
${ }^{147} \mathrm{Nd}$ & $0,193 \pm 0,006$ & $0,206 \pm 0,003$ \\
${ }^{153} \mathrm{Sm}$ & $(6,31 \pm 0,21) \times 10^{-5}$ & - \\
${ }^{95} \mathrm{Zr}$ & $11,28 \pm 0,17$ & $10,05 \pm 0,08$ \\
\hline$=e^{t_{d} \lambda_{L a} \cdot e^{-t_{d} \lambda_{B a}-1}}$ &
\end{tabular}

A TAB. 5.12 mostra que os valores dos fatores de interferência obtidos teoricamente e experimentalmente para alguns radionuclídeos apresentam diferenças.

A seguir, serão discutidos os valores dos fatores de interferência determinados teoricamente para cada radionuclídeo.

\subsubsection{Fator de interferência obtido teoricamente para o ${ }^{141} \mathrm{Ce}$}

No caso do ${ }^{141} \mathrm{Ce}$, os valores dos fatores de interferência determinados teoricamente e experimentalmente ficaram próximos, conforme pode ser visto na FIG 5.21. 


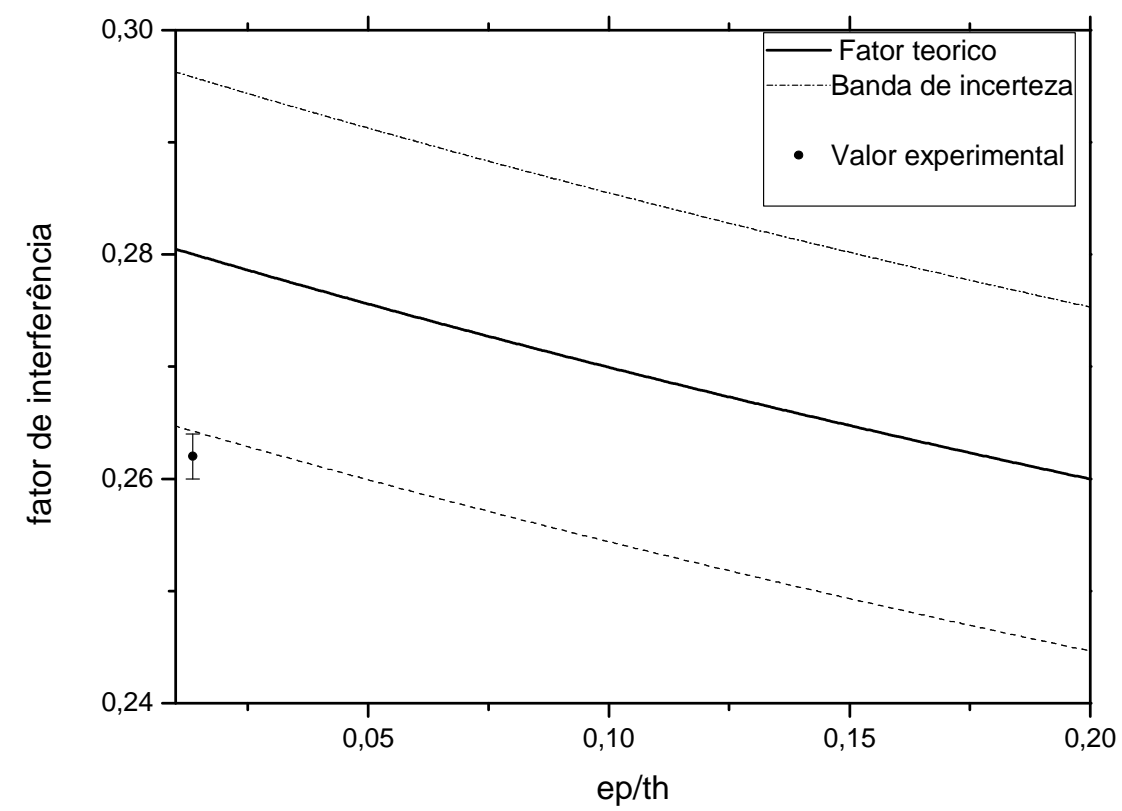

FIGURA 5.21 - Comparação entre valor do fator de interferência obtido experimentalmente e o valor teórico em função da razão entre fluxo de nêutrons térmicos e epitérmicos para o ${ }^{141} \mathrm{Ce}$.

Verifica-se pela análise do gráfico da FIG. 5.21 que o valor obtido para o fator de interferência obtido experimentalmente ficou abaixo do valor teórico, mesmo considerando a barra de erro do fator experimental. Este problema pode ter sido ocasionado em virtude do fator de interferência teórico ter sido calculado utilizando o valor médio entre as medidas da razão entre fluxo de nêutrons epitérmicos e térmicos.

\subsubsection{Fator de interferência obtido teoricamente para o ${ }^{143} \mathrm{Ce}$}

No caso do ${ }^{143} \mathrm{Ce}$ a diferença entre os valores determinados teoricamente e experimentalmente é mais acentuada. Conforme pode ser visto no gráfico da FIG. 5.22. 


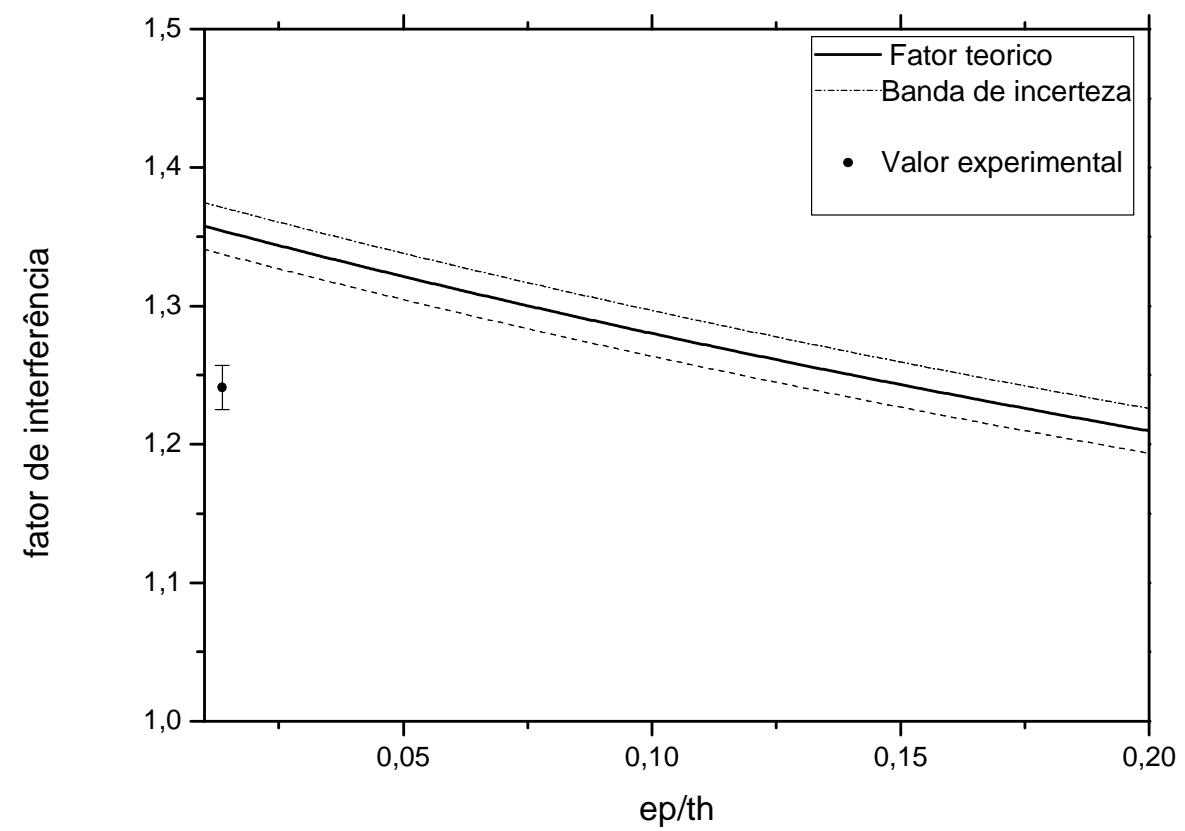

FIGURA 5.22 - Comparação entre valor do fator de interferência obtido experimentalmente e o valor teórico em função da razão entre fluxo de nêutrons térmicos e epitérmicos para o ${ }^{143} \mathrm{Ce}$.

Al-Jobori et al. (1990) determinaram um fator de interferência experimental para ${ }^{143} \mathrm{Ce}$ de 1,38 ao passo que o fator calculado teoricamente foi de 0,94, ou seja, o erro relativo entre o experimental e teórico foi de aproximadamente $31 \%$.

Foram encontrados na literatura poucos dados referentes ao fator de interferência para $0{ }^{143} \mathrm{Ce}$. Contudo é importante lembrar a determinação da concentração de $\mathrm{Ce}$ em amostras ricas em $U$ deve ser feita preferencialmente utilizando o radioisótopo ${ }^{141} \mathrm{Ce}$, pois este possui meia vida maior do que o ${ }^{143} \mathrm{Ce} \mathrm{e}$ a interferência devida a fissão do $U$ é menor.

Conforme sugerido por Al-Jobori et al. (1986), caso haja a necessidade de realizar a determinação deste elemento é recomendado utilizar o fator de interferência obtido experimentalmente, pois a determinação deste não depende de outros parâmetros nucleares.

\subsubsection{Fator de interferência obtido teoricamente para $0^{140} \mathrm{La}$}

A diferença entre os valores determinados teoricamente $e$ experimentalmente para $0{ }^{140} \mathrm{La}$, que pode ser verificada na TAB. 5.10, está 
relacionada com a formação deste elemento pelo decaimento do ${ }^{140} \mathrm{Ba}$, pois a equação (16), utilizada no cálculo do fator de interferência teórico, não considera a formação do ${ }^{140}$ La por outros meios e reações que não seja devido à fissão direta do $\mathrm{U}$, por isso ocorre essa diferença entre os valores teóricos e experimentais.

A determinação da constante $k$ presente na equação (33) foi realizada por três metodologias distintas, a saber:

1) Considerando nula a formação do ${ }^{140}$ La pela fissão direta do $U$ e realizando a determinação dos fatores de interferência experimentais para diferentes tempos de decaimento, aqui denominada $k$ (experimental);

2) Substituindo os parâmetros nucleares reportados na literatura e o valor da razão entre os fluxos de nêutrons epitérmicos e térmicos na equação (33), aqui denominada por $k^{1}$;

3) Realizando o ajuste do gráfico presente na FIG. 5.15, aqui denominada $k^{2}$.

$\mathrm{Na}$ TAB. 5.13 são apresentados os valores das constantes $k, k^{1} \mathrm{e} k^{2}$ para $0{ }^{140} \mathrm{La}$ determinadas pelas três metodologias diferentes.

TABELA 5.13 - Valores obtidos para a constante $k$ do fator de interferência do ${ }^{140}$ La por três metodologias diferentes.

\begin{tabular}{cc}
\hline Metodologia & Valor obtido \\
\hline$k$ (experimental) & $0,00239 \pm 0,00002$ \\
$k^{1}$ & $0,00239 \pm 0,00003$ \\
$k^{2}$ & $0,00231 \pm 0,00002$ \\
\hline
\end{tabular}

Os valores obtidos para a constante $k$ pelas três metodologias diferentes apresentaram boa concordância.

\subsubsection{Fator de interferência obtido teoricamente para $0{ }^{99} \mathrm{Mo}$}

Devido à alta razão entre seção de choque epitérmica e seção de choque térmica, $\mathrm{O}^{99} \mathrm{Mo}$ é tido como um dos elementos que mais sofre variação do fator de interferência em função da razão entre os fluxos de nêutrons epitérmicos e térmicos. Na FIG. 5.23 é apresentado um gráfico da variação do fator de interferência, assim como o valor do fator de interferência obtido experimentalmente neste trabalho e por diferentes autores. 


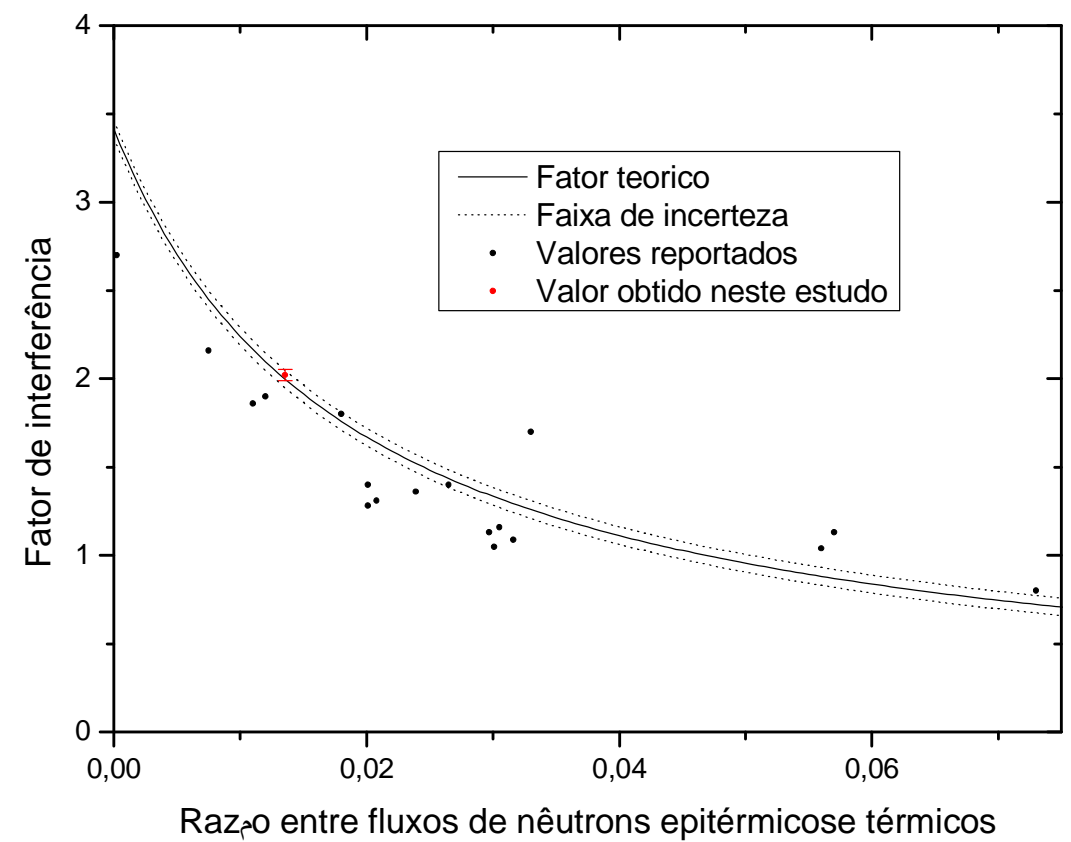

FIGURA 5.23 - Comparação entre os valores dos fatores de interferência para o ${ }^{99} \mathrm{Mo}$ determinados experimentalmente e teoricamente entre diferentes autores.

Como pode ser visto pela análise do gráfico da FIG. 5.23 o valor do fator de interferência obtido experimentalmente e teoricamente para o ${ }^{99}$ Mo apresentaram boa concordância.

\subsubsection{Fator de interferência obtido teoricamente para $0{ }^{147} \mathrm{Nd}$}

No caso do ${ }^{147} \mathrm{Nd}$ também foi feito o gráfico da FIG. 5.24 para comparação entre o fator de interferência obtido experimentalmente e previsão teórica em função do fluxo de nêutrons epitérmicos e térmicos. 




FIGURA 5.24 - Comparação entre valor do fator de interferência obtido experimentalmente e o valor teórico em função da razão entre fluxo de nêutrons térmicos e epitérmicos para o ${ }^{147} \mathrm{Nd}$.

A análise do gráfico da FIG. 5.24 indica que os valores dos fatores de interferência obtidos teoricamente e experimentalmente para $0{ }^{147} \mathrm{Nd}$ encontramse dentro da banda de incerteza, indicando desta forma uma boa concordância entre os resultados obtidos pelas duas metodologias.

\subsubsection{Fator de interferência obtido teoricamente para $0{ }^{153} \mathrm{Sm}$}

No caso do ${ }^{153} \mathrm{Sm}$ é impossível fazer uma comparação gráfica entre os valores dos fatores de interferência obtidos experimentalmente e teoricamente, visto que a determinação deste elemento em amostras ricas em $U$ sofre interferência espectral de raios $\mathrm{X}$ do ${ }^{239} \mathrm{Pu}$.

Contudo é possível analisar a variação do fator de interferência teórico em função da razão entre os fluxos de nêutrons epitérmicos e térmicos utilizando a equação (16). Esta variação está presente no gráfico da FIG. 5.25. 


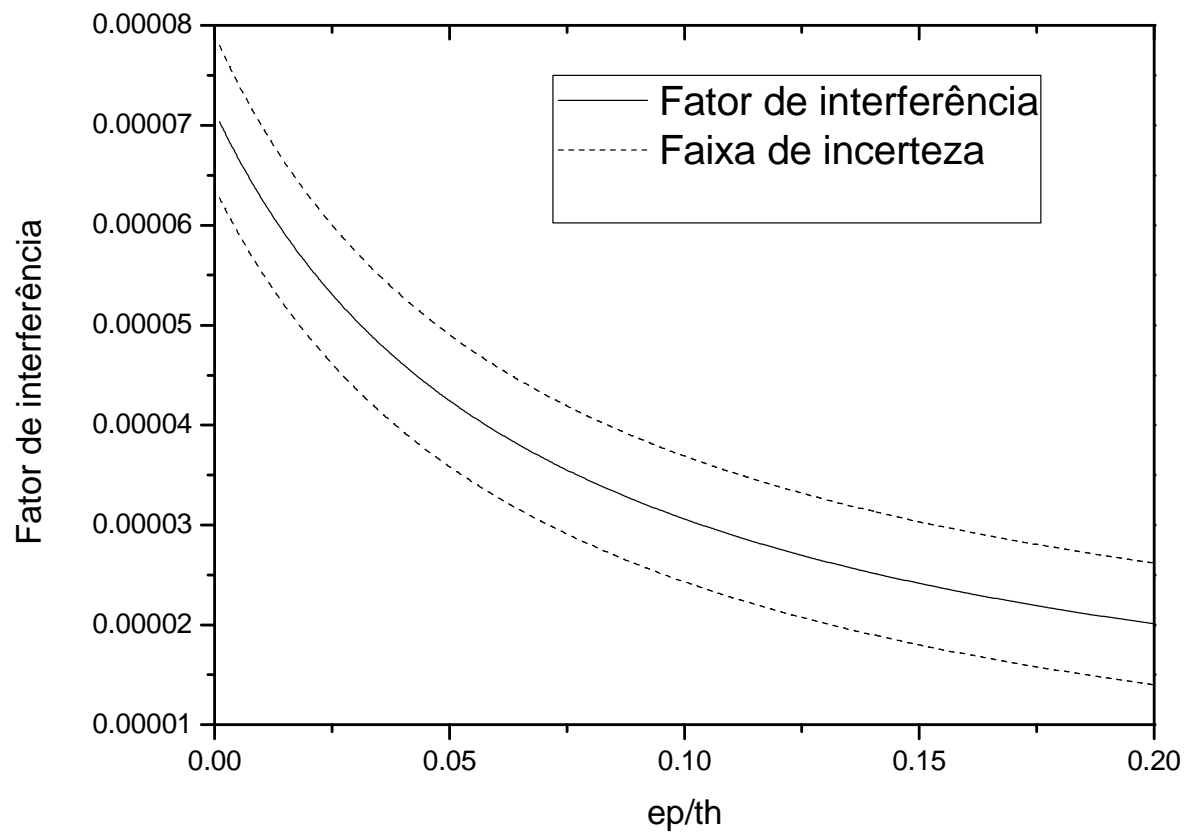

FIGURA 5.25 - Variação do fator de interferência teórico do ${ }^{153} \mathrm{Sm}$ em função da razão entre fluxos térmicos e epitérmicos.

A FIG. 5.25 indica que os fatores de interferência obtidos teoricamente para $0{ }^{153} \mathrm{Sm}$ possuem valores na ordem de $10^{-5}$, ao passo que os fatores de interferência obtidos experimentalmente neste estudo possuíram valores com ordens de grandeza entre $10^{-1}$ e $10^{-2}$ (vide FIG. 5.18). Por estes dados conclui-se que a interferência devido à fissão do $U$ no caso do ${ }^{153} \mathrm{Sm}$ é proveniente em sua grande maioria de raios $X$ emitidos na conversão interna do ${ }^{239} \mathrm{Pu}$.

Devido a essa interferência dos raios $X$ do ${ }^{239} \mathrm{Pu}$ a determinação do fator de interferência do ${ }^{153} \mathrm{Sm}$ é considera um outro caso especial, pois como visto no gráfico da FIG. 5.25 a variação deste fator teórico não corresponde aos valores dos fatores de interferência encontrados experimentalmente.

A atividade no fotopico em $103 \mathrm{keV}$ dos padrões de $U$ utilizados na determinação do fator de interferência experimental do ${ }^{153} \mathrm{Sm}$ pode, se considerarmos desprezível a contribuição devido à fissão do $\mathrm{U}$, ser representado por duas componentes: uma delas oriunda da ativação do ${ }^{152} \mathrm{Sm}$ e a outra dos raios $\mathrm{X}$ do ${ }^{239} \mathrm{Pu}$. Portanto o fator de interferência experimental do ${ }^{153} \mathrm{Sm}$ pode ser descrito por meio da seguinte relação (35). 


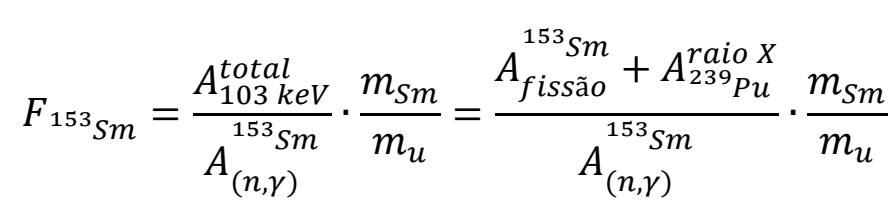

Onde os termos $A_{\text {fissão }}^{153}$ e $A_{239}^{\text {raio } \mathrm{Pu}}$ representam as atividades no fotopico em 103 $\mathrm{keV}$ provinda dos raios gama do ${ }^{153} \mathrm{Sm}$ e dos raios $\mathrm{X}$ do ${ }^{239} \mathrm{~Np}$, respectivamente.

A atividade do radioisótopo ${ }^{153} \mathrm{Sm}$ pode ser obtida utilizando a equação (6). Contudo para calcular a atividade dos raios $X$ do ${ }^{239} \mathrm{Pu}$ logo após a irradiação é necessário determinar o número de átomos de ${ }^{239} \mathrm{~Np}$ formados logo após a irradiação, utilizando a seguinte relação:

$$
N_{0}^{239_{N p} p}\left(t_{i}\right)=\frac{m_{u} \cdot a_{238_{U}} \cdot N_{A}}{M_{U} \cdot \lambda_{239_{N}} \cdot\left(\lambda_{239_{N}}-\lambda_{239_{U}}\right)} \cdot k_{233_{U}}^{(n, r)} \cdot\left[\lambda_{239_{N} p} \cdot\left(1-e^{-\lambda_{239_{U}} t_{i}}\right)-\lambda_{239_{U}} \cdot\left(1-e^{-\lambda_{239_{N}{ }_{N}} t_{i}}\right)\right]
$$

Onde $t_{i}$ é o tempo de irradiação e $k_{238_{U}}^{(n, \gamma)}$ pode ser calculado pela seguinte relação:

$$
k_{238}^{(n, \gamma)}=\sigma_{t h}^{238} U(n, r) \cdot \phi_{t h}+\sigma_{e p}{ }^{238} U(n, r) \cdot \phi_{e p}
$$

Conforme discutido anteriormente a maior pare da atividade do fotopico em $103 \mathrm{keV}$ medido no padrão de $\mathrm{U}$ é proveniente dos raios $\mathrm{X}$ do ${ }^{239} \mathrm{Pu}$. Considerando essa informação pode-se determinar um valor de fator de interferência efetivo para o ${ }^{153} \mathrm{Sm}$ como função do tempo de decaimento utilizando o valor do número de átomos iniciais de ${ }^{239} \mathrm{~Np}$ logo após a irradiação por meio da equação (38):



Sendo $I^{X R a y}$ a intensidade dos raios $\mathrm{X}$ do ${ }^{239} \mathrm{Pu}$. Os parâmetros $k_{235 U}^{f}$ e $k_{152 S m}^{(n, \gamma)}$ são obtidos utilizando as seguintes equações:

$$
\begin{aligned}
& k_{23 S_{U}}^{f}=\sigma_{t h}^{U^{235}(n, f)} \cdot \phi_{t h}+\sigma_{e p}^{U_{e p}^{235}(n, f)} \cdot \phi_{e p} \\
& k_{152}^{(n, \gamma)}=\sigma_{t h}^{152} S m(n, \gamma) \cdot \phi_{t h}+\sigma_{e p}^{152} S m(n, \gamma) \cdot \phi_{e p}
\end{aligned}
$$


O gráfico da FIG. 5.26 mostra o fator de interferência efetivo obtido utilizando a equação (38) junto com os pontos experimentais do fator de interferência do ${ }^{153} \mathrm{Sm}$ obtido para diferentes tempo de decaimento.

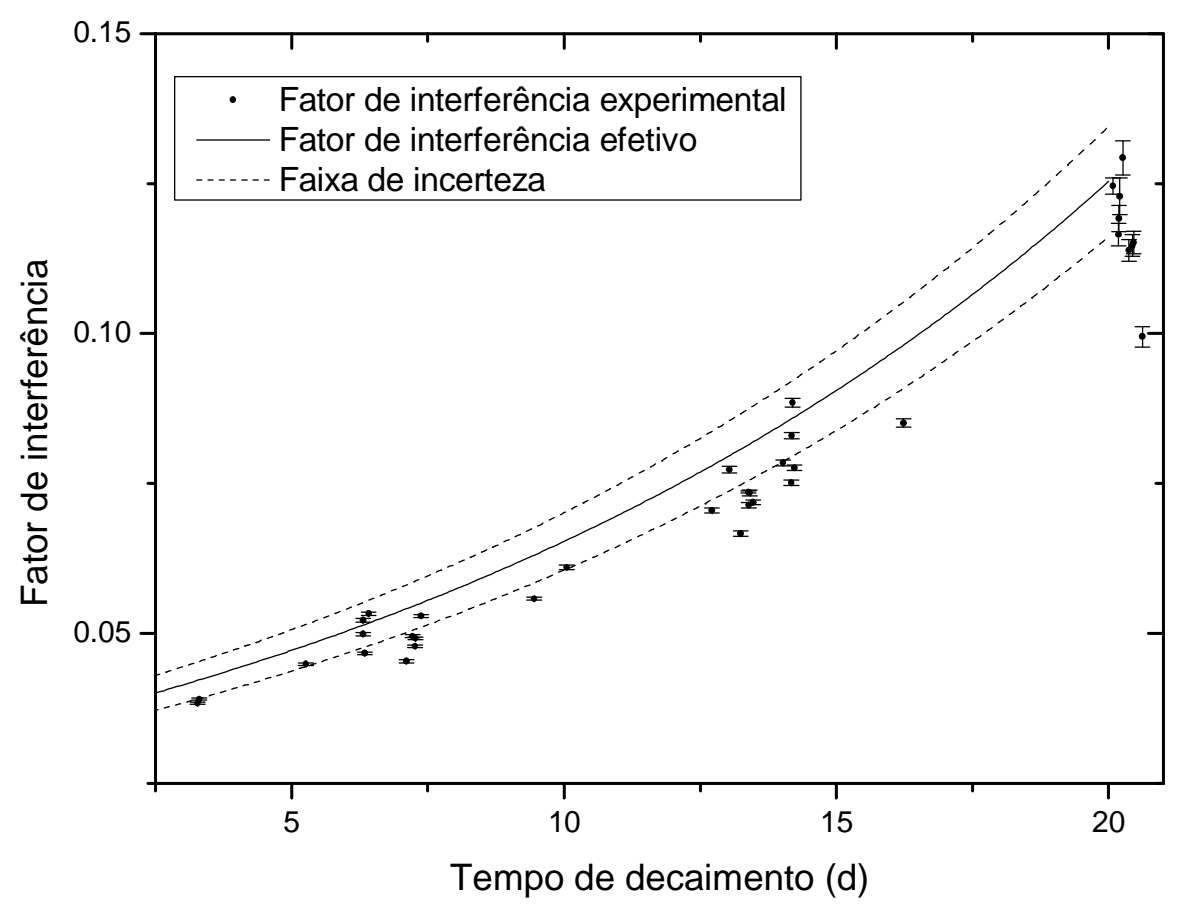

FIGURA 5.26 - Comparação entre os valores dos fatores de interferência determinados experimentalmente e o fator de interferência determinado utilizando a equação (40).

Como pode ser verificado pela análise do gráfico da FIG. 5.26, os valores determinados experimentalmente e fator de interferência efetivo utilizando a equação (40) apresentaram boa concordância.

A banda de incerteza do fator de interferência efetivo é maior do que a do fator de interferência experimental em virtude dos valores dos fluxos de nêutrons térmicos e epitérmicos apresentarem desvios padrões relativos da ordem de $10 \%$.

\subsubsection{Fator de interferência obtido teoricamente para o ${ }^{95} \mathrm{Zr}$}

$O$ fator de interferência determinado teoricamente para ${ }^{0}{ }^{95} \mathrm{Zr}$ apresentou valor elevado quando comparado com o valor do fator de interferência determinado experimentalmente, conforme visto na TAB. 5.10. 
Esta discrepância entre valores obtidos experimentalmente e teoricamente tem sido comum quando analisados os resultados obtidos por diferentes pesquisadores. Na FIG. 5.27 são apresentados os valores dos fatores de interferência obtidos experimentalmente por diferentes autores em função da razão entre fluxo de nêutrons epitérmicos e térmicos.

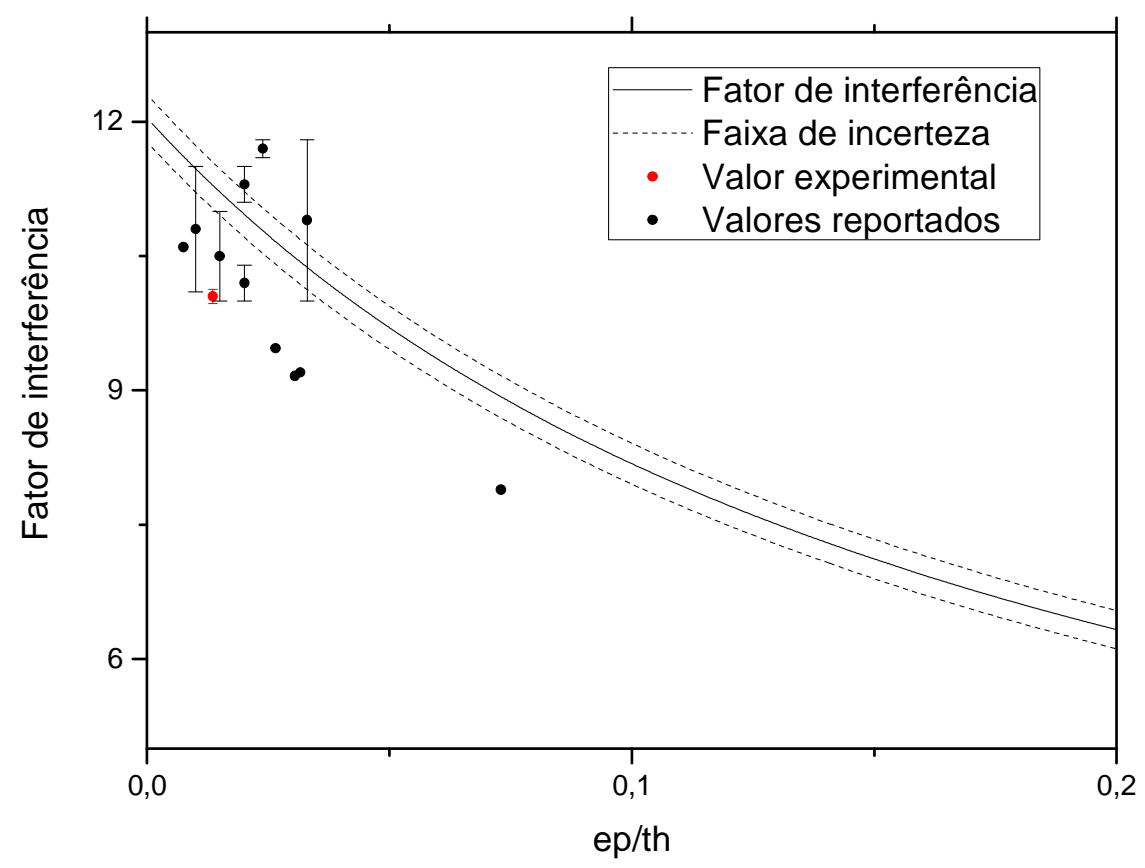

FIGURA 5.27 - Comparação entre valores de fatores de interferência para ${ }^{95} \mathrm{Zr}$ determinados experimentalmente e teoricamente entre diferentes pesquisadores.

Conforme mostrado na FIG. 5.15 diversos autores obtiveram diferentes valores entre os fatores de interferência determinados experimentalmente e teoricamente. Martinho (1998), sugere que os possíveis erros na determinação dos fatores interferência para $0{ }^{95} \mathrm{Zr}$ sejam devidos à utilização de padrões de $U$ empobrecidos de ${ }^{235} \mathrm{U}$, que são sub produtos de instalações de enriquecimento. A mesma subestimação dos valores experimentais com relação aos teóricos pode ser observada nos outros casos em que o rendimento de fissão é alto (valores próximos a $6 \%$ ) como o ${ }^{99} \mathrm{Mo}$, o ${ }^{141} \mathrm{Ce} \mathrm{e} \mathrm{o}{ }^{143} \mathrm{Ce}$. 


\subsection{Aplicação dos fatores de interferência nas análises de MRCs.}

Neste item serão apresentados e discutidos os valores obtidos da concentração dos elementos alvos deste estudo na análise de alguns MRCs aplicando a correção devido à interferência do U presente na equação (41).

$$
C_{R}=C_{a p}-F \cdot C_{U}
$$

Sendo $C_{R}$ a concentração real; $C_{a p}$ a concentração aparente; $F$ o fator de interferência do radioisótopo utilizado na determinação da concentração do elemento de interesse e $C_{U}$ a concentração de $U$ na amostra.

Para a correção da concentração dos elementos presentes nos materiais de referência foram aplicados os fatores de interferência determinados experimentalmente, conforme sugerido por Glascock et al. (1986).

Os valores das concentrações determinadas serão apresentados por meio das médias aritméticas das concentrações obtidas nas diferentes determinações.

Para avaliar a exatidão dos resultados obtidos em comparação com os valores dos certificados dos materiais de referência foi calculado o valor do teste estatístico $E_{n}$-score (Konieczka \&Namiesnik, 2009):

$$
E_{n}=\frac{x_{l a b}-x_{r e f}}{\sqrt{u_{x l a b}^{2}+u_{x r e f}^{2}}}
$$

Sendo $x_{l a b}$ e $x_{r e f}$ são os valores obtidos na análise e os valores dos certificados dos materiais de referência, respectivamente; $u_{x l a b}$ e $u_{x r e f}$ são as incertezas expandidas das concentrações obtidas nas análises e do certificado do material de referência, respectivamente.

Os valores $E_{n}$-score considerados satisfatórios são aqueles que estão entre -1 e 1 (Konieczka \&Namiesnik, 2009).

Para o cálculo da concentração dos elementos nos MRCs foram realizadas as devidas correções de umidade conforme orientações presentes nos certificados destes materiais.

A análise da precisão dos resultados obtidos para a concentração dos elementos nos MRCs foi realizada utilizando o critério de HORRAT (Wood, 1999). 
Neste método o Desvio Padrão Relativo $(D P R)$ obtido nas análises das alíquotas dos MRCs irradiadas é comparado com o Desvio Padrão Relativo previsto pela equação de Horwitz $\left(D P R_{H}\right)$. O Valor de HORRAT é calculado utilizando a seguinte equação:

$$
H O R R A T=\frac{D P R}{D P R_{H}}
$$

Os valores de HORRAT compreendidos entre 0,5 e 2 são considerados como sendo aceitáveis.

O valor de $D P R_{H}$ é derivado da equação de Horwitz (Wood, 1999; Thompson, 2000) e depende do valor da concentração do elemento que se deseja analisar. Por meio da equação (44) é determinado o desvio padrão relativo $\left(D P R_{H}\right)$ utilizado na análise da precisão pelo critério de HORRAT.

$$
D P R_{H}=2^{(1-0,5 \log C)}
$$

Os valores obtidos pelo critério de HORRAT para os MRCs apresentaram valores entre 0,15 e 1,28. Os valores de HORRAT que ficaram fora da faixa de aceitabilidade foram para os elementos La e Sm presentes nos materiais de referência IAEA-SL-1 Lake Sedment.

\subsubsection{Material de referência NIST 8704 - Buffalo River Sediment}

Foram realizadas irradiações de 4 alíquotas deste material de referência a fim de se aplicar a correção devido à interferência de produtos de fissão do U.

Em cada uma das irradiações foram realizadas 3 contagens com diferentes tempos de decaimento para sanar possíveis problemas de interferências.

Os valores de concentrações obtidas sem uso da correção $\left(C_{a p}\right)$ e a concentração obtida aplicando a correção $\left(C_{R}\right)$ estão apresentados na Tabela 5.14 . 
TABELA 5.14 - Concentrações dos elementos no material de referência NIST RM 8704 Buffalo River Sediment e valores do certificado, em mg kg-1.

\begin{tabular}{cccccc}
\hline Elemento & Radioisótopo & $\boldsymbol{C}_{\boldsymbol{a p}} \pm \mathbf{D P}$ & $\boldsymbol{C}_{\boldsymbol{R}} \pm \mathbf{D P}[\mathbf{D P R}]$ & $\begin{array}{c}\text { Valor do } \\
\text { certificado (NIST, } \\
\mathbf{2 0 0 8})^{(\mathbf{a})}\end{array}$ & $\mathbf{E}_{\mathbf{n}}$-Score \\
\hline $\mathbf{C e}$ & ${ }^{141} \mathbf{C e}$ & $68,47 \pm 5,19$ & $67,66 \pm 5,19[7,6]$ & $66,5 \pm 2$ & 0,17 \\
$\mathbf{L a}$ & ${ }^{140} \mathbf{L a}$ & $31,01 \pm 2,22$ & $30,94 \pm 2,22[7,1]$ & - & \\
$\mathbf{M o}$ & ${ }^{99} \mathbf{M o}$ & $11,46 \pm 2,47$ & $5,69 \pm 2,47[43,4]$ & - & \\
$\mathbf{N d}$ & ${ }^{147} \mathbf{N d}$ & $31,46 \pm 7,05$ & $26,21 \pm 10,68[40,7]$ & - & \\
$\mathbf{S m}$ & ${ }^{153} \mathbf{S m}$ & $5,77 \pm 0,44$ & $5,63 \pm 0,44[7,8]$ & - & \\
$\mathbf{Z r}$ & ${ }^{95} \mathbf{Z r}$ & $341,37 \pm 45,87$ & $310,32 \pm 45,87[14,78]$ & - & $-0,08$ \\
$\mathbf{U}$ & ${ }^{239} \mathbf{N p}$ & $3,04 \pm 0,53$ & - & $3,09 \pm 0,13$ & \\
\hline
\end{tabular}

$C_{a p}=$ concentração aparente; $C_{R}=$ concentração real; $\mathrm{DP}=$ desvio padrão dos valores obtidos na média aritmética das 4 alíquotas; ${ }^{(a)} \mathrm{O}$ valor do certificado é dado com 0 valor da incerteza expandida (95\%); DPR= Desvio Padrão Relativo.

Dentre os elementos alvo deste estudo apenas o $\mathrm{Ce}$ e o $\mathrm{U}$ possuem concentração certificada pelo fornecedor, entretanto foram quantificados neste estudo os elementos La, Mo, Nd, Sm e Zr. Estes resultados de La, Mo, Nd, Sm e Zr obtidos podem ser importados para futura certificação deste MRC.

As concentrações de $\mathrm{Ce}$ e $\mathrm{U}$ obtidas apresentaram boa concordância com os valores certificados, como pode ser visto pela TAB. 5.14 e FIG.5.28. Os valores de $E_{n}$-score obtidos foram menores que 1 indicando que os dados obtidos estão dentro da faixa dos valores certificados a um nível de confiança de $68 \%$. 




FIGURA 5.28 - Valores de $E_{n}$-score obtidos para Ce e U no material de referência NIST RM 8704 Buffalo River Sediment.

\subsubsection{Material de referência IRMM BCR-667- Estuarine Sediment}

Foram também analisadas quatro alíquotas deste material e os resultados obtidos são apresentados na TAB.5.15. Nesta Tabela estão presentes os valores obtidos sem a correção (concentração aparente) juntamente com os valores corrigidos com o uso do fator de correção de interferência e os valores certificados.

TABELA 5.15 - Concentrações de elementos no material de referência IRMM BCR-667 Estuarine Sediment e valores do certificado, em $\mathrm{mg} \mathrm{kg}^{-1}$.

\begin{tabular}{|c|c|c|c|c|c|}
\hline Elemento & Radioisótopo & $C_{a p} \pm \mathrm{DP}$ & $C_{R} \pm \mathrm{DP}[\mathrm{DPR}]$ & $\begin{array}{c}\text { Valor do } \\
\text { certificado } \\
\text { (IRMM,1990) }^{(\mathbf{a})}\end{array}$ & $E_{n}$-Score \\
\hline $\mathrm{Ce}$ & ${ }^{141} \mathrm{Ce}$ & $60,04 \pm 3,74$ & $59,45 \pm 3,71[6,2]$ & $56,7 \pm 2,4$ & 0,58 \\
\hline La & ${ }^{140} \mathrm{La}$ & $28,91 \pm 1,58$ & $28,82 \pm 1,59[5,5]$ & $27,8 \pm 0,9$ & 0,51 \\
\hline Mo & ${ }^{99} \mathrm{Mo}$ & $8,72 \pm 0,91$ & $4,15 \pm 0,91[21,9]$ & - & \\
\hline Nd & ${ }^{147} \mathrm{Nd}$ & $26,27 \pm 1,45$ & $25,81 \pm 1,45[5,6]$ & $25,0 \pm 1,3$ & 0,34 \\
\hline Sm & ${ }^{153} \mathrm{Sm}$ & $4,47 \pm 0,47$ & $4,35 \pm 0,46[10,6]$ & $4,66 \pm 0,19$ & $-0,36$ \\
\hline $\mathbf{Z r}$ & ${ }^{95} \mathrm{Zr}$ & $178,62 \pm 10,10$ & $155,91 \pm 10,10[6,5]$ & - & \\
\hline $\mathbf{U}$ & ${ }^{239} \mathrm{~Np}$ & $2,37 \pm 0,39$ & - & $2,26 \pm 0,14$ & 0,01 \\
\hline
\end{tabular}


Os resultados da TAB. 5.15 mostram uma boa concordância com os valores certificados o que pode ser verificado pelos valores de $E_{n}$-score. Com relação à aplicação dos fatores de interferência verifica-se que a contribuição devida à fissão do $\mathrm{U}$ é pequena para os elementos $\mathrm{Ce}, \mathrm{La}, \mathrm{Nd}$ e $\mathrm{Sm}$, isto porque a magnitude da correção depende dos valores dos fatores de interferência e a concentração de $U$ presente na amostra. As únicas exceções foram o Mo e o Zr, em virtude dos altos valores dos fatores de interferência para os radioisótopos utilizados na determinação da concentração destes elementos.

Para este material de referência foram encontrados os elementos Mo e Zr que não possuem valores no certificado.

Os valores de $E_{n}$-score dos elementos que possuem valores no certificado para este material de referência estão na FIG.5.29, para melhor visualização.

Deve-se notar que as medidas de concentração de ${ }^{153} \mathrm{Sm}$ nos MRCs não foram efetuadas exatamente no mesmo tempo de decaimento em que os fatores de correção foram determinados, sendo os MRCs sempre analisados posteriormente devido à sua atividade mais elevada.

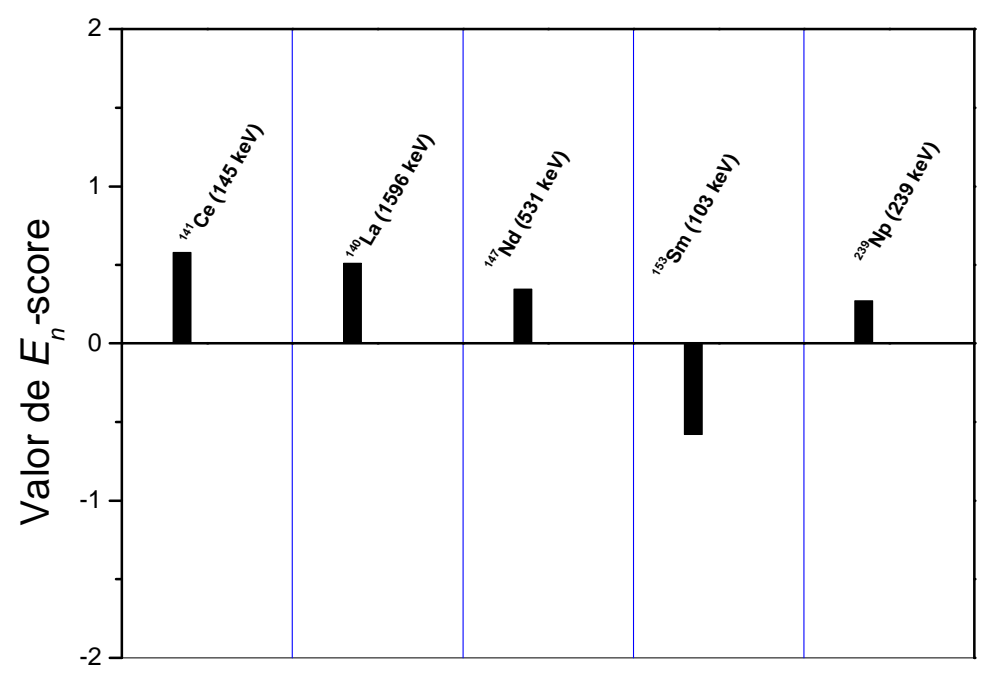

FIGURA 5.29 - Valores de En-score obtidos para o material de referência IRMM BCR-667 Estuarine Sediment. 


\subsubsection{Material de referência IAEA-SL-1 Lake Sediment}

Foram realizadas análises de quatro alíquotas deste material e na TAB.

5.16 são apresentados os valores obtidos sem a correção (concentração aparente) juntamente com os valores corrigidos $\left(C_{R}\right)$ e os valores certificados.

TABELA 5.16 - Concentrações dos elementos no material de referência IAEA-SL1 Lake Sediment e valores do certificado, em $\mathrm{mg} \mathrm{kg}^{-1}$.



\begin{tabular}{cccccc}
\hline $\mathrm{Ce}$ & ${ }^{141} \mathrm{Ce}$ & $110,2 \pm 5,7$ & $109,2 \pm 5,7[5,2]$ & $117(100-134)$ & $-0,37$ \\
$\mathrm{La}$ & ${ }^{140} \mathrm{La}$ & $51,31 \pm 0,60$ & $51,19 \pm 0,60[1,2]$ & $52,6(49,5-55,7)$ & $-0,18$ \\
$\mathrm{Mo}$ & ${ }^{99} \mathrm{Mo}$ & $13,15 \pm 4,20$ & $5,02 \pm 4,19[80,57]$ & - & \\
$\mathrm{Nd}$ & ${ }^{147} \mathrm{Nd}$ & $44,51 \pm 1,66$ & $43,68 \pm 1,66[3,8]$ & - & \\
$\mathrm{Sm}$ & ${ }^{153} \mathrm{Sm}$ & $8,58 \pm 0,26$ & $8,38 \pm 0,28[3,3]$ & $9,25(8,74-9,76)^{*}$ & $-1,28$ \\
$\mathrm{Zr}$ & ${ }^{95} \mathrm{Zr}$ & $258,2 \pm 29,2$ & $229,6 \pm 28,7[12,5]$ & - & \\
$\mathrm{U}$ & ${ }^{239} \mathrm{~Np}$ & $4,25 \pm 0,68$ & - & $4,02(3,69-4,35)^{*}$ & 0,25 \\
\hline
\end{tabular}

$C_{a p}=$ concentração aparente; $C_{R}=$ concentração corrigida; $\mathrm{DP}=$ desvio padrão dos valores obtidos na média aritmética das 4 alíquotas; (a) $O^{O}$ valor do certificado é dado com o valor da incerteza expandida ( $95 \%$ ); DPR= Desvio padrão relativo.

A FIG. 5.30 que mostra os valores de $E_{n}$-score para os elementos presentes no certificado para melhor visualização.

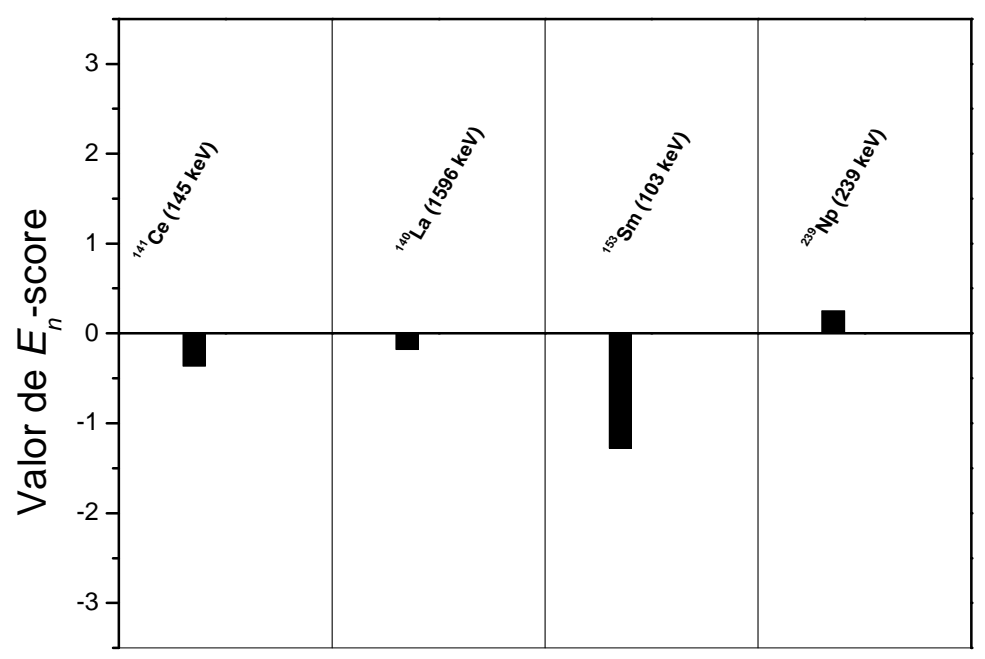

FIGURA 5.30 - Valores de En-score obtidos para o material de referência IAEASL-1 Lake Sediment. 
Pode ser verificado pela análise do gráfico da FIG. 5.30 que os resultados obtidos das concentrações dos elementos deste material de referência ficaram todas subestimadas, este fato não pode ser atribuído à aplicação da correção devido à interferência da fissão do $U$, uma vez que os valores obtidos sem a aplicação desta correção já estão subestimados.

Vale comentar que este material de referência foi produzido em 1979 e a última atualização dos valores certificados data de 1999, portanto existe a possibilidade de deste material ter sofrido alterações. Outro ponto a ser ressaltado é que para o cálculo da umidade foi usada, por conta da indisponibilidade deste $\mathrm{MRC}$, uma massa bastante inferior à recomendada no certificado e que o valor obtido para a perda de umidade deste material foi muito maior que os outros dois MRCs e maior que o valor limite indicado no certificado, portanto os valores subestimados podem ter relação com a superestimação da perda de umidade.

\subsubsection{Considerações sobre os resultados obtidos nas análises dos MRCs}

Os resultados obtidos na concentração de Ce que mais se aproximaram dos valores dos certificados foram por meio da transição gama de $145,44 \mathrm{keV}$ do ${ }^{141} \mathrm{Ce}$, utilizando os dados da primeira contagem. Este comportamento foi confirmado nas análises de todos os materiais de referência utilizados neste trabalho. Portanto nas determinações de concentração de $\mathrm{Ce}$ aconselha-se que as determinações de concentrações sejam realizadas nas primeiras contagens pelo fotopico em $145 \mathrm{keV}$ do ${ }^{141} \mathrm{Ce}$.

Os melhores resultados da concentração de $\mathrm{Sm}$ foram obtidos na $1^{\circ} \mathrm{e}$ $2^{\circ}$ contagens, devido à meia vida do $\mathrm{Sm}$ ser de $46,27 \mathrm{~h}$, portanto na terceira contagem quase não resta mais atividade do radioisótopo ${ }^{153} \mathrm{Sm}$ nos materiais de referência analisados.

A determinação da concentração de $\mathrm{Nd}$ foi realizada utilizando a transição gama de $531 \mathrm{keV}$ proveniente do ${ }^{147} \mathrm{Nd}$, entretanto esperou-se o tempo de decaimento apropriado para a determinação da concentração em razão da interferência do ${ }^{133}$ I discutido no capítulo 5.1.5.

A aplicação da correção devida à fissão do U não provocou alterações significativas nas concentrações determinadas sem a utilização da correção, isto porque a razão entre concentração de $U$ e concentração do elemento de interesse é baixa para estes materiais de referência. 


\subsection{Determinação da magnitude da interferência}

A concentração real do elemento de interesse $\left(C_{R}\right)$ determinada utilizando a equação (41) é diretamente proporcional à concentração de $U$ e também ao fator de interferência devido à fissão do $U$ do radioisótopo utilizado na análise.

O erro percentual devido à presença de $U$ em uma análise pode ser calculado em função da razão entre a concentração de $U$ e a concentração aparente do elemento de interesse presentes na amostra por meio da equação (45):

$$
\text { Erro }=F \cdot \frac{C_{U}}{C_{a p}} \cdot 100 \%
$$

Para os elementos alvo deste estudo que não sofrem interferências nas determinações dos fatores de interferência (como o ${ }^{140} \mathrm{La} \mathrm{e} \mathrm{o}{ }^{153} \mathrm{Sm}$ ) é possível fazer um gráfico da magnitude do erro percentual em função da razão entre a concentração de $U$ e a concentração do elemento de interesse presente na amostra.

O gráfico da FIG. 5.31 apresenta a magnitude do erro percentual em função da razão entre concentração de $U$ e concentração aparente na determinação de $\mathrm{Ce}$, Mo, $\mathrm{Nd}$ e $\mathrm{Zr}$ utilizando os seus respectivos radioisótopos utilizados nas análises: ${ }^{141} \mathrm{Ce},{ }^{143} \mathrm{Ce},{ }^{99} \mathrm{Mo} \mathrm{e}{ }^{95} \mathrm{Zr}$. 




Razão entre cencetração de U e concentração aparente do elemento

FIGURA 5.31 - Erro percentual devido à fissão do U em função da razão entre as concentrações de $U$ e do elemento de interesse para os radioisótopos ${ }^{141} \mathrm{Ce}$, ${ }^{143} \mathrm{Ce},{ }^{99} \mathrm{Mo},{ }^{147} \mathrm{Nd}$ e ${ }^{95} \mathrm{Zr}$.

Verifica-se pela análise do gráfico presente na FIG. 5.31 que para os diferentes radioisótopos utilizados na INAA a magnitude dos erros relacionados à interferência dos produtos de fissão são diferentes quando comparados com uma mesma razão entre concentração de $U$ e concentração do elemento de interesse, isto em razão dos diferentes valores dos fatores de interferência para cada radioisótopo.

Por exemplo para um erro de $10 \%$ na determinação da concentração de Ce é necessário ter uma razão entre concentração de $U$ e Ce na amostra de 0,38 quando o radioisótopo utilizado na análise é ${ }^{141} \mathrm{Ce}$, ao passo que quando é utilizado o ${ }^{143} \mathrm{Ce}$ essa razão é de aproximadamente 0,08 , ou seja, a interferência devida à fissão do U é maior quando a análise da amostra é feita utilizando o radioisótopo ${ }^{143} \mathrm{Ce}$. Sendo assim é preferível que a determinação da concentração de Ce pela INAA seja realizada utilizando o radioisótopo ${ }^{141} \mathrm{Ce}$ quando a amostra apresenta $U$ em sua composição.

O ${ }^{95} \mathrm{Zr}$ e $0{ }^{99} \mathrm{Mo}$ apresentam valores de fatores de interferência elevados, no caso da determinação de Zr e Mo utilizando estes radioisótopos é 
necessário ter uma razão entre concentração de $U$ e concentração aparentes destes elementos de 0,01 e 0,05, respectivamente, para se ter a mesma magnitude de erro percentual envolvido na medida. Ou seja, quanto maior for o valor do fator de interferência maior será o erro envolvido nas medidas se for desconsiderada a interferência de produtos de fissão do ${ }^{235} \mathrm{U}$.

O cálculo do erro na determinação da concentração de La devido à fissão do $U$ é um caso especial pois depende da razão entre $U$ e La presente na amostra que se deseja analisar e também do tempo de decaimento, conforme discutido no capítulo 5.1.3 desta dissertação.

A determinação da magnitude do erro associado à presença de $U$ pode ser calculada em função do tempo de decaimento e da razão entre $U$ e La presente na amostra utilizando a equação (46).

$$
\text { Erro }=0,002392 \cdot\left(e^{0,3584 t_{d}}-1\right) \cdot \frac{C_{U}}{C_{a p}^{L a}} \cdot 100 \%
$$

Sendo $t_{d}$ o tempo de decaimento em dias e $C_{a p}^{L a}$ a concentração aparente de La na amostra.

Na FIG. 5.32 é apresentado um gráfico com a magnitude do erro associado à medida de La em função da razão entre a concentração de $U$ e La para diferentes tempos de decaimento. 


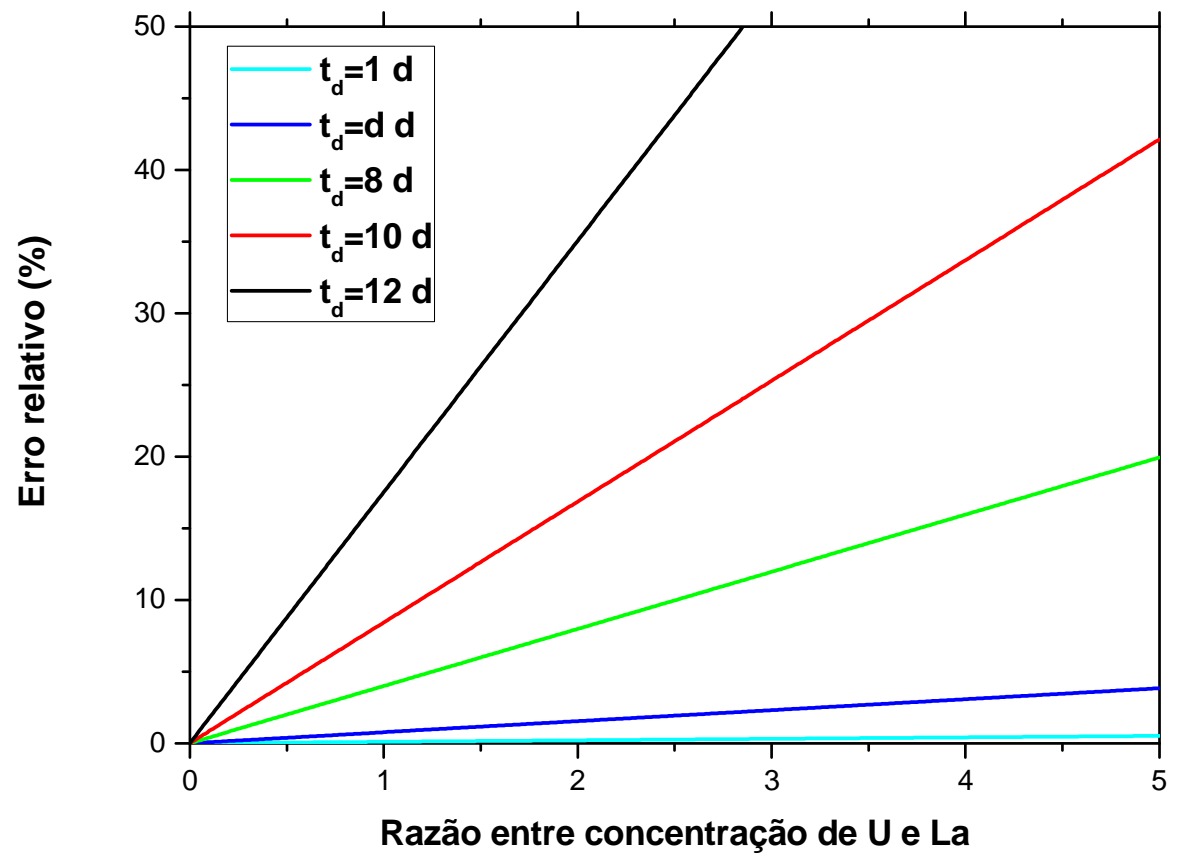

FIGURA 5.32 - Erro percentual devido à fissão do $U$ em função da razão entre as concentrações de U e de La para diferentes tempos de decaimento.

A magnitude do erro proveniente da fissão do $U$ aumenta com o tempo de decaimento na determinação da concentração de La em amostras com alto teor de U, conforme verificado no gráfico presente na FIG. 5.32.

Os resultados analíticos na determinação de La pela NAA que sofrem menos interferência do ${ }^{140} \mathrm{La}$ provindo de produto de fissão ${ }^{140} \mathrm{Ba}$ são aqueles obtidos com baixo tempo de decaimento, portanto é necessário que nas análises do La seja respeitado um compromisso entre meia vida do ${ }^{140} \mathrm{La}(1,68 \mathrm{~d})$, possíveis interferências espectrais de outros elementos presentes na amostra e determinação com baixo tempo de decaimento, para que a interferência devido à fissão do U seja baixa.

Outro radioisótopo cujo fator de interferência varia com o tempo de decaimento é o ${ }^{153} \mathrm{Sm}$, conforme discutido no Capítulo 5.1.6, portanto a magnitude do erro associado na determinação da concentração de Sm pela NAA em amostras ricas em U também dependerá do tempo de decaimento.

Conforme apresentado no gráfico da FIG. 5.19 os valores dos fatores de interferência para $0{ }^{153} \mathrm{Sm}$ apresentam valores aproximados para mesmos tempos de decaimento. Portanto foi feito um gráfico para se ter uma ideia da 
magnitude do erro devido à fissão do U na determinação da concentração de Sm na FIG. 5.33.



FIGURA 5.33 - Erro percentual na concentração de Sm devido à fissão do U em função da razão entre as concentrações de $U$ e de Sm para diferentes tempos de decaimento.

Para o caso de ${ }^{153} \mathrm{Sm}$ conclui-se pela análise da FIG. 5.33 que o erro devido a interferência do $U$, e principalmente pelos raios $\mathrm{X}$ do ${ }^{239} \mathrm{Pu}$, aumenta com o tempo de decaimento. Cabe neste caso ao analista esperar um tempo adequado para diminuir possíveis interferências nesta região do espectro de modo que sejam minimizadas outras fontes de interferência na determinação da concentração de Sm pela transição gama de $103 \mathrm{keV}$. 


\section{CONCLUSÕES}

Neste trabalho, foram medidos os fatores de interferência dos radioisótopos ${ }^{141} \mathrm{Ce},{ }^{143} \mathrm{Ce},{ }^{140} \mathrm{La},{ }^{99} \mathrm{Mo},{ }^{147} \mathrm{Nd},{ }^{153} \mathrm{Sm}$ e ${ }^{95} \mathrm{Zr}$ pelo método experimental e teórico na posição 14B, prateleira 3 do reator IEA-R1 do IPENCNEN/SP operando em 4,5 MW. Foi feita a comparação destes valores com os já reportados na literatura em outras instalações e os fatores de interferência propostos foram aplicados em análises de materiais de referência contendo urânio.

Alguns resultados já esperados foram confirmados neste estudo, como: os fatores de interferência devido à fissão do $U$ variam fortemente em função do produto de fissão analisado em virtude das diferenças entre os rendimentos de fissão cumulativo dos radioisótopos; a magnitude da interferência devida aos produtos de fissão depende não apenas do valor do fator de interferência do radioisótopo utilizado na análise, mas também da razão entre a concentração de $U$ e do elemento de interesse presente na amostra; e os valores dos fatores de interferência dos produtos de fissão do $U$ apresentam resultados diferentes quando comparados com os valores obtidos por diferentes pesquisadores em virtude das diferenças entre as condições sob as quais as amostras são irradiadas, mais precisamente pela diferença entre a razão entre fluxos de nêutrons epitérmicos e térmicos.

$\mathrm{Na}$ determinação dos produtos de fissão do $U$ deve-se ter cuidado especial quando os radioisótopos de interesse não são produzidos diretamente na fissão do $U$, como o caso do ${ }^{140}$ La que em sua maior parte é formado pelo decaimento do ${ }^{140} \mathrm{Ba}$. Neste caso, um fator de interferência dependente do tempo de decaimento foi obtido.

Pela análise da diferença entre os valores dos fatores de interferência obtidos experimentalmente e teoricamente para $0{ }^{153} \mathrm{Sm}$ conclui-se que a interferência deste radioisótopo é, em sua maior parte, provinda dos raios $X$ do ${ }^{239} \mathrm{Pu}$ e que para o fator de interferência ser aplicado a medida deve ter o mesmo tempo de decaimento que foi usado na determinação deste fator.

Foi proposto um fator de interferência efetivo em função do tempo de decaimento para o ${ }^{153} \mathrm{Sm}$, que considera a interferência no fotopico em $103 \mathrm{keV}$ oriunda dos raios $\mathrm{X}$ do ${ }^{239} \mathrm{Pu}$. Neste caso o fator de interferência proposto neste 
estudo apresentou boa concordância com os valores dos fatores de interferência determinados experimentalmente neste estudo.

Análises estatísticas foram aplicadas nos valores dos fatores de interferência obtidos e um valor foi recomendado para cada radioisótopo estudado. Esse valor foi o obtido pela média aritmética, devido à melhor estimação dos erros dos fatores. Os valores de desvio padrão obtidos pelos outros tratamentos estatísticos apresentaram desvio padrão menores do que os obtidos pela média aritmética, e não representaram adequadamente a dispersão dos pontos utilizados no cálculo dos fatores de interferência experimentais.

Para verificar a qualidade desses fatores, eles foram aplicados na determinação dos valores de concentração dos elementos estudados em MRCs. Essas análises apresentaram bons resultados, como foi verificado por meio dos valores de $E_{n}$-score, indicando que os fatores de interferência recomendados têm boa exatidão e precisão, sendo portanto recomendados para uso em medidas de NAA cujas irradiações sejam feitas na mesma posição onde foram determinados esses fatores de interferência.

A magnitude da correção devida aos produtos de fissão é maior quando são utilizados os radioisótopos ${ }^{95} \mathrm{Zr}$, ${ }^{99} \mathrm{Mo}$ e ${ }^{143} \mathrm{Ce}$ em virtude destes elementos apresentarem fatores de interferência maiores que os demais radioisótopos pesquisados. 


\section{REFERÊNCIAS BIBLIOGRÁFICAS}

AL-JOBORI, S. M.; AL-ATIA, M. J.; HUSSIEN, A. K. INAA of Zr, La, Ce and Nd in geological samples in the presence of different uranium concentrations. Journal of Radioanalytical and Nuclear Chemistry, v. 139, n. 2, p 31-36, 1990.

BITELLI, U. U. Cálculo da distribuição espacial e energética de nêutrons no núcleo do reator IPEN/MB-01. 1998. Dissertação (Mestrado) - Instituto de Pesquisas Energéticas e Nucleares, São Paulo.

CAPANNESI, G.; ROSADA, A.; MANIGRASSO, M.; AVINO, P. Rare earth elements, thorium and uranium in ores of the North-Latium (Italy).Journal of Radioanalytical and Nuclear Chemistry, v. 291, p. 163-168, 2012.

COSTA, L. A. Análise por ativação neutrônica: estudo de interferências primárias nas determinações de alumínio, magnésio, manganês e sódio. 2007. Dissertação (Mestrado) - Instituto de Pesquisas Energéticas e Nucleares, São Paulo.

DANKO, B.; DYBCCZYNSKI, R. Determination of molybdenum in biological materials by radiochemical neutron activation analysis. Journal of

Radioanalytical and Nuclear Chemistry, v. 216, n. 1, p 51-57, 1997.

DE CORTE, F.; VAN LIERD, S. Determination and evaluation of fission $\mathrm{k}_{0}$-factors for correction of the ${ }^{235} \mathrm{U}(\mathrm{n}, \mathrm{f})$ interference in $\mathrm{k}_{0}-\mathrm{NAA}$. Journal of Radioanalytical and Nuclear Chemistry, v. 2348, n. 1, p. 97-101, 2001.

DE SOETE, D.; GIBBELS, R.; HOSTE, J. Neutron activation analysis. London: John Wiley \& Sons, 1972.

DOS SANTOS, M. A.; AREZZO, B. Rendimento da ${ }^{115} \mathrm{Ag}$ na Fissão do ${ }^{232} \mathrm{Th}$ com Nêutron de 14 MeV. Comissão Nacional de Energia Nuclear, 1972.

FIRESTONE, R. B. Table of isotope CD room edition. Wiley-Interscience, 1996.

FRIEDLANDER, M.; KENNEDY, J. W.; MILLER, J. M. Nuclear and radiochemistry. New York: John Wiley \& Sons, 1981.

GLASCOCK, M. D.; NABELEK, P. I.; WINRICH, D. D.; COVENEY, R. M. Jr. Correcting for uranium fission in instrumental neutron activation analysis of highuranium rocks. Journal of Radioanalytical and Nuclear Chemistry, v. 99, n. 1, p. 121-131, 1986.

GOUVEIA, M. A.; PRUDENCIO, M. I.; FREITAS, M. C.; MARTINHO, E.; CABRAL, J. M. P. Interference from uranium fission interference in the determination of rare earths, zirconium and ruthenium by instrumental neutron activation analysis in rock and minerals. Journal of Radioanalytical and Nuclear Chemistry, v. 114, n. 2, p. 309-318, 1987. 
GREENBERG, R. R.; BODE, P.; FERNANDES, E. A. N. Neutron activation analysis: A primary method of measurement. Spectrochimica Acta, v. 66, n. 3-4, p. 193-241, 2011.

http://www.kayelaby.npl.co.uk/atomic and nuclear physics/4 2/4 2 1.html (acessado em 07/11/2012).

http://mmi3.eu/neutron-research/techniques-for-/chemical-analysis.html (acessado em 07/11/2012).

http://www.inb.gov.br/pt-br/WebForms/interna2.aspx?secao id=48 (acessado em 07/11/2012).

IAEA. International Atomic Energy Agency. Nuclear Data for safe guards.

Disponível em <http://www-nds.iaea.org/sgnucdat/index/c3.htm>, acesso em 13 nov. 2012.

IAEA. International Atomic Energy Agency. Nuclear Data for safe guards. Disponível em <http://www-nds.iaea.org/sgnucdat/a5.htm>, acesso em 13 nov. 2012.

IAEA. International Atomic Energy Agency. Practical aspects of operating a neutron activation analysis laboratory. IAEA TEC-DOC-564. Vienna (1990).

IAEA. International Atomic Energy Agency. Reference Material IAEA-SL-1 Trace and minor elements in Lake sediment, 1999.

IRMM. Certified Reference Material BCR-667 Estuarine Sediment, 1999.

ISRAEL SCIENCE AND TECHNOLOGY HOMEPAGE. List of periodic table elements sorted by atomic number. Disponível em <http://www.science.co.il/ptelements.asp>. Acessado em 06 fev. 2014.

JAMES, M. F.; MILLS, R. W.; WEAVER, D.R. The use of normalized residual in averaging experimental data and in treating outliers. Nuclear Instruments \& Methods in Physics Research, A 313, p. 277-282, 1992.

KAWABE, I.; INOUE, T.; KITAMURA, S. Comparison of REE analyses of GSJ carbonate reference rocks by ICP-AES and INAA: Fission and spectral interferences in INAA determination of REE in geochemical samples with high U/REE ratios. Geochemical Journal, v. 28, p. 19-29, 1994.

KONIECZKA, P.; NAMIESNIK, J. Quality assurance and quality control in the analytical chemical laboratory. London, CRC Press, 2009.

KOSKINAS, M. F. Medida do fluxo térmico, epitérmico e rápido no reator IEAR1 pelo método de ativação de folhas. 1979. Dissertação (Mestrado) - Instituto de Pesquisas Energéticas e Nucleares, São Paulo. 
LNHB. Laboratoire National Henri Bacquerel. Recommended data. Disponível em http://www.nucleide.org/DDEP WG/DDEPdata.htm.

LANDSBERGER, S. Spectral interference from uranium fission in neutron activation analysis. Chemical Geology, v. 57, p. 415-421, 1986.

MANN, S. P. Introdução à estatística. Rio de Janeiro: LTC, 2006.

MACMAHON, D.; PEARCE, A.; HARRIS, P. Convergence of techniques for the evaluation of discrepant data. Applied Radiation and Isotope, v. 60, p. 275-281, 2004.

MARIANO, D. R. Implementação do método $k_{0}$-INAA no laboratório de análise por ativação com nêutrons do IPEN utilizando o programa $k_{0}$-IAEA.

Aplicação à análise de amostras geológicas. 2012. Dissertação (Mestrado) Instituto de Pesquisas Energéticas e Nucleares, São Paulo.

MARTINHO, E.; GOUVEIA, M. A.; PRUDÊNCIO, M. I.; REIS, M. F.; CABRAL, J. $M$. P.Factor for correcting the ruthenium interference in instrumental neutron activation analysis of barium in uraniferous samples. Applied Radiation and Isotopes, v. 42, n. 11, p. 1067-1071, 1991.

MARTINHO, E. AAN de zircônio na presença de urânio e a correção de interferência da cisão. ITN/RPI-R-98/51. Sacavém: 1998.

MARTINHO, E. Determination of ${ }^{235} \mathrm{U}$ abundance in uranium by neutron activation on the basis of molybdenum fission interference. Journal of Radioanalytical and Nuclear Chemistry, v. 241, n. 2, p. 271-276 (1999).

MIYAMOTO, Y.; HABA, H; KAJIKAWA, A.; MATSUMO, K.; NAKANISHI, T.; SAKAMOTO, K. Interference in neutron and photon activation analysis. Journal of Radioanalytical and Nuclear Chemistry, v.239, n. 1 p. 165-175, 1999.

NIST. Reference Material 8704 Buffalo River Sediment, 2008.

NPL. National Physical Laboratory. X-ray adsorption edges and characteristic Xray line energies (keV). Disponível em

<http://www.kayelaby.npl.co.uk/atomic_and_nuclear_physics/4_2/4_2_1.html>, acesso em 13 nov. 2012.

PARK, K. S.; KIM, N. B.; WOO, H. J.; LEE, K. Y.; YOON, Y. Y.; LEE, J. H. Interference in neutron activation analysis of rocks by uranium fission. Journal of Radioanalytical and Nuclear Chemistry, v. 168, n. 1, p. 153-161, 1993.

PIETRA, R.; SABBIONI, E.; UBERTALLI, L.; ORVINI, E.;VOCATURO, G.; COLOMBO, F.; ZANONI, M.Trace elements in tissues of a worker affected by rare earths pneumoconiosis. A study carried out by neutron activation analysis.

Journal of Radioanalytical and Nuclear Chemistry, v. 92, n. 2, p. 247-259, 1985. 
RAJPUT, M. U.; MACMAHON, T. D. Technique for evaluating for discrepant data. Nuclear Instruments \& Methods in Physics Resarch, A 312, p. 289-295, 1992.

ROCIO, M. A. R.; SILVA, M. M.; CARVALHO, P. S. L.; CARDOSO, J. G. R. Terras-raras: situação atual e perspectivas. Disponível em <http://www.bndes.gov.br/SiteBNDES/export/sites/default/bndes_pt/Galerias/Arqui vos/conhecimento/bnset/set3511.pdf>, acessado em 01/02/2013.

THOMPSON, M. Recent trends in inter-laboratory precision at ppb and sub-ppb concentrations in relation to fitness for purpose criteria in proficiency testing. The Analyst Communication, v. 125, p. 385-386, 2000.

TIPLER, P. A.; LLEWELLYN, R. A. Física Moderna. 3.ed. Rio de Janeiro: LTC, 2001.

TSHIASHALA, M. D. A. Instrumental neutron activation analysis in geochemistry: Emphasis on spectral and uranium fission product interferences. Journal of Radioanalytical and Nuclear Chemistry, v.265, n. 3, p. 511-514, 2005.

VOBECKY, M. Nuclear interferences of uranium fission products in neutron activation analysis. Radiochemical Radioanalytical Letters, v. 37, p. 231-232, 1979.

YOST, D. M.; RUSSELL Jr, L. H.; GARNER, C. S. The rare-earth elements and compounds. New York: John Wiley \& Sons, 1947. Journal of Radioanalytical and Nuclear Chemistry, v. 291, p. 163-168, 2012

WOOD, R. How to validate analytical methods. Trends in Analytical Methods, v. 18, n. 9, p. 624-632, 1999. 